\title{
Development and Evaluation of Passive Integrated Transponder Tag Technology, 2000-2002
}

Sandra L. Downing, Earl F. Prentice, Edmund P. Nunnallee, and Bruce F. Jonasson

\author{
Report of research by \\ Fish Ecology Division \\ Northwest Fisheries Science Center \\ National Marine Fisheries Service \\ National Oceanic and Atmospheric Administration \\ 2725 Montlake Boulevard East \\ Seattle WA 98112 \\ for \\ Division of Fish and Wildlife \\ Bonneville Power Administration \\ U.S. Department of Energy \\ P.O. Box 3621 \\ Portland, Oregon 97208-3621 \\ Project 83-319, Contracts 307 and 5289
}

April 2004 


\section{EXECUTIVE SUMMARY}

Since 1984, the National Marine Fisheries Service (NMFS) has conducted research in cooperation with the Bonneville Power Administration (BPA) to expand and improve technology for passive-integrated-transponder tags (PIT tags) throughout the Columbia River Basin.

Timely and accurate information derived from PIT-tag technology is increasingly critical to resource stakeholders in developing recovery programs and in assessing the effectiveness of efforts to enhance survival of juvenile and adult salmonids. Continued development of PIT-tag technology will enable researchers to address issues expressed in the NMFS biological opinions for operation of the Federal Columbia River Power System (FCRPS).

This biennial report covers research conducted from 2000 to 2002 (FY01 and FY02); this work was divided into the following seven projects:

1. Development of 134.2-kHz ISO-based interrogation systems for fish ladders

2. Installation of 134.2-kHz ISO-based systems into fish ladders

3. Fish evaluations of 134.2-kHz ISO-based systems in fish ladders

4. EMI-monitoring stations

5. Installation, evaluation, and maintenance of the ISO-based flat-plate system for juvenile fish

6. Development and evaluation of an in-stream interrogation system

7. Information transfer, technical reviews, and technical support

Below are individual summaries for each of these projects.

\section{Development of 134.2-kHz ISO-based Interrogation Systems For Fish Ladders}

NMFS initiated a project in 1997 to develop interrogation systems for detection of adult salmonids in fish ladders, concentrating on detection in fish ladder orifices. Interrogation systems consist of antenna and transceiver systems.

1.1. Antenna System--The main objective for the development of an antenna system was to develop a standardized design that could be used throughout the CRB. A new antenna system with a 1-inch chamfer and 2-inch air gap was designed in summer 
2000; to keep the weight down, this design used closed-cell foam instead of glass beads. Determining the antenna configuration (e.g., number of wraps, impedance value) was one of the first subtasks to be completed in FY01.

This new antenna design appeared acceptable until the end of October 2001, when the tuning values for several transceivers at BWSL dramatically decreased. These values displayed a stair-step pattern, where current would drop and then remain constant for a time and then drop again. Simulation tests conducted to duplicate the problem suggested strongly that some moisture had reached either the antenna wires or the capacitors.

NMFS removed and replaced two antenna housings so that the problem antennas could be dissected, and dissection showed conclusively that moisture had entered the antenna housings. Subsequent testing demonstrated that the closed-cell foam was incompatible with the fiberglass, resulting in pinholes forming in the outer fiberglass shell.

Although the manufacturing process was improved, testing during 2002 confirmed that approximately $20 \%$ of the orifice antennas installed were identified as containing moisture. Although an antenna might contain moisture, until that moisture reaches critical electronic components, it should not impact the performance of the interrogation unit. During 2002, moisture did not appear to have reached any critical electronic components in any of the identified antennas, as an evaluation showed that performances of interrogation units with antennas containing moisture were comparable to those of units with antennas that did not contain moisture.

Alternative materials were investigated to replace the fiberglass, and antennas made with both PVC and a copolymer tested as watertight. The copolymer will be used in the 2003 production of orifice and vertical slot antennas.

1.2. Transceiver System--Destron Technologies made some modifications to its FS1001A transceiver in FY01. The most significant change was making it possible to utilize a 24-V, DC power module that made it possible to detect tags in the large antennas (2 x $6 \mathrm{ft}$ ) required for in-stream interrogations systems and made it possible to design interrogation systems for counting windows where all fish would need to pass through the antennas. NMFS also worked with Destron Technologies to develop a virtual test tag for the FS1001A transceiver. 


\section{Installation of 134.2-kHz ISO-based Systems into Fish Ladders}

2.1. 2001 Installation--The interrogation system that was installed into the Washington Shore Ladder at Bonneville Dam (BWSL) was significantly different from the prototypes tested during 2000: it included different transceiver systems, antenna housings, and antenna cables; a timer test tag in the submerged antenna housing (along with its own cable); and improved grounding options for both the transceiver and the shield.

During January and February 2001, the U.S. Corps of Engineers (Corps) and its contractors installed 24 antenna housings into the orifices of 12 weirs (Weirs 34-37 and 52-59) in BWSL. Although the Corps headed the installation, NMFS worked closely with them to ensure that the installation succeeded. Under dry ladder conditions, NMFS and Destron Technologies determined which grounding scheme for the shields worked best.

When the transceivers were installed, we found that the variable frequency drives in the motor controllers for the screen cleaners in the downstream migrant channel of Powerhouse II were causing considerable electromagnetic interference (EMI) with some of the transceivers. The noise levels were substantially attenuated when filters were installed on the line side of each of the three motor controllers.

2.2. 2002 Installations--As installations change from research-based to production operations, the tasks performed by NMFS are taken over by Pacific States Marine Fisheries Commission (PSMFC). During FY01 and early FY02, NMFS attempted to transcribe all of the steps required for installation, inspection, and testing of these systems. However, the experience and knowledge gained over the years during the development of this equipment was so extensive that complete documentation was well beyond the scope of this effort. Therefore, NMFS served as technical advisors to both the Corps and PSMFC during the FY02 installations at Bonneville and McNary Dams.

\section{Fish Evaluations of 134.2-kHz ISO-based Systems in Fish Ladders}

Biologists and fisheries managers need to know the probability of detecting a PIT-tagged fish in a particular FCRPS fish ladder in order to develop and evaluate study plans and make management decisions. As part of the FY01 BWSL evaluation, NMFS and BPA used both direct and indirect methods to derive estimates of tag-reading efficiencies for that ladder. The direct method compares the number of tagged fish detected to the number of tagged fish released into the PIT-tag interrogation system. 
Indirect methods are based on the number of tagged fish detected among detection systems. University of Washington researchers developed an indirect statistical model based on the number of fish read at a particular weir and subsequent weirs to derive an estimate of detection probability $(\mathrm{P})$ for an entire fish ladder.

The two methods could be compared with the BWSL installation because it is unique among fish ladders in that fish can be diverted from the main ladder into the AFF where they can be captured, tagged, and released back into the main ladder. To get estimates using the direct method, NMFS tagged and released several hundred adult salmonids into the ladder. The Corps had installed video equipment to record the fish using the overflows and orifices for four weirs (Weirs 37, 52, 53, and 56). With this setup, NMFS could estimate tag-reading efficiencies for orifices, weirs, and for the entire ladder.

\subsection{Evaluation of Bonneville Washington Shore Fish Ladder--NMFS} tagged and released salmonids during 2001 to determine tag-reading efficiencies for different salmonid populations. The data analyses focused on the upper eight weirs. The 2001 tagging results for spring chinook salmon indicated that having detectors in four consecutive weirs would have been sufficient to yield a reading efficiency of $95 \%$ (the overall ladder efficiency was 97\%). The indirect method yielded a reading efficiency of $100 \%$ for the entire fish ladder. The indirect analysis report included an alternative model that did not depend on independence of weirs-which lowered the overall detection probabilities to 0.97 - 0.99 . The modelers did note that their estimates should be taken as upper limits for actual detection efficiencies since their models could not take into account fish that were never detected by the system.

The orifice-based system in BWSL detected fish well until the fall when coho and fall chinook salmon used the weir overflows (and thus avoided detection) at much higher rates than expected. The overall reading efficiency with all eight weirs for fall chinook salmon was basically $90 \%$ and for coho, it was in the $75-80 \%$ range. The B-run steelhead population was detected at the $95 \%$ level with six weirs.

Although the orifice-based system appeared to be less effective than the fisheries community wanted for fall chinook and coho salmon, the installation proceeded for Bonneville and McNary Dams because valuable data would still be collected. Based on technology advances that had led to the development of large antennas (2' x 6'), it became feasible to design interrogation systems for ladder locations where all fish would have to go through the antennas and thus could not avoid detection by using the weir overflows. Destron Technologies designed a prototype interrogation system with two 
antennas that was installed into the counting-station area in the McNary Oregon Ladder where its performance could then be directly compared to the orifice-based system in the same ladder.

3.2. 2001 Evaluation of Alternative Direct Methods--To use the direct method in the fish ladders to be newly outfitted for 2002, fish would need to be captured, anesthetized, tagged, held until recovery, transported and then released at some point between weirs having PIT-tag interrogation antennas. In 2001, we evaluated this method in BWSL: results suggested that the behavior of these fish would not be representative of river-run fish volitionally ascending a fish ladder; thus information produced using this method could be suspect. Therefore, for analyzing the other fish ladders in 2002, it was decided to use fish double tagged with radio and PIT tags and PIT-tagged fish that had been detected at an upstream dam.

\subsection{Evaluation of Interrogation Systems for Adult Salmonids at}

Bonneville and McNary Dam--During 2002, we analyzed the performances of the PIT-tag interrogations systems installed at Bonneville and McNary Dams in two reports already submitted to BPA. These reports covered:

- Comparison between the counting-window and orifice-based interrogation systems installed in the McNary Oregon Ladder

- Determination of reading efficiencies for tagged salmonids in the BWSL

- Determination of reading efficiencies for salmonids double tagged with radio and PIT tags

- Performance of orifice antennas containing moisture

- Orifice passage behavior in fish ladders at Bonneville and McNary Dams

\section{EMI-Monitoring Stations}

During the development tests at the AFF in the spring of 2000, both natural and man-made sources of EMI were recorded that produced EMI at levels that prevented PIT tags from being detected. This experience made it apparent that it would be prudent to monitor future installation sites for 1 year in advance of the scheduled installation in order to identify sources of EMI in time to eliminate them before production systems were installed.

Two methods were used to monitor EMI sources in 2001: actual interrogation units installed into the orifices themselves at Bonneville and McNary Dams and an interrogation unit placed on the powerhouse deck near the top of the McNary Washington 
Ladder. Both are effective at identifying the presence of significant levels of EMI that travels through the air; however, only the in-ladder approach would be able to identify noise traveling through the reinforcement bar in the ladder.

During 2001, NMFS installed and maintained six EMI-monitoring stations at Bonneville and McNary Dams. The monitoring results for each station are presented separately. Although the individual sites had slightly different EMI patterns, monitoring from early April through the end of October did not show any patterns that raised concerns about proceeding with the installation of production systems.

Furthermore, data collected at the BWSL site gave us the potential for investigating whether there was a correlation in the noise levels for an interrogation unit and how it performed (i.e., average number of reads per fish). Data from April, July, and October showed that there did not appear to be a direct correlation between noise levels and median values for reads per fish. The data also showed that the general noise pattern for each antenna was basically the same over the year.

Ideally EMI-monitoring equipment would be installed in locations planned for antennas within a ladder to reduce the risk associated with installation. However, the knowledge gained from multiple installations has provided several technical solutions to overcome most EMI problems encountered during production installations. Therefore from a time and cost standpoint, the most practical approach to determining if an EMI problem exists is to install monitoring equipment as near to the locations of interest as possible. Since EMI problems can occur periodically, it is important that monitoring be conducted over the entire fish migration season and not just for a few days.

\section{Installation, Evaluation, and Maintenance of the ISO-based Flat-Plate System for Juvenile Fish}

Like the rest of the PIT-tag equipment at the juvenile fish facilities, the $400-\mathrm{kHz}$ flat-plate system at Bonneville Dam was replaced with an ISO-based system in time for the 2000 smolt migration. Unlike the other facilities, this flat-plate system utilized a transceiver developed and produced by Patten Engineering because the DestronTechnologies FS1001 transceiver system could not produce the necessary field with the larger antennas located at this site.

On 9 April 2001, NMFS conducted fish tests using 257 hatchery chinook salmon and 253 hatchery steelhead. Overall tag-reading efficiencies for all four antennas combined were 97.7 and $96.8 \%$ for chinook salmon and steelhead respectively. No fish 
test was conducted in 2002 because the interrogation system had no modifications and similar results had been found in 2000 and 2001.

Because this site uses a different transceiver than the rest of the juvenile fish facilities, NMFS has been in charge of operating and maintaining the system. During the 2001 juvenile migration season, no PIT-tag data were lost because of electronic component failure; however, mechanical problems were encountered. About mid-way through the migration season, problems started to occur with the pneumatic lift system that raises the flat-plate antenna array when fish are being subsampled. On a number of occasions the lift could not be made to operate, which meant no subsample could be taken. At the end of the season, the lift system was removed by NMFS so it could be redesigned and fabricated before the next juvenile migration. Only minor electronic problems were encountered during the 2002 field season; however, the Corps had several problems in June and July with flow control in the channel. The trap is raised whenever water flow is erratic, which means no PIT-tag data are collected. The longest down time was for several days in July.

Since construction of the juvenile fish facility for Powerhouse I is not yet scheduled, a flat-plate system at this location will continue to be needed. Therefore, NMFS recommends that the current setup be converted to a system based on the FS1001A transceiver, which can be used with the larger antennas needed for this site. This would allow the responsibility of operation and maintenance to be transferred to PSMFC. Since this conversion would involve replacing the antennas, this change would also allow the original temporary sample box that was designed in 1996 to operate for only 2 to 3 years to be replaced.

\section{Development and Evaluation of an In-stream Interrogation System}

Many juvenile salmon are presently being captured, PIT tagged, and released in small streams, in part to determine the effectiveness of stock restoration efforts. Currently, the only means of obtaining movement information on these tagged fish is to recapture them or wait until they pass a dam or trap that includes a PIT-tag interrogation system. These methods provide valuable information, but leave large voids in our understanding of fish biology and ecology. In 2000, NMFS started a development project whose ultimate goal is to develop a "stand alone" in-stream interrogation system (i.e., system that could be located in a remote area without access to the power grid).

To evaluate antenna and transceiver technology for this development project during FY01 and FY02, we worked cooperatively with the US Geological Service at 
Rattlesnake Creek and with a NMFS researcher at Valley Creek near Stanley, Idaho. In addition, we contracted Destron Technologies to modify their equipment to work more effectively for in-stream systems.

6.1. Transceiver Systems--During FY01 at Rattlesnake Creek, EMI levels varied significantly over time with no noticeable pattern. In fact, wide fluctuations were observed, even within a 1-min interval (10-40\% change). At times, EMI levels remained consistently high enough to interfere with tag reading. EMI is more noticeable with the in-stream interrogation systems because unlike at dams, these large antennas do not have RF shields. Sources that contributed to the observed high EMI levels included the AC electrical ground to the transceivers, sporadic ambient sources, and the transceivers themselves.

Other events noticed at the Rattlesnake Creek site during 2001 were large variations in the tune of the antennas caused by changing environmental parameters such as ambient temperatures and water levels. To deal with the impact of environmental parameters on system tune, it was recommended that Destron Technologies design an auto-tune component for its FS1001A transceiver.

NMFS hosted a workshop in 2001 for in-stream researchers. An extensive survey was distributed at the workshop, and its results indicated that one goal shared by many biologists was to interrogate streams that were 25-50 m wide. Currently, the only way to accomplish this would be to have multiple antennas spanning the stream. The only technological solution presently available to handle multiple antennas spanning a stream is to have these antennas be multiplexed so that they do not interfere with each other (in this approach only one antenna is active at a time).

In FY02, NMFS contracted Destron Technologies to develop add-on components to perform auto-tune and antenna-switching (multiplexing) functions. During FY02, Destron Technologies developed prototype auto-tuning and multiplexing components for its FS1001A transceiver. Destron Technologies and NMFS will test these prototype components at the NMFS Pasco Research Station in early FY03.

6.2. Antenna Systems--To determine the direction of fish movement, two in-stream antennas were anchored $15 \mathrm{~m}$ apart during the installation in Rattlesnake Creek. This setup also permitted two different antenna designs to be evaluated under various stream flow conditions. In FY01, pass-through and pass-by designs were evaluated at Rattlesnake Creek. 
The main advantage of the pass-through antenna design is that the fish swim through the antenna; therefore, the tagged fish are in optimal orientation for detection and they are swimming through the largest section of the tag-energizing field. Consequently, these antennas have large read windows. The disadvantage is that it is possible for debris to collect on the antenna and cause it to break from its moorage or cause stream channel alteration.

The advantages of the pass-by antenna design are that antennas are below the water surface and they can be anchored tightly to the substrate of the stream. The main limitation of this design is that the tag-energizing field is small. Therefore, the effective read distance for the installed pass-by antenna was much less (e.g., $15-20 \mathrm{~cm}$ ) than it was for the pass-through design (e.g., $\sim 61 \mathrm{~cm}$ read window in center of an antenna).

In December 2001, debris during high-water conditions removed the pass-through antenna. The pass-by antenna housing design withstood the debris and bottom load impact during the high-water conditions. However, fish under these conditions may have avoided detection by passing too far above the antenna.

Therefore in FY02, we designed a pivoting "hybrid" antenna that incorporated both pass-by and pass-through features. In this design, only the upstream portion of the antenna is anchored to the stream substrate via pivots attached on each end of the antenna. This leaves the downstream end floating free, which enables the antenna to adjust to different stream flow conditions. At Rattlesnake Creek, this antenna functioned without problems during high flow and detected several PIT-tagged fish that the pass-by antenna did not detect. Similar hybrid antennas were installed at both interrogation sites in Valley Creek in 2002.

The pivoting hybrid design appears effective for in-stream research; however, EMI problems continued during 2002 with the large unshielded antennas. Therefore, we recommend more research to find solutions that will reduce or eliminate EMI problems.

6.3. Power Systems--In 2001, we examined fuel-cell technology with the assistance of BPA personnel. We had hoped that a demonstration project using this technology could be arranged in 2001. However, after several months of negotiations and testing, the conclusion was that although the technology was promising, it was too expensive and unreliable at this time for in-stream applications. Therefore in FY02, we contracted power system experts from the Washington State University Energy Program to help design and assemble a power system using a combination of batteries, solar panels, and a propane generator for the Valley Creek site. 
The stand-alone power system consisted of four 12V DC 110 amp-hour glass-mat storage batteries, four 150-watt solar panels, and a propane-operated generator. It was installed in September 2002 and is presently under evaluation; its performance will be documented in the FY03 report.

\section{Information Transfer, Technical Reviews, and Technical Support}

As in previous years, NMFS actively advised other agencies on PIT-tag related matters, such as facility designs to accommodate PIT-tag systems, PIT-tag system maintenance, assistance in using prototype equipment and the MULTIMON computer program, and information transfer. They also provided assistance in adapting PIT-tag technology for investigations into new areas. Because NMFS personnel designed or codeveloped many of the present PIT-tag systems and their components, these personnel are an important resource for users of PIT-tag technology throughout the CRB. Specific technology transfer activities of NMFS personnel during the reporting period are itemized in this report. 


\section{CONTENTS}

EXECUTIVE SUMMARY ................................................................................ iii

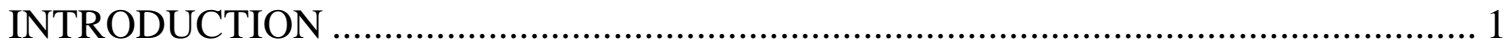

DEVELOPMENT OF 134.2-kHz ISO-BASED INTERROGATION ............................ 2

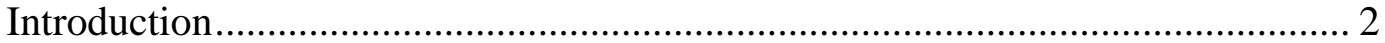

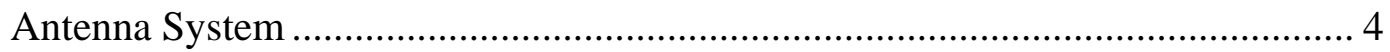

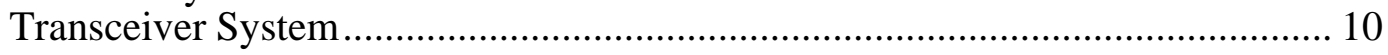

INSTALLATION OF 134.2-kHz ISO-BASED SYSTEMS INTO FISH LADDERS ..... 12

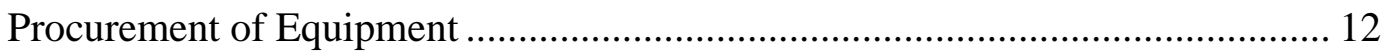

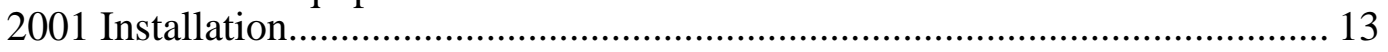

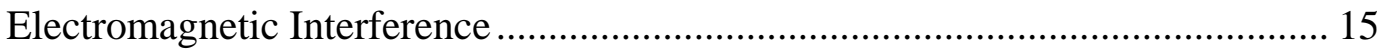

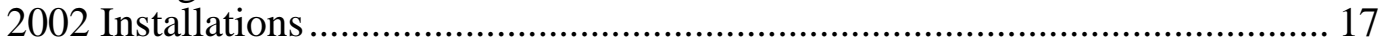

FISH EVALUATIONS OF 134-kHz ISO-BASED SYSTEMS IN FISH LADDERS .... 18

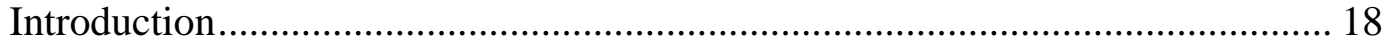

Evaluation of the Prototype Production PIT-Tag Interrogation System Installed into the Washington Shore Fish Ladder at Bonneville Dam .................... 19

Analysis of the Data on a Run-Time Basis............................................ 19

Analysis of the Data by Species............................................................. 33

Current Status of Pit-Tag Detection of Adult Salmonids in Fish Ladders and Possible Next Steps .......................................................... 41

2001 Evaluation of Alternative Direct Methods .................................................. 47

2002 Evaluation of Interrogation Systems for Adult Salmonids at Bonneville and McNary Dam ..................................................................................... 48

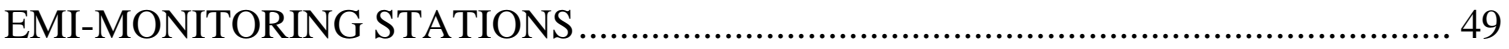

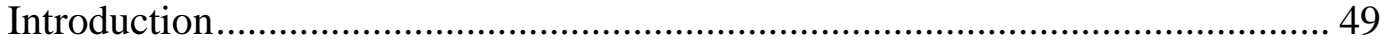

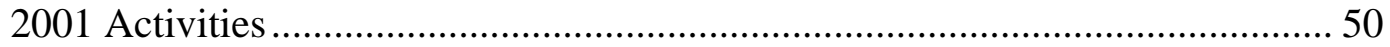

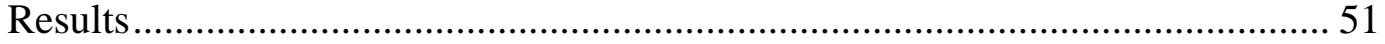

McNary Oregon Ladder................................................................... 51

McNary Washington Ladder................................................................ 54

Cascades Island Ladder at Bonneville Dam .............................................. 56

Bradford Island Ladder at Bonneville Dam-A Branch .............................. 56

Bradford Island Ladder at Bonneville Dam-B Branch .............................. 59

Bonneville Washington Shore Ladder .................................................... 64

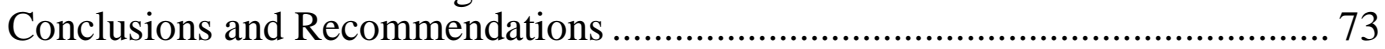

INSTALLATION, EVALUATION, AND MAINTENANCE OF THE ISO-BASED

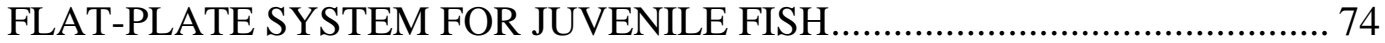

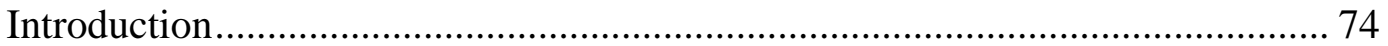

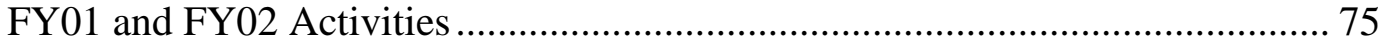

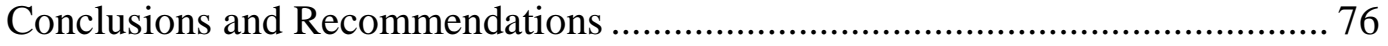




\section{DEVELOPMENT AND EVALUATION OF AN IN-STREAM INTERROGATION}

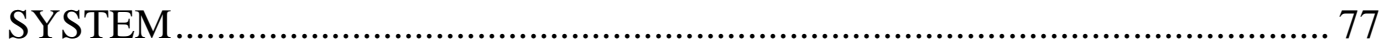

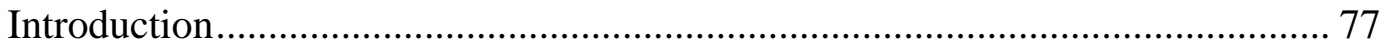

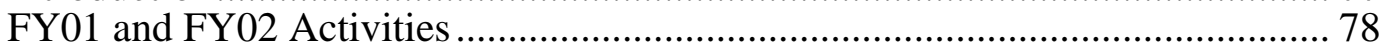

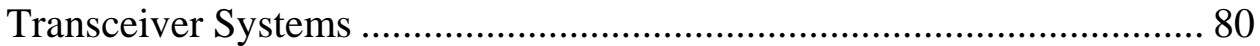

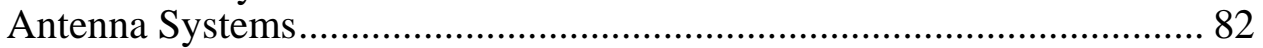

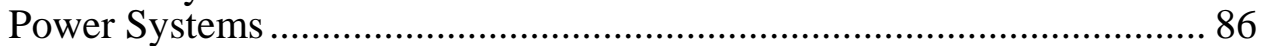

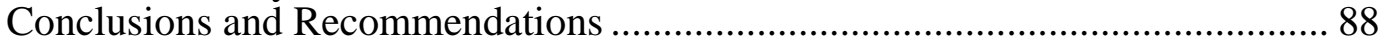

INFORMATION TRANSFER, TECHNICAL REVIEWS, AND TECHNICAL

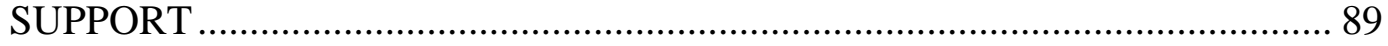

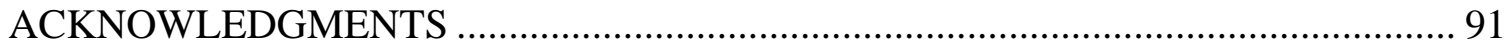

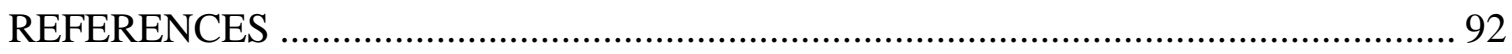

APPENDIX A: Analysis of Electrical Leakage from Underwater PIT-tag Antenna

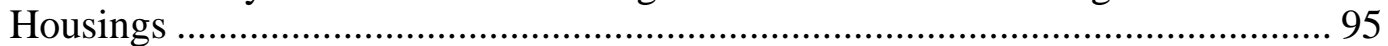

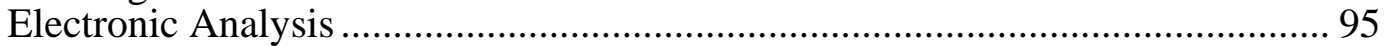

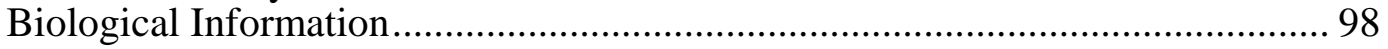

APPENDIX B: Performance of Interrogation Systems in Fish Ladders for Adult Salmonids (Spring 2002) .............................................................................. 100

APPENDIX C: Preliminary Data Analysis Report on Adult Ladder PIT-Tag Detection Efficiency at Bonneville Powerhouse II ......................................................... 109 


\section{INTRODUCTION}

Since 1984, the National Marine Fisheries Service (NMFS) in cooperation with the Bonneville Power Administration (BPA) has conducted a research project to develop and evaluate technology for passive-integrated-transponder tags (PIT tags) throughout the Columbia River Basin (CRB). Work conducted as part of this project between October 2000 and September 2002 (FY01 and FY02) was divided into seven individual elements, which are covered separately in this report.

The efforts by personnel associated with this project have produced and will continue to produce products that aid resource stakeholders in assessing the effectiveness of actions taken to enhance the survival of juvenile and adult salmonids. These products and their uses include:

- $\quad$ Survival and migration timing information on stocks to evaluate water management strategies and fish passage/collection facilities

- $\quad$ Data needed for the management and restoration of salmonids and other fish stocks listed under the Endangered Species Act (ESA)

- Information required for the management of multiple species in a variety of habitats

- $\quad$ Tools that enable fisheries researchers and managers to address previously unanswerable questions and critical uncertainties

These products are also used in genetic, physiology, behavior, and captive broodstock research on endangered species. The continued development of PIT-tag technology will enable researchers and fisheries managers to address issues expressed in both of NMFS biological opinions for operation of the Federal Columbia River Power System (FCRPS)(NMFS 1995a, 2000) and the proposed Snake River Recovery Plan (NMFS 1995b; tasks 2.1.d, 2.3.b.4, 2.4.a, 2.6.c.2, and 2.9.d). 


\section{DEVELOPMENT OF 134.2-kHz ISO-BASED INTERROGATION SYSTEMS FOR FISH LADDERS}

\section{Introduction}

The ability to detect returning PIT-tagged adult salmon has long been established as a critical need by the fisheries community: this need was included in the 1995 NMFS biological opinion (BiOp) and by the Northwest Power Planning Council in its 1994 Fish and Wildlife Program. In the 1995 BiOp, the U.S. Army Corps of Engineers (Corps), BPA, and NMFS were directed to "complete the design and development of adult fish PIT-tag detector systems in adult fish passage facilities at mainstem dams immediately, followed by installation with no adverse effect to adult passage" (NMFS 1995; Incidental Take Statement para. 14).

The NMFS 1998 supplemental BiOp and $2000 \mathrm{BiOp}$ also emphasized the need for adult detection systems at FCRPS projects (NMFS 1998, 2000). Specifically, data collected from adult interrogation would support investigations addressing transport benefits, adult passage rates between dams, travel time, fallback rates, and smolt-to-adult return rates (SARs) of ESA-listed salmonids (NMFS 2000, Section 10.5.1.7).

The first interrogation system for adult salmon was installed at Lower Granite Dam in 1986, and the second was installed in the Adult Fish Facility (AFF) at Bonneville Dam in 1998. These were 400-kHz systems that used electronics developed for juvenile fish; they could interrogate adult salmon transiting 31-cm diameter pipes, but did not have the reading range needed to interrogate fish transiting fish ladders. At Lower Granite Dam, all adults pass through the 400-kHz detectors. At Bonneville Dam, only a fraction of adults passing the dam is interrogated since interrogation takes place only in the AFF.

During development of the ISO-based interrogation system for juvenile salmonids (1996-2000), NMFS recognized that the longer reading range possible with the 134.2-kHz ISO tags would allow detection of adult salmon in fish ladders. Because there were no commercially available transceiver systems with the necessary sensitivity to read tags in fish ladders, NMFS initiated a project in FY98 to develop suitable interrogation systems. This work initially concentrated on detection in fish ladder orifices because these would require smaller antennas than other choke points within fish ladders (e.g., counting windows or vertical slots) and because the few scientific papers describing adult 
salmonids migrating up ladders indicated that approximately $90 \%$ used the orifices and $10 \%$ used the weir overflows.

Some development work on detecting fish that use weir overflows was conducted, but complete development was postponed because the technology was not available to permit 100\% detection of these fish (Downing et al. 2001). The hope was that technology would evolve to the point where interrogation systems could be deployed in the counting windows or vertical slots within the fish ladder. With such systems in place, the issue of weir overflow use would no longer be an issue, since all fish would have to pass through or by PIT-tag antennas. However, we went ahead with the development of an orifice-based system despite the fact that the system would not detect $100 \%$ of the fish because of the strong expressed immediate need for adult detections from the fisheries community.

The implementation goal of the 1998 development project was to install, at a minimum, orifice-based interrogation systems that would cover all of the ladders at Bonneville Dam for 2002, when fish tagged with ISO tags would start to return in statistically significant numbers. The NMFS $2000 \mathrm{BiOp}$ required that detectors be installed at appropriate FCRPS projects prior to the expected return of any adult salmon from the 2001 juvenile migration (Section 10.5.1.6). In the spring of 2001, the fish ladders at McNary Dam were added to the work planned for 2002. Installation of interrogation systems at additional dams was scheduled for 2003 and beyond.

To reach the implementation goal, we needed to satisfy the goal of developing an orifice-based interrogation system that could be installed into any FCRPS fish ladder. Interrogation systems consist of antenna systems (antenna housings and the internal coil windings) and transceiver systems that decode the return signals and transmit tag codes to the data-collection computer. The NMFS research and development team was responsible for overseeing the development of these components.

Work to develop an interrogation system progressed through three phases: development, wherein knowledge about fish behavior was gained and technology was developed; evaluation, where components for a production system would be identified and a prototype system deployed and evaluated in the Washington Shore Ladder at Bonneville Dam (BWSL); and implementation, where production systems would be installed into the rest of the fish ladders at Bonneville and McNary Dams. The deployment and evaluation of the prototype full-ladder system conducted in FY01 is described below. This report also covers work conducted in FY02 when problems arose with the antenna housings. 
Regional coordination and participation in critical planning and decisions were essential to the success of this development project. The Adult PIT-Tag Oversight Committee (APTOC), which is co-chaired by BPA and Corps, and includes members from other federal and state fisheries agencies, tribal nations, and Pacific States Marine Fisheries Commission (PSMFC), was the central means for ensuring regional participation. The APTOC addressed technical issues and provided collective insight on policy and implementation matters. This committee was responsible for such tasks as drafting a requirements document for a transceiver that would work in an orifice-based interrogation system and drafting a management plan that included project objectives, goals, and schedule. These types of documents were then sent out for regional review and comment. This approach was set up to obtain fisheries management input and thus ensure that the final system would satisfy regional research needs.

\section{Antenna System}

The overall goal for the development of the antenna system for orifices was to develop a standardized design that could be used throughout the CRB. By the end of FY99, NMFS had made the recommendation to use the insert-only housing design for the orifices (Downing et al. 2000). The fiberglass material used to fabricate the prototype housings appeared to have held up well after 2 years: when the antenna housings installed in January 1999 in the Cascades Island Ladder were inspected in December 1999 and in February 2001, only small nicks $(\sim 0.5 \mathrm{~cm})$ in the fiberglass gel-coat were apparent in the housings. Furthermore, electronic tests measuring tuning frequency that were conducted during 1999 and 2000 had not shown any degradation (Downing et al. 2001).

Videotape evidence collected by the Corps during FY01 continued to document that fish species (e.g., salmonids and lamprey) did not hesitate to use the modified orifices (Stansell and Beck 2001). The Corps and the NMFS regional office had agreed in July 2000 that all antenna housings installed throughout the FCRPS could have 1-inch chamfers on both the upstream and downstream sides (Downing et al. 2001).

Standardization to a 1-inch chamfer would permit the maximum antenna-coil width to be wrapped.

A new 1-inch chamfer with a 2-inch air gap was designed in summer 2000 (see Figure 1 in Downing et al. 2001). To keep the weight down, this design used closed-cell foam instead of glass beads as filler to produce the 2-inch separation between the water and coil. Determining the configuration (e.g., number of wraps, impedance value) was 
one of the first subtasks to be completed in FY01. Tests conducted by NMFS and Destron Technologies by Digital Angel (formerly Destron Fearing) were run at the NMFS Pasco Field Station in early October 2000 on an 18-inch test antenna to determine the configuration that resulted in minimal difference between tuning the antennas in air and tuning them underwater. This is the antenna configuration that was used by International Design Technologies (IDT) for all antenna housings fabricated in FY01.

This design appeared acceptable until the end of October 2001, when the tuning current values for several transceivers at BWSL (Orifice antennas 3A, 7B, 9A) dramatically decreased (Fig. 1). The values for Antenna 4B decreased to a lesser degree. The current values displayed a stair-step pattern, where they would drop and then remain constant for a time and then drop again. Simulation tests conducted in the laboratory to duplicate the problem suggested strongly that to achieve this stair-step pattern it was necessary for some moisture to reach the high voltage side of the antenna (either wires or the capacitors). Retuning the antennas on 22 November did improve the current values for the problematic antennas (Fig. 1).

The resonant frequency measurements (Downing et al. 2001) that NMFS had been using to measure change in antenna performance over time turned out not to be as sensitive as the current value measurements. Though the three orifice antennas (3A, 7B, and 9A) that had the largest drops in tuning current values also had the largest changes in resonant frequency values, we would have only flagged Antenna 7B with the 0.6 change as being problematic (Table 1).

Since we needed to determine what was happening to the antennas in order to decide whether to delay the scheduled installations for Bonneville and McNary Dams, NMFS and BPA requested an early dewatering of the ladder by the Corps in November. The Corps was able to comply with a 4-d dewatering in early December. A team of personnel from NMFS, Destron Technologies, IDT, and PSMFC worked on the problem in the ladder and during subsequent laboratory testing. During November, NMFS had developed a very sensitive test using a megohmmeter instrument to determine whether there was moisture present in the antenna cable and within the antenna.

Using a megohmmeter before the ladder was dewatered, the team identified a list of "suspicious" antennas in addition to the ones identified by drops in current within the transceivers. Until the team could enter the ladder, it was unknown whether the problem was due to the cables connecting the transceivers and antennas, the antennas within the fiberglass housings, or both. The answer turned out to be both. Cleaning and drying the antenna cables fixed many of the suspicious antennas, but testing indicated that moisture 

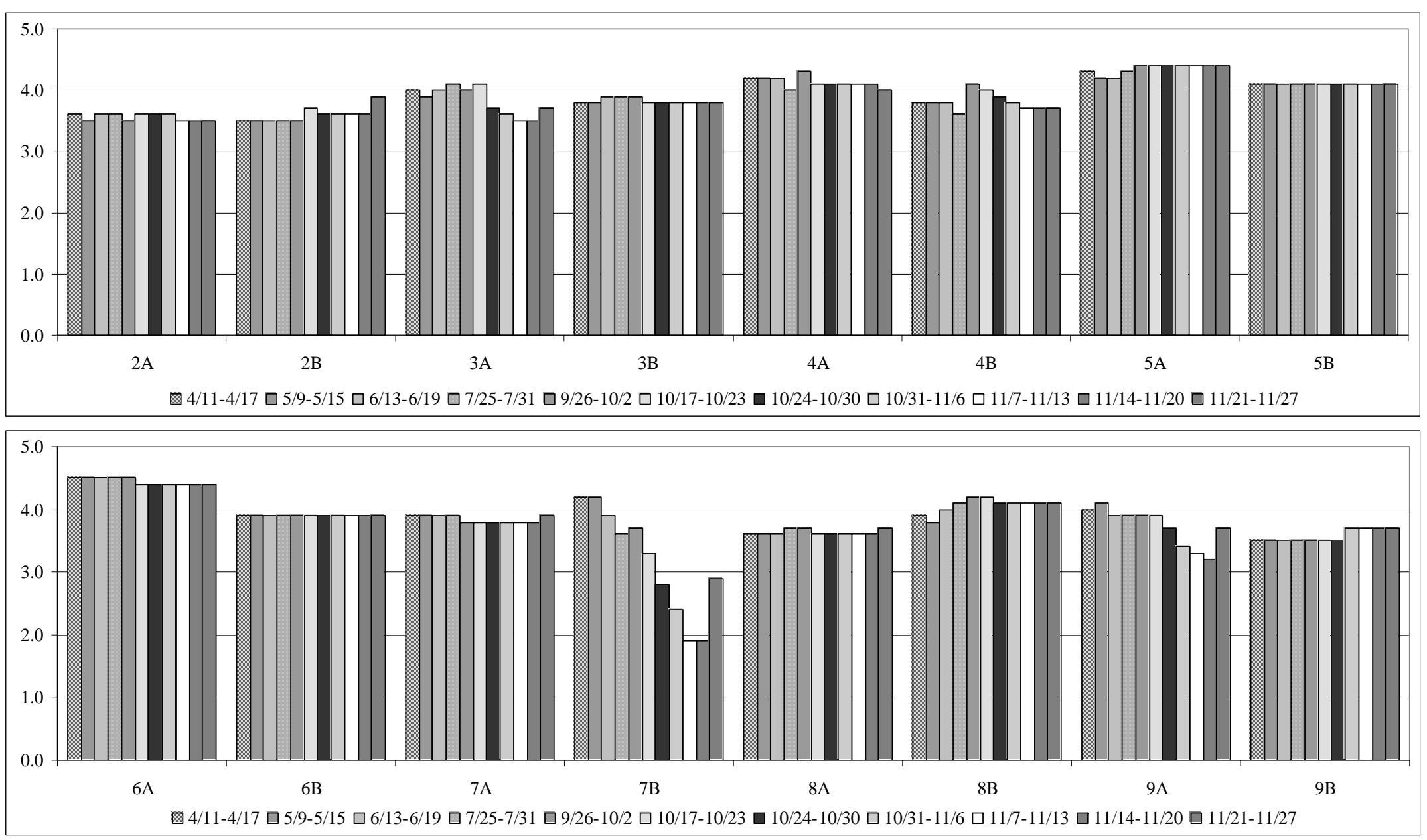

Figure 1. Antenna tuning current values collected during 2001 for the interrogation units in the upper eight-weir section of the prototype system installed into BWSL. Some of these 2001 values show the stair-step pattern exhibited by antennas containing moisture (Antennas 3A, 7B, \& 9A). The transceivers were retuned on 22 November. 
Table 1. Resonant frequency values for the orifice antennas in BWSL for measurements taken in April and November 2001 and the differences between the two measurements. The antennas with the largest differences were $3 \mathrm{~A}, 7 \mathrm{~B}$, and $9 \mathrm{~A}$.

\begin{tabular}{|c|c|c|c|}
\hline \multicolumn{4}{|c|}{ Resonant frequency $(\mathrm{kHz})$} \\
\hline Antenna & April & November & Difference \\
\hline $2 \mathrm{~A}$ & 122.8 & 122.9 & -0.1 \\
\hline $2 \mathrm{~B}$ & 123.4 & 123.5 & -0.1 \\
\hline $3 \mathrm{~A}$ & 123.1 & 122.9 & 0.2 \\
\hline 3B & 122.6 & 122.5 & 0.0 \\
\hline $4 \mathrm{~A}$ & 124.0 & 124.0 & 0.0 \\
\hline $4 \mathrm{~B}$ & 123.8 & 123.8 & 0.0 \\
\hline $5 \mathrm{~A}$ & 124.4 & 124.3 & 0.0 \\
\hline $5 B$ & 123.1 & 123.2 & 0.0 \\
\hline $6 \mathrm{~A}$ & 123.7 & 123.8 & -0.1 \\
\hline $6 \mathrm{~B}$ & 123.7 & 123.8 & -0.1 \\
\hline $7 \mathrm{~A}$ & 122.9 & 122.9 & 0.0 \\
\hline $7 \mathrm{~B}$ & 123.1 & 122.5 & 0.6 \\
\hline $8 \mathrm{~A}$ & 123.5 & 123.6 & -0.1 \\
\hline $8 B$ & 122.4 & 122.5 & -0.1 \\
\hline $9 \mathrm{~A}$ & 122.6 & 122.3 & 0.3 \\
\hline $9 B$ & 122.6 & 122.7 & -0.1 \\
\hline
\end{tabular}


remained inside several housings. NMFS removed and replaced two antenna housings so that the problem antennas could be dissected at the IDT facility. Dissection of the removed housings conclusively showed that water had entered the antenna housings and reached the capacitors in one case, and the high-voltage wires behind the connector in the other case. Subsequent testing demonstrated that the closed-cell foam was incompatible with the fiberglass--forcing air to be released during the vacuum sealing of the fiberglass. This resulted in pinholes being formed in the outer fiberglass shell.

The manufacturer designed an alternative manufacturing process that reduced the foam and increased the thickness of the outer fiberglass shell. This appeared to improve the situation, so the installations planned for Bonneville and McNary Dams were continued. All of the antennas were tested in water under higher-than-normal pressure before they were installed into a fish ladder.

After each antenna was manufactured, it was transported to the NOAA Western Regional Center in Seattle where a dive tank was used for testing. Testing took place in January and February 2002. Each antenna was connected to a cable and submerged to a depth of 20 feet, where it was subjected to a water pressure of approximately 9 psi (maximum water depth in fish ladders is typically 8 feet or 3.5 psi). The antennas were initially submerged for $30 \mathrm{~min}$ and then at the end of January the duration was increased to 60 min after a few had failed soon after they were lifted out of the dive tank. A megohmmeter was used to measure for moisture before the antennas were submerged, at the end of the submersion, after the antenna housing had been lifted out of the tank (to confirm that any problems observed were not in the cable), and then $2 \mathrm{~h}$ later after the permanent antenna cable had been attached.

Identifying antennas containing moisture at this early stage enabled some to be repaired before they were installed into a fish ladder. Despite this effort, some antennas that had passed this test ended up showing that they contained moisture after the fish ladders were watered up. In other cases, there was no time to fix the antennas containing moisture before they had to be installed so that fish ladders could be watered up.

Approximately 20\% of the orifice antennas installed in 2002 have been identified as consistently testing positive for containing moisture (Table 2). Although, an antenna might contain moisture, until that moisture reaches critical electronic components, it should not impact the performance of the interrogation unit. During 2002, this appeared to be true, as an evaluation showed that performances of interrogation units with antennas containing moisture were comparable to those of units with antennas that did not contain moisture (Downing and Prentice 2003). 
Table 2. List of antennas in each ladder for which all sets of measurements made in 2002 indicated that the antenna probably contained moisture. Information provided by PSMFC.

Fish ladder

Bonneville Dam

Bradford A branch

Bradford B branch

Cascades Island

Washington Shore Ladder (upper section)

McNary Dam

Oregon Ladder

Washington Ladder
Antenna IDs for

antennas containing moisture

02, 0A, 0F

$14,18,20$

OF, 10

$4 \mathrm{~B}, 5 \mathrm{~B}, 8 \mathrm{~A}, 8 \mathrm{~B}, 9 \mathrm{~A}$

08, 0D, 0E, 0F, 10, 11

07, 0E, 0F, 10

Because of the potential for moisture to reach the electronics of an antenna, some members of the fisheries community feared that an antenna with moisture that had reached the high voltage side might cause jeopardy to fish in close proximity to such an antenna. We investigated this concern in January 2002 and found that this moisture presented minimal risk. The report from this investigation is presented in Appendix A.

Because the design for fiberglass antennas did not always produce watertight antennas, the multi-agency technical team for APTOC recommended investigating alternative materials to replace the fiberglass. The private sector on its own fabricated antenna housings out of PVC (IDT) and a copolymer (Destron Technologies) during the summer of 2002. The technical team then convened to determine a testing protocol for these housings.

NMFS tested the PVC housing for 2 months by hanging it at 20 feet from the pier at the NOAA Western Regional Center. It did not fail. Destron Technologies did its own in-house testing of the copolymer antenna and installed two antennas into the counting-window interrogation system at McNary Oregon Ladder in July 2002. The copolymer antenna in the counting window has not failed to date. Based on these results, this material was used to manufacture the antennas installed into Ice Harbor and Lower Granite Dams during January-February 2003. 


\section{Transceiver System}

To ensure that a transceiver system for fish ladders would be produced in time to interrogate the returning salmonids in all Bonneville Dam fish ladders by 2002, NMFS and BPA took a "spread the risk" approach in 1998 and simultaneously supported several development efforts. At the end of FY99, we had two promising transceiver systems, the DF-Adult (original design work was done when Destron Technologies by Digital Angel was called Destron Fearing) and the open-architecture system (using the analog board produced by Patten Engineering; Downing et al. 2000).

The first critical step in evaluation was to select a transceiver system for the full-ladder test scheduled for 2001. This was accomplished by conducting a thorough evaluation of both transceiver systems in the fall of 2000. This provided the fisheries community with status information on both systems and what was needed to make both systems into production models. To select the transceiver system, the multi-agency evaluation team (Transceiver and Antenna Technical Team or TATT) performed the fish tests during the end of FY00. A series of electronic lab tests was performed in early FY01 and a summary of the results was reported (TATT 2000; Downing et al. 2001).

The summary indicated that the transceiver system selected was the DF-Adult system manufactured by Destron Technologies. The evaluation determined that the DF-Adult system had only a few firmware changes that needed to be made while the open-architecture system was 6-12 months away from being a production unit. For its production run, Destron Technologies gave the DF-Adult system the model number FS1001A, in which the A stands for adult.

The evaluation team preferred the virtual test tag developed for the open-architecture system to the physical deployment of a timer test tag in the submerged antenna housings that Destron Technologies had included with its transceiver system. Consequently, NMFS worked with Destron Technologies to develop a similar product for the FS1001A transceiver (Fig. 2). This work was completed in August 2001, and the virtual tag component was included in the production units installed in FY02. Destron Technologies did not need to make any modifications to continue to satisfy UL certification, which it received in 2000 for transceivers designed to interrogate juvenile salmonids (model FS1001).

Destron Technologies made some modifications to its FS1001A transceiver in FY01. The most significant change was making it possible to utilize different power modules with the same transceiver. Laboratory tests demonstrated that incorporating a 
24-V, DC power module made it possible to detect tags in the large antennas ( 2 x $6 \mathrm{ft}$ ) required for in-stream interrogations systems. Destron Technologies recognized that this upgraded transceiver would also enable them to design an antenna that would work in many of the narrower counting stations at the CRB dams. The ability to install an interrogation system into the counting stations, where all fish would have to transit these antennas, would overcome the problem of fish avoiding detection by using the weir overflows, a weakness of the orifice-based interrogation system. To test this concept, Destron Technologies installed a two-antenna system into the Oregon Ladder at McNary Dam in January and February 2002. NMFS helped evaluate this system during 2002 (Downing and Prentice 2003).

This upgraded transceiver also made it possible for the fisheries community to design antennas for the vertical slots in the fish ladders at Ice Harbor and Lower Granite Dams; these were installed for 2003. Thus technology advancements in 2001 and 2002 made it possible to monitor alternative choke points in fish ladders where the fish must swim through the antennas. For salmonid populations that are surface oriented, this should significantly improve the probability of detecting tagged fish compared to the orifice-based design.

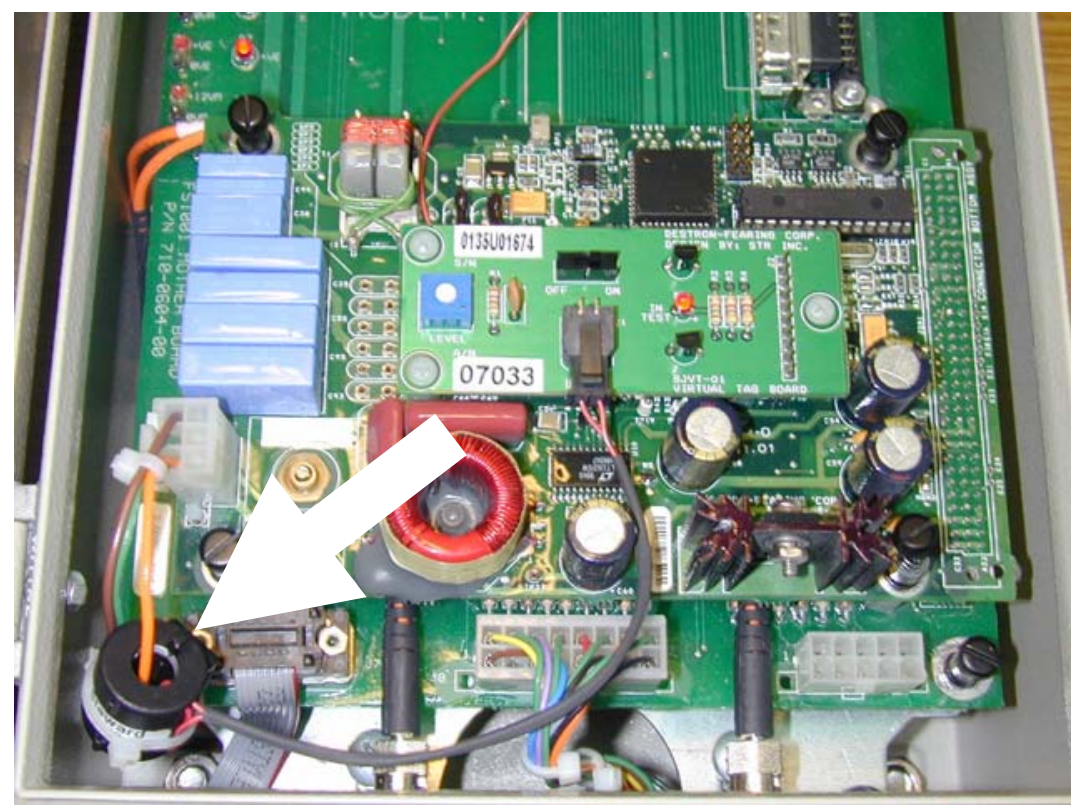

Figure 2. Arrow points to the virtual test tag designed for the FS1001A transceiver. The new component was attached to the analog board within the transceiver. 


\section{INSTALLATION OF 134.2-kHz ISO-BASED SYSTEMS INTO FISH LADDERS}

\section{Procurement of Equipment}

NMFS personnel worked with Destron Technologies to test and design shields that reduced both radio-frequency (RF) emissions by the antenna and RF interference from outside sources. During FY00, NMFS personnel fabricated and installed prototype RF shields into some of the orifices within the AFF exit ladder, where their effectiveness was tested (Downing et al. 2001). Based on what was learned during the AFF installation, the fabrication design was modified to simplify installation into the Bonneville Washington Shore Ladder (BWSL) orifices by the Corps contractor in 2001. NMFS opted to fabricate in-house the RF shields that were installed during FY01 because this would enable rapid modifications to be made to the shields if required.

During 2000-2001, no sites had demonstrated ambient electromagnetic interference (EMI) patterns that would be better dealt with using the unshorted shield design; therefore the design was changed in FY02. The 3-inch gap at the top of the shield was eliminated, and holes drilled in the bottom were redesigned to ensure better grout bonding. Grout is used to fill in gaps and to help hold the antenna and shield in position within the orifice. NMFS acquired bids for manufacturing the shields for the 2002 installations and monitored their production. Isolation bushings in the updated design were thought to be extraneous, but when testing in the fish ladders in December 2001 demonstrated they were critical, NMFS quickly had them fabricated.

During FY01 and FY02, BPA directly issued the contract for the antenna molds and housings. NMFS was responsible for monitoring the production of the antenna housings and for conducting functional tests on the delivered antenna systems. As indicated in the last section, for the 2002 installations, all of antenna housings were pressure tested in water (this was done in a dive tank). BPA also directly issued the contract for the transceivers. 


\section{Installation}

The interrogation system that was installed into the BWSL was significantly different from what had been tested in the AFF during 2000: it included a different transceiver system, antenna housing, and antenna cable; a timer test tag in the submerged antenna housing (along with its own cable); and improved grounding options for both the transceiver and the shield.

The Corps and its contractors installed 24 antenna housings into the orifices of 12 weirs (Weirs 34-37 and 52-59) in BWSL. For this work, the ladder was dewatered from 9 January through 26 February 2001. Although the Corps headed the installation, NMFS worked closely with them to ensure that the installation plans were complete. In addition, NMFS monitored the actual installation. There were several surprises when the ladder was dewatered. For example, there was a steel grating that spanned an entire weir pool that would have badly interfered with the PIT-tag equipment; the Corps agreed to replace it with a fiberglass grating. NMFS R\&D team monitored the installation of RF shields, antenna housings, and cables.

Under dry ladder conditions, NMFS and Destron Technologies conducted preliminary tests in BWSL in February that determined there was little inter-unit interference; therefore a sophisticated synchronization scheme was not needed. Ambient RF noise levels, AC impedance, resonant frequency and "Q" were also measured or calculated for each orifice unit. Other tests were conducted to determine which grounding scheme for the shields worked best. The transceivers were installed after the ladder was watered up. These tests were repeated in April to confirm the operational status of the entire interrogation system (Table 3). NMFS was responsible for maintaining the interrogation system over the entire season.

During February, the Fisheries Field Unit (FFU) of the Corps installed hardware for the video cameras into Weirs 37, 52, 53, and 56. This consisted of installing grooved metal strips that were used to insert the cameras and control their positioning. 
Table 3. Electronic measurements made for each orifice antenna in the BWSL on 4 April 2001 after the ladder was watered up and all transceivers were installed.

Measurements were made using an oscilloscope and a function (sine wave) generator.

\begin{tabular}{|c|c|c|c|c|c|}
\hline Antenna & $\begin{array}{c}\text { Resonant } \\
\text { frequency }^{\mathrm{a}} \\
(\mathrm{kHz})\end{array}$ & $\begin{array}{c}\text { Max. voltage } \\
\text { applied }^{\mathrm{b}} \\
\text { (mV pp) }\end{array}$ & $\begin{array}{c}\text { Current } \\
\text { at Res. Freq. }^{\mathrm{c}} \\
\text { (mA pp) }\end{array}$ & $\begin{array}{l}\text { AC Impedance } \\
\text { (mV pp/mA pp) }\end{array}$ & $\begin{array}{c}\text { Calculated } \\
\text { Q } \\
\end{array}$ \\
\hline $2 \mathrm{~A}$ & 122.81 & 150.0 & 248 & 0.60 & 44.34 \\
\hline $2 B$ & 123.41 & 158.5 & 245 & 0.65 & 47.83 \\
\hline $3 \mathrm{~A}$ & 123.10 & 145.5 & 253 & 0.58 & 50.04 \\
\hline $3 B$ & 122.59 & 171.0 & 228 & 0.75 & 45.40 \\
\hline $4 \mathrm{~A}$ & 124.00 & 133.4 & 256 & 0.52 & 57.41 \\
\hline $4 B$ & 123.79 & 178.5 & 256 & 0.70 & 43.59 \\
\hline $5 \mathrm{~A}$ & 124.36 & 139.2 & 258 & 0.54 & 62.18 \\
\hline $5 B$ & 123.14 & 151.0 & 254 & 0.59 & 51.74 \\
\hline $6 \mathrm{~A}$ & 123.68 & 141.4 & 278 & 0.51 & 54.97 \\
\hline $6 B$ & 123.65 & 156.2 & 275 & 0.57 & 50.26 \\
\hline 7A & 122.89 & 146.2 & 279 & 0.52 & 52.07 \\
\hline $7 \mathrm{~B}$ & 123.10 & 196.0 & 276 & 0.71 & 37.88 \\
\hline $8 \mathrm{~A}$ & 123.49 & 164.0 & 278 & 0.59 & 47.50 \\
\hline $8 B$ & 122.42 & 203.5 & 278 & 0.73 & 37.10 \\
\hline $9 A$ & 122.59 & 211.5 & 277 & 0.76 & 37.15 \\
\hline 9B & 122.59 & 181.0 & 276 & 0.66 & 38.07 \\
\hline $\mathrm{AA}$ & 121.04 & 250.0 & 256 & 0.98 & 28.96 \\
\hline$A B$ & 121.48 & 300.0 & 268 & 1.12 & 25.20 \\
\hline BA & 122.60 & 260.0 & 268 & 0.97 & 30.27 \\
\hline $\mathrm{BB}$ & 121.63 & 255.0 & 258 & 0.99 & 28.62 \\
\hline CA & 122.45 & 140.0 & 261 & 0.54 & 29.87 \\
\hline CB & 121.90 & 192.5 & 260 & 0.74 & 34.83 \\
\hline DA & 122.98 & 168.0 & 259 & 0.65 & 39.80 \\
\hline$\underline{\mathrm{DB}}$ & 123.13 & 173.5 & 261 & 0.66 & 39.21 \\
\hline
\end{tabular}

${ }^{\mathrm{a}}$ Resonant frequency was determined by adjusting the generator frequency to obtain minimum voltage and zero phase shift of the signal being applied directly to the antenna.

${ }^{\mathrm{b}}$ Maximum voltage measured when applying the output of the generator at $134.2 \mathrm{kHz}$ to the antenna through a 300-ohm resistor.

${ }^{\mathrm{c}}$ Current measured at resonant frequency using a clamp-on current scope probe. 


\section{Electromagnetic Interference}

During the fish tests conducted in spring 2000 in the AFF ladder, NMFS R\&D team and Destron Technologies observed some ambient EMI in the RF range that significantly impacted the ability to detect tags (Downing et al. 2001). In fact, testing

was aborted on one day because of high ambient noise conditions. Consequently, firmware modifications were made to permit the transceivers to report RF noise levels and thus help identify sources of EMI.

It was determined in 2001 that the variable frequency drives within the motor controllers for the screen cleaners located in the downstream migrant channel of Powerhouse II were causing considerable noise that was periodically recorded by some of the transceivers in BWSL. Since EMI is generated in waves, noise levels are not constant, and because it only takes 31 milliseconds to decode a PIT tag, it is still possible sometimes to read a tag under noisy conditions. In general, when average noise levels are above $15 \%$ with the FS1001A transceiver, some PIT tags are not detected.

The Corps changed the frequency of the motor controller drives on 6 April 2001 in an attempt to decrease noise; however, average noise levels in some of the transceivers due to screen cleaner operation were still high enough that something more needed to be done (top graph in Fig. 3). The noise levels were substantially attenuated on 24 April when filters were installed on the line side of each of the three motor controllers (bottom graph in Fig. 3). On 24 April, the cleaners were run continuously for about an hour (0930-1045 on graph).

During this time, the average noise level did not significantly increase, but there were spikes of moderate amplitude in the peak noise levels. This pattern suggests that the filters removed a large amount of the noise, but not all. General noise monitoring of the transceiver installation continued during 2001, but no further action was necessary in regard to noise generated by the screen cleaners. 

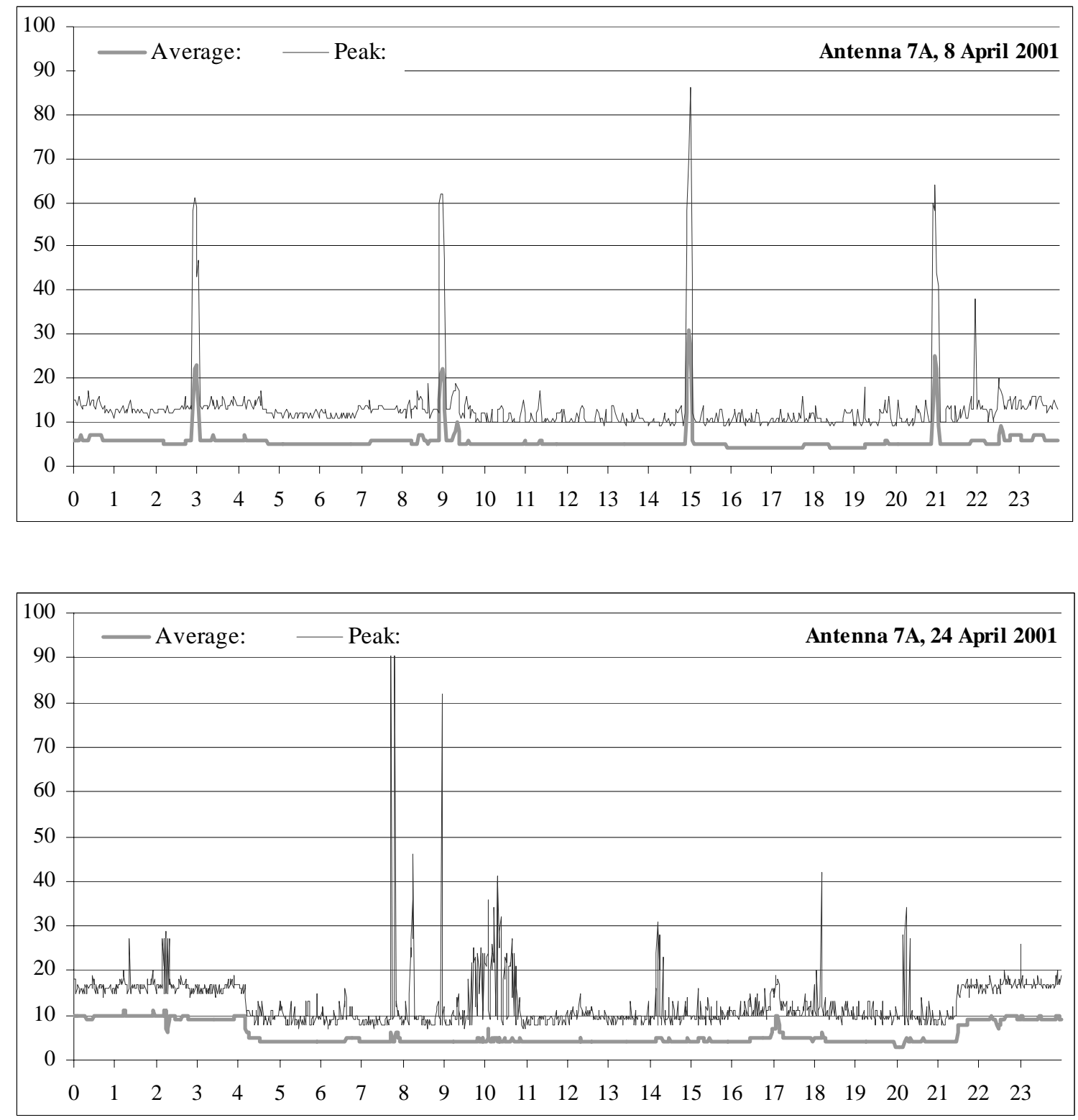

Figure 3. Daily graphs of the average and peak noise levels (percentages) for Antenna 7A in BWSL for 8 April (top) and 24 April (bottom). Filters were installed on the line side of each of the three motor controllers for the screen cleaners located in the downstream-migrant channel of Powerhouse II on 24 April. On 24 April, the cleaners were run continuously for about an hour (0930-1045 on graph). 


\section{Installations}

As installations change from research-based to production operations, the tasks performed by NMFS are taken over by PSMFC. During FY01 and early FY02, NMFS attempted to transcribe all of the steps required for installation, inspection, and testing of these systems. However, the experience and knowledge gained over the years during the development of this equipment was so extensive that complete documentation was well beyond the scope of this effort. Therefore, NMFS served as technical advisors to both the Corps and PSMFC during the FY02 installations at Bonneville and McNary Dams. In this role, NMFS personnel helped inspect the installations during critical points such as concrete cutting, shield and antenna housing installations, and electrical hookups. 


\section{FISH EVALUATIONS OF 134-kHz ISO-BASED SYSTEMS IN FISH LADDERS}

\section{Introduction}

Biologists and fisheries managers need to know the probability of detecting a PIT-tagged fish in a particular FCRPS fish ladder in order to develop and evaluate study plans and make management decisions. As part of the FY01 BWSL evaluation, NMFS and BPA used both direct and indirect methods to derive estimates of tag-reading efficiencies for that ladder. The direct method compares the number of tagged fish monitored to that of a known number of tagged fish released in a position that they must pass the PIT-tag interrogation system.

This method is only accurate for the time and conditions of the test and does not necessarily represent reading efficiency over a prolonged period. The indirect method of determining tag-reading efficiency is a statistical method based on the number of tagged fish monitored while not knowing the actual number of fish passing through the system. BPA funded the University of Washington to develop an indirect statistical model based on the number of fish read at a particular weir and subsequent weirs to derive an estimate of the big P (probability) for an entire fish ladder. They used both the released test fish and river-run fish for testing their model.

The two methods could be compared with the BWSL installation because it is unique among fish ladders in that fish can be diverted from the main ladder into the AFF where they can be captured, tagged, and released back into the main ladder. To facilitate this comparison, orifice PIT-tag interrogation units were installed in weirs both above and below the AFF exit. Therefore, theoretically all fish exiting the AFF after they were tagged would be interrogated regardless of migration direction. The exception being for fish that used the weir overflows exclusively for the weirs covered (hopefully to minimize this impact, the design cover 8 multiple weirs in the upper section). The Corps had installed video equipment to record the fish using the overflows and orifices for four weirs (Weirs 37, 52, 53, and 56). To get estimates using the direct method, NMFS tagged and released several hundred adult salmonids into the ladder in 2001. With this setup, NMFS could estimate tag-reading efficiencies for orifices, weirs, and for the entire ladder. 


\section{Evaluation of the Prototype Production PIT-Tag Interrogation System Installed into the Washington Shore Fish Ladder at Bonneville Dam (2001)}

\section{Analysis of the Data on a Run-Time Basis}

PIT-tagged salmonids were used in a series of tests to evaluate the PIT-tag prototype production interrogation system installed into the Washington Shore fish ladder in early 2001. The test fish were tagged at the AFF; all fish were interrogated prior to tagging for existing PIT tags and interrogated again after tagging to verify the presence and operation of the newly inserted PIT tag.

The COE and BPA had installed orifice detectors into 12 weirs: 4 weirs downstream (334-337) and 8 weirs upstream (352-359) of the fish release point. To determine if tag reading efficiencies were different for various run times, the tests were conducted at three different periods over the course of 2001: a) during the spring chinook run (April), b) during the summer chinook and shad runs (June), and c) during the fall chinook run (September).

The main objective of the fish tests and the general evaluation of the installed system was to determine if the system performance was adequate so that similar installations planned for 2002 could proceed. As part of this evaluation, estimates of reading efficiencies for individual orifice detectors and the overall ladder were made for each series of fish tests. Another objective of this evaluation was to try to determine the number of weirs that were needed to achieve a $95 \%$ overall system reading efficiency.

Statistical models to derive estimates of tag reading efficiencies for the overall ladder were developed by the University of Washington and Pacific States Marine Fisheries Commission. The test fish were used to verify the accuracy of these models.

This short summary is meant to address the major points of interest to APTOC to help them in deciding whether to proceed with the installations planned for Bonneville and McNary Dams in 2002. It is worth noting that performance of the orifice detectors themselves has been excellent: analysis of the videotapes taken on orifices from four weirs have shown only two fish missed by the PIT-tag equipment. In other words, the video results show that the individual orifices have detected over $99 \%$ of the tagged fish transiting them (Stansell and Beck 2002). Therefore, the main focus of this report is to examine the overall ladder efficiencies for different runs and whether having detection in eight weirs is sufficient for meeting the needs of the fisheries community. 
Fish Tagged during April 2001--A total of 316 salmonids were PIT-tagged at the AFF on April 11, 16,17,18, 24 and 25 April 2001. Table 4 shows the number and percentage of fish tagged per species. Presented in Figure 4 are the numbers of spring chinook salmon passing Bonneville Dam in 2001 and the 10-year average for April. The 2001 run of spring chinook salmon was the largest in recorded history.

Table 4.

\section{Fish tagged in April 2001}

\begin{tabular}{lcc} 
Species & Number tagged & Percent tagged \\
\hline Spring chinook & 303 & 95.9 \\
Steelhead & 13 & 4.1 \\
Total & 316 & \\
\hline
\end{tabular}

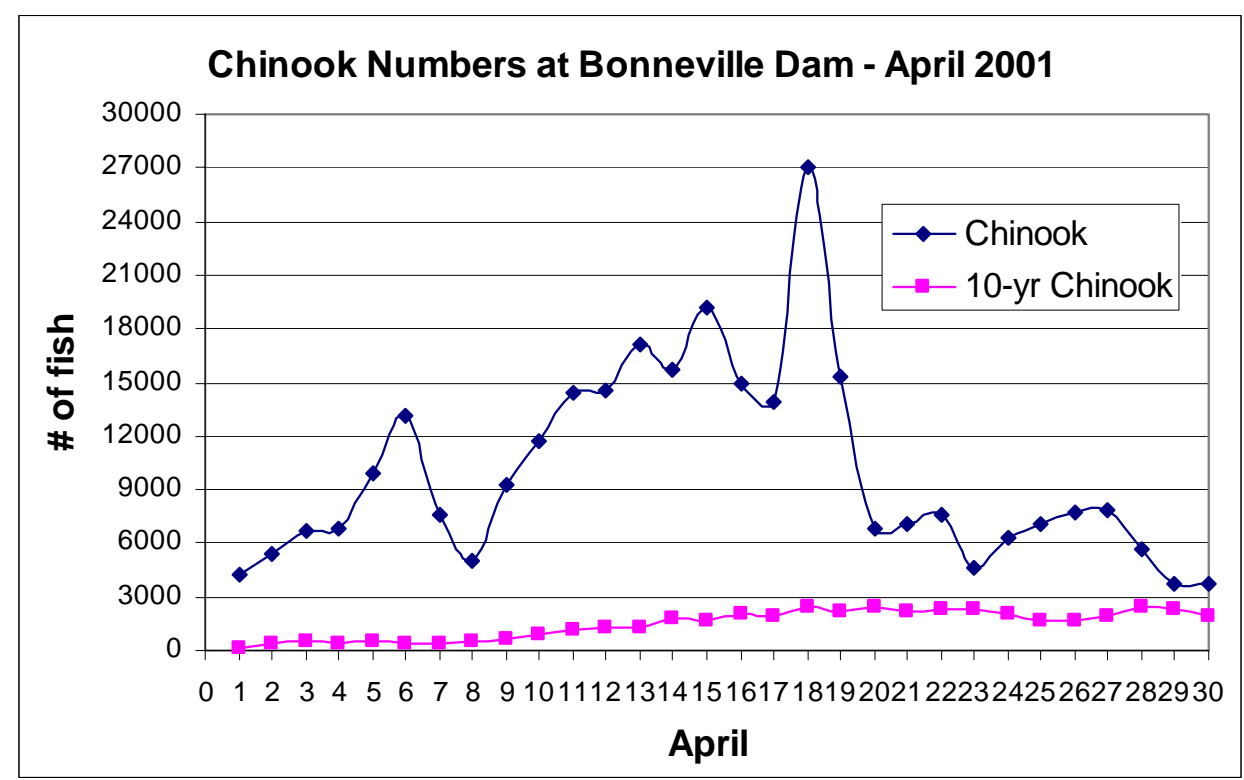

Figure 4.

Table 5 shows the distribution by species that had no PIT-tag detection after being tagged and released. Overall, no PIT-tag records were recorded for 3.2\% of the fish we tagged during the April tagging period. The low number of steelhead tagged may be the reason its percentage appears out of proportion compared to the chinook or the higher percentage might indeed reflect a real behavioral difference between species. 


\section{Table 5.}

\begin{tabular}{lccc}
\hline \multicolumn{3}{c}{ Fish tagged in April 2001 } \\
Species & Number tagged & Not detected (n) & Not detected (\%) \\
\hline Spring chinook & 303 & 8 & 2.6 \\
Steelhead & 13 & 2 & 15.4 \\
Total & 316 & 10 & 3.2 \\
\hline
\end{tabular}

The focus of this analysis was on the upper eight weirs. Table 6 shows the number and percentage of fish read on different numbers of weirs for fish tagged in April 2001. Figure 5 graphically depicts the data in Table 6 for the percentage of fish read in each of the 10 categories. In the table and histogram, 0 indicates that a fish was not read on any of the 12 weirs, the 1 to 8 categories represent the number of upper weirs that a fish was read on, and "down" indicates the fish was only read on the lower weirs at the BWSL. Around $90 \%$ of the fish were read on four or more of the upper eights weirs; with more than $75 \%$ being detected on all eight upper weirs.

Table 6.

\begin{tabular}{lccc}
\hline & \multicolumn{2}{c}{ Fish tagged in April 2001} & \\
Number of Weirs & Fish (n) & Number of Weirs & Fish (\%) \\
\hline 0 & 10 & 0 & 3.2 \\
1 & 4 & 1 & 1.3 \\
2 & 6 & 2 & 1.9 \\
3 & 1 & 3 & 0.3 \\
4 & 3 & 4 & 0.9 \\
5 & 5 & 5 & 1.6 \\
6 & 12 & 6 & 3.8 \\
7 & 21 & 7 & 6.6 \\
8 & 244 & 8 & 77.2 \\
Down & 10 & Down & 3.2 \\
Total & 316 & & \\
\hline
\end{tabular}




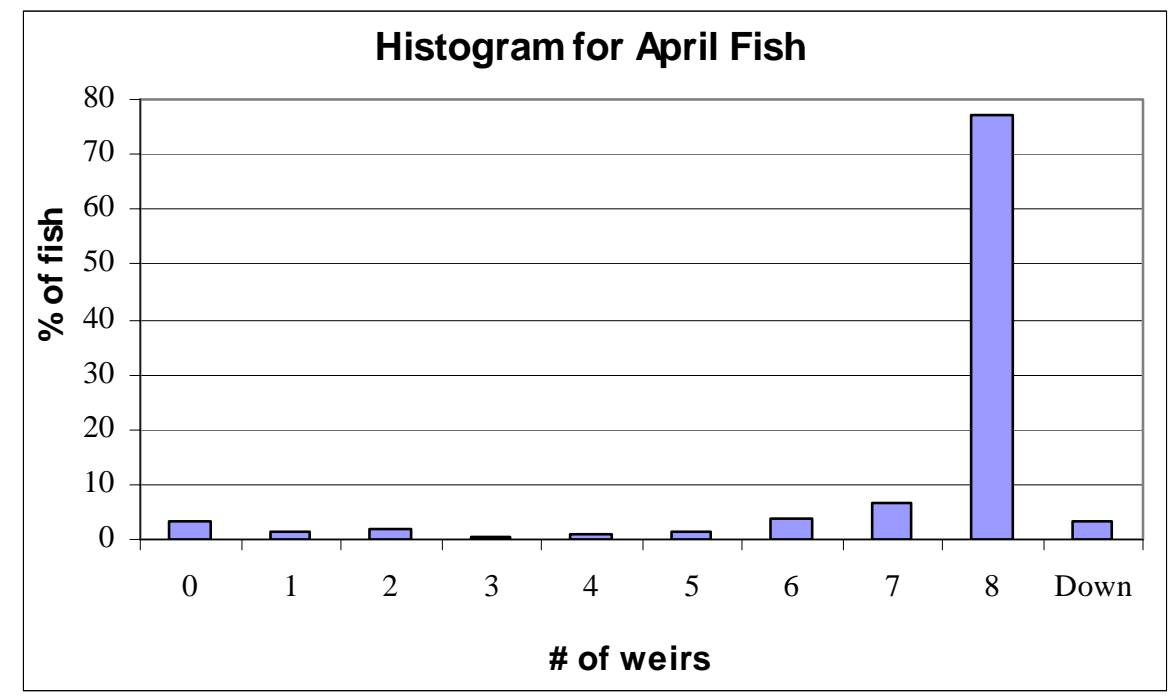

Figure 5.

To make the analysis of the ladder reading efficiency faster, we only analyzed the fish that ascended the ladder on Day 1 or the day they were tagged (Table 7). Based on any 4 consecutive weirs, we found that $93.1 \%$ of the fish would have been recorded with just 4 weirs installed. Using all of the fish tagged in April, we achieved the goal of 95\% reading efficiency (RE\%) for the entire ladder with 6 weirs installed.

Table 7.

\begin{tabular}{lrrrrr}
\hline \multicolumn{5}{c}{ RE for different number of weirs } \\
Date & 4 & 5 & 6 & 7 & \multicolumn{1}{c}{8} \\
\hline \multirow{2}{*}{$11-\mathrm{Apr}$} & 84.4 & 86.7 & 91.1 & 95.6 & 95.6 \\
$16-\mathrm{Apr}$ & 85.7 & 87.8 & 87.8 & 87.8 & 89.8 \\
$17-\mathrm{Apr}$ & 96.0 & 100.0 & 100.0 & 100.0 & 100.0 \\
$18-\mathrm{Apr}$ & 95.8 & 95.8 & 95.8 & 98.6 & 98.6 \\
$24-\mathrm{Apr}$ & 100.0 & 100.0 & 100.0 & 100.0 & 100.0 \\
$25-\mathrm{Apr}$ & 94.3 & 94.3 & 95.7 & 95.7 & 97.1 \\
& & & & & 96.0 \\
Combined & 93.1 & 94.4 & 94.7 & 96.7 \\
\hline
\end{tabular}


Fish Tagged during June 2001-- Because of the success of the interrogation system during the spring run, our intent in June was primarily to check on the performance of the equipment (i.e., to determine if we were getting as many reads per fish as we had in the spring). Another objective was to tag summer chinook salmon and steelhead to determine if tag-reading efficiencies changed with run time. On 13 June, a total of 52 salmonids were PIT tagged (Table 8).

During June, the water depth is increased in the fish ladders at Bonneville Dam to accommodate shad. Historically the period chosen to tag was near the peak of the shad migration; however 13 June turned out to be one of the low days for shad in 2001 (Figure 6). The number of chinook salmon migrating past Bonneville Dam during the tagging period was still 3 times the 10-year average.

Table 8.

Fish tagged in June 2001

Species Number tagged Percent tagged

Summer chinook 36

69.2

Steelhead 16

30.8

Total 52

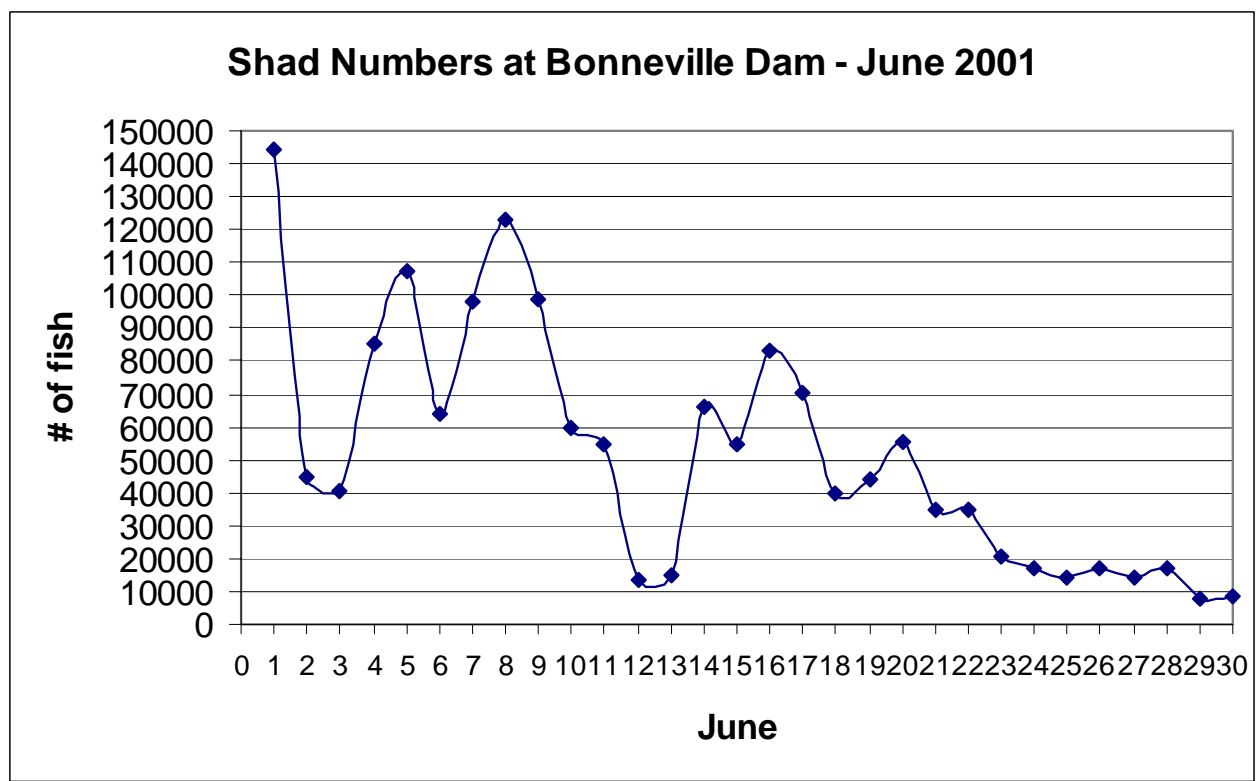

Figure 6. 
Table 9 shows the distribution by species that had no PIT-tag detection after being tagged and released. Overall, we have no PIT-tag records for $11.5 \%$ of the fish we tagged, which was about 3 times higher than during the April test. Although the number of steelhead tagged was still low, the higher percentage agreed with the April data and suggested there may indeed be a difference between the two species.

The U.S. Army Corps of Engineers (COE) analyzed the video data from overhead cameras and determined that all six fish not detected by the PIT-tag equipment did indeed use the overflows for the upper weirs in which they had cameras installed (Weirs 52, 53, and 56) (Stansell and Beck 2002).

Table 9.

\begin{tabular}{lccc}
\hline Species & \multicolumn{2}{c}{ Fish tagged in June 2001} & \\
Number & Number not \\
tagged & detected & $\begin{array}{c}\text { Percent not } \\
\text { detected }\end{array}$ \\
\hline Summer chinook & 36 & 2 & 5.6 \\
Steelhead & 16 & 4 & 25.0 \\
Total & 52 & 6 & 11.5 \\
\hline
\end{tabular}

Table 10 depicts the number and percentage of fish read on the different numbers of weirs for fish tagged in June 2001. The histograms in Figure 7 depict the percentage of fish read for each of the 10 categories, as shown in Table 10. In the table and histogram, 0 indicates that a fish was not read on any of the 12 weirs, categories 1-8 represent the number of upper weirs on which a fish was read, and "down" indicates the fish was read only on the lower weirs at BWSL. Around 73\% of the fish were read on four or more upper weirs compared to $90 \%$ with the April fish. Furthermore only around $60 \%$ were read on all eight upper weirs compared to $75 \%$ of the April fish. 
Table 10.

Fish tagged in June 2001

\begin{tabular}{cccc} 
Number of Weirs & Fish (n) & Number of Weirs & Fish (\%) \\
\hline 0 & 6 & 0 & 11.5 \\
1 & 2 & 1 & 3.8 \\
2 & 4 & 2 & 7.7 \\
3 & 2 & 3 & 3.8 \\
4 & 0 & 4 & 0.0 \\
5 & 1 & 5 & 1.9 \\
6 & 3 & 6 & 5.8 \\
7 & 3 & 7 & 5.8 \\
8 & 31 & 8 & 59.6 \\
Down & 0 & Down & 0.0 \\
Total & 52 & & \\
\hline
\end{tabular}

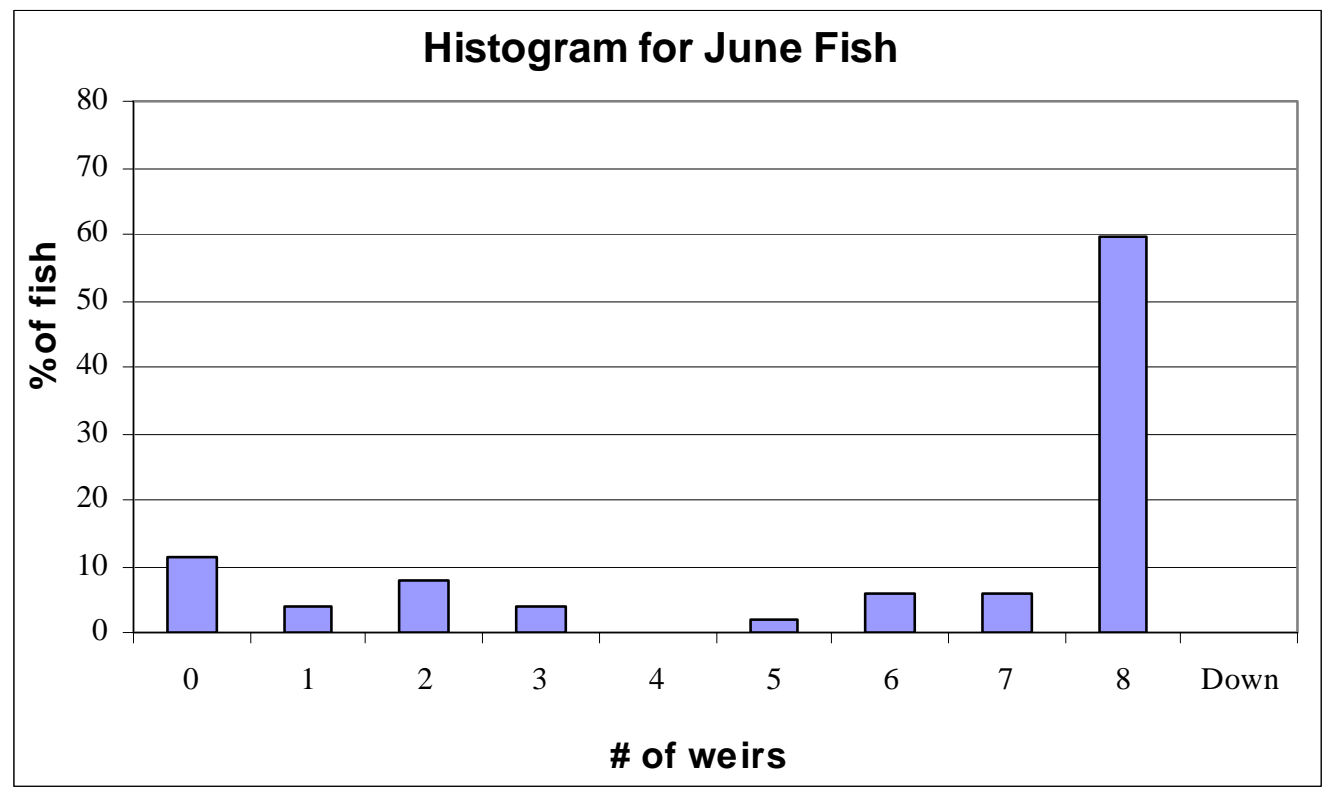

Figure 7. 
Again to make the analysis of ladder reading efficiency faster, we only analyzed the fish that ascended the ladder on Day 1 or the day they were tagged. Based on any four consecutive weirs, we found that $75 \%$ of the fish would have been recorded with only four weirs wired; even with eight weirs installed, we only detected $88.5 \%$ of the fish (Table 11). These results were much lower than the 93\% and 97\% levels observed with the spring run.

When the video results confirmed that these fish had indeed used the overflows, this made us concerned that the 8-weir interrogation system might not be sufficient for the fall chinook salmon.

Table 11.

\begin{tabular}{lccccc}
\hline & \multicolumn{5}{c}{ RE for different number of weirs (\%) } \\
Date & 4 & 5 & 6 & 7 & 8 \\
\hline 13 Jun & 75.0 & 75.0 & 80.8 & 86.5 & 88.5 \\
& & & & & \\
Combined & 75.0 & 75.0 & 78.8 & 86.5 & 88.5 \\
\hline
\end{tabular}

Fish Tagged during September 2001--A total of 277 salmonids were PIT-tagged on 18, 19, 24, and 25 September 2001 (Table 12). The 2001 fall return was about twice the 10-year average for chinook salmon and steelhead and about 8 times the average for coho salmon (Figure 8).

Table 12.

\begin{tabular}{lcc}
\hline & $\begin{array}{c}\text { Fish tagged in September } 2001 \\
\text { Species }\end{array}$ & Percent tagged \\
\hline Fall chinook & 158 & 57.0 \\
Steelhead & 88 & 31.8 \\
Coho & 31 & 11.2 \\
Total & 277 & \\
\hline
\end{tabular}




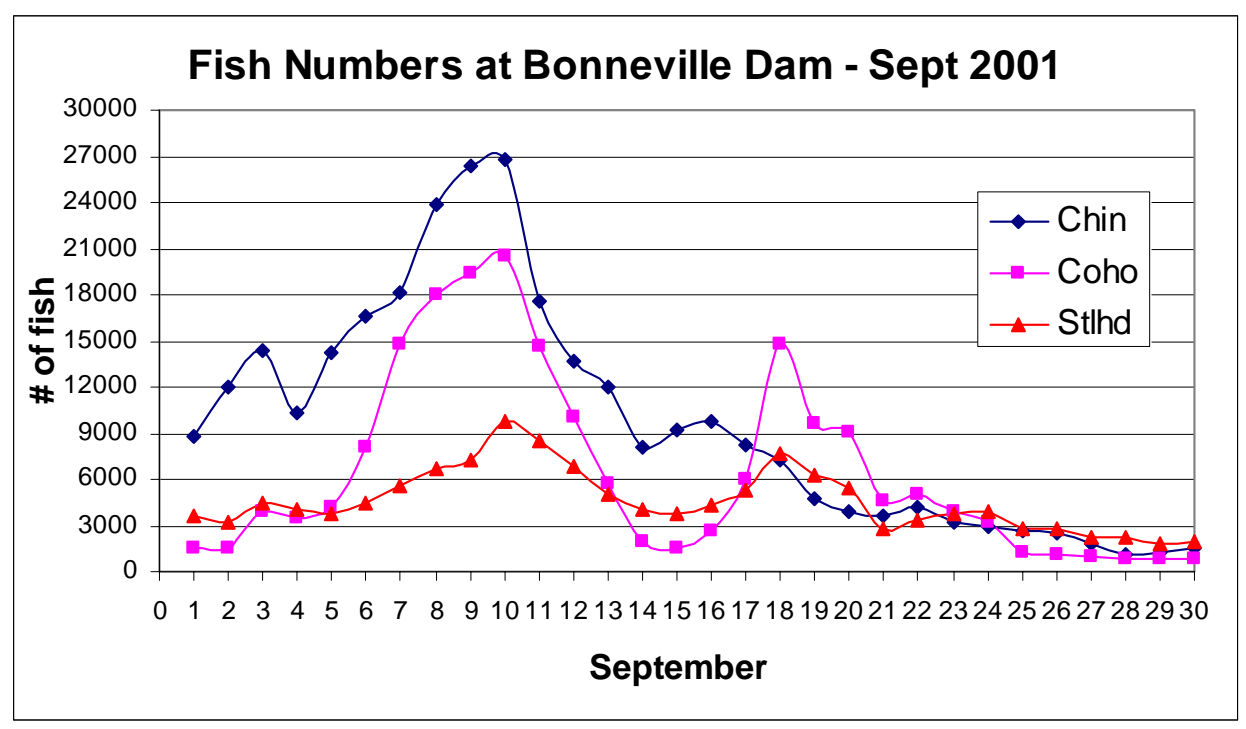

Figure 8.

Table 13 shows the distribution by species that had no PIT-tag detection after being tagged and released. Overall, we have no PIT-tag records for $9.4 \%$ of the fish we tagged, which is about 3 times the percentage for salmonids tagged in April. Note that there was a disproportionately high percentage of coho salmon that were not read; coho are a surface oriented fish and this could in part account for their apparent overflow usage. Also unlike the previous two test periods, steelhead did not show a high percentage of no reads during this test period.

Table 13.

Fish tagged in September 2001

\begin{tabular}{lccc} 
Species & Number tagged & Number not detected & Percent not detected \\
\hline Fall chinook & 158 & 15 & 9.5 \\
Steelhead & 88 & 4 & 4.5 \\
Coho & 31 & 7 & 22.6 \\
Combined & 277 & 26 & 9.4 \\
\hline
\end{tabular}


Table 14 shows the number and percentage of fish read on the different numbers of weirs for fish tagged in September 2001. The histograms in Figure 9 depict the percentage of fish read for each of the 10 categories presented in Table 14 . In the table and histogram, 0 indicates that a fish was not read on any of the 12 weirs, the 1 to 8 categories represent the number of upper weirs that a fish was read on, and "down" indicates the fish was only read on the lower weirs at BWSL.

Around $75 \%$ of the fish were read on 4 or more upper weirs compared to $90 \%$ with the April fish. Furthermore, only around 50\% were read on all 8 upper weirs compared to 75\% with the April fish. This strongly suggests that more fish were using multiple overflows during this fall run. In fact, Robert Stansell (Corps) and other biologists working at Bonneville Dam indicated that they had never seen so many fish using the overflows as at the peak of the 2001 fall run.

\section{Table 14.}

\begin{tabular}{|c|c|c|c|}
\hline \multirow[b]{2}{*}{ Number of Weirs } & \multicolumn{3}{|c|}{ Fish tagged in September 2001} \\
\hline & Fish $(\mathrm{n})$ & Number of Weirs & Fish (\%) \\
\hline$\overline{0}$ & 26 & 0 & 9.4 \\
\hline 1 & 11 & 1 & 4.0 \\
\hline 2 & 11 & 2 & 4.0 \\
\hline 3 & 14 & 3 & 5.1 \\
\hline 4 & 11 & 4 & 4.0 \\
\hline 5 & 13 & 5 & 4.7 \\
\hline 6 & 17 & 6 & 6.1 \\
\hline 7 & 27 & 7 & 9.7 \\
\hline 8 & 142 & 8 & 51.3 \\
\hline Down & 5 & Down & 1.8 \\
\hline Total & 277 & & \\
\hline
\end{tabular}




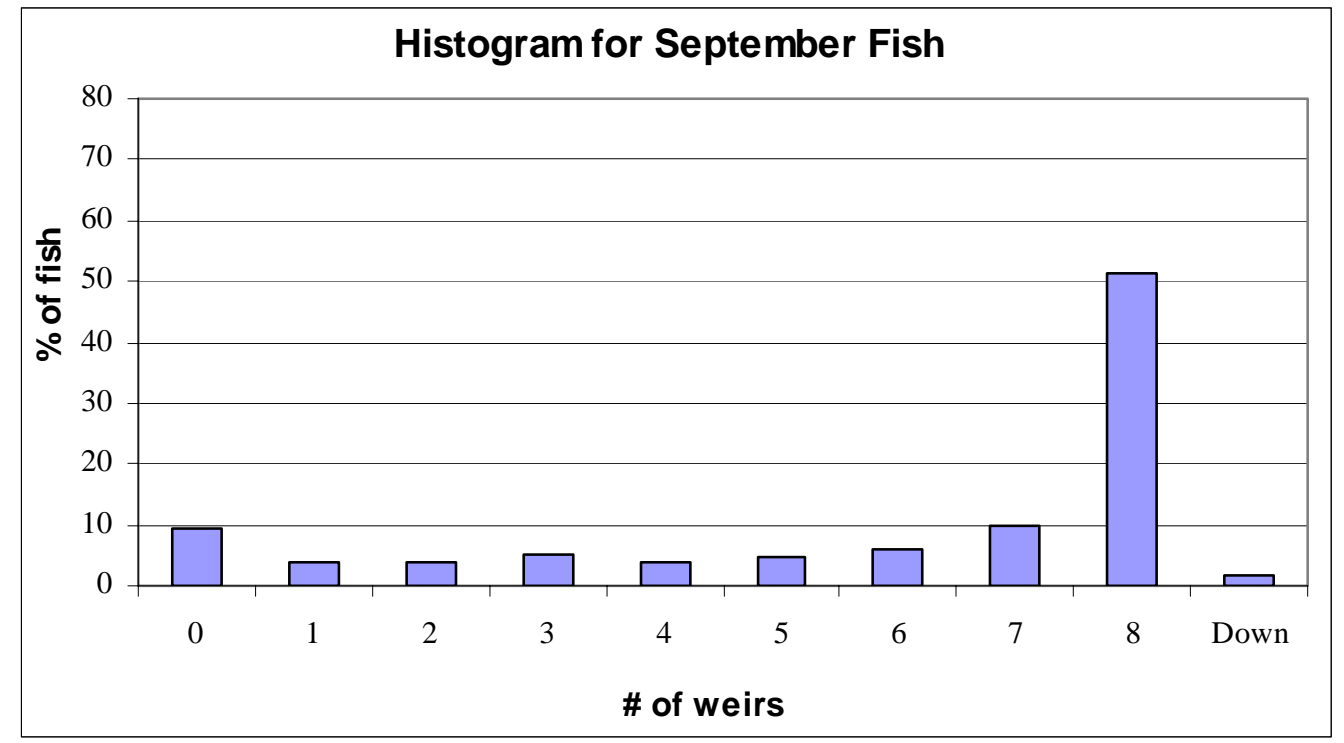

Figure 9.

Like above for analyzing the ladder reading efficiency, we only analyzed the fish that ascended the ladder on Day 1 or the day they were tagged. Based on any 4 consecutive weirs, we found that $78.5 \%$ of the fish would have been recorded with just 4 weirs wired, and with 8 weirs installed, we only detected $90 \%$ of the fish during the fall run (Table 15).

We do not yet have the COE video data to determine whether the 26 fish not detected in September were taped using the overflows.

\section{Table 15.}

\begin{tabular}{lccccc}
\hline & \multicolumn{5}{c}{ RE for different number of weirs (\%) } \\
Date & 4 & 5 & 6 & 7 & 8 \\
\hline 18-Sep & 62.1 & 69.0 & 79.3 & 82.8 & 82.8 \\
19-Sep & 80.2 & 86.0 & 90.7 & 90.7 & 91.9 \\
25-Sep & 81.8 & 84.8 & 90.9 & 90.9 & 90.9 \\
26-Sep & 80.0 & 85.0 & 87.5 & 88.8 & 90.0 \\
& & & & & \\
Combined & 78.5 & 83.5 & 88.5 & 89.3 & 90.0 \\
\hline
\end{tabular}


Peak of Fall Run Information--To examine further the multiple overflow use by fish during the fall run, we analyzed one day (11 September) during the peak of the run (see Figure 8). Table 16 shows the number and percentage of fish read on the various numbers of weirs for 11 September 2001. The histograms in Figure 10 depict the percentage of fish read for each of the 10 categories presented in Table 16. In the table and histogram, 0 indicates that a fish was not read on any of the 12 weirs, the 1 to 8 categories represent the number of upper weirs that a fish was read on, and "down” indicates the fish was only read on the lower weirs at BWSL.

Note the higher percentage of fish using only 1-3 weirs. It was $27.8 \%$ on this date while it was 3.5\% in April, and $13.1 \%$ for the tagging dates in September (Table 17). What we cannot get from this analysis is the number of fish that passed undetected by the PIT-tag system. If we reanalyze the data using the assumption that $9 \%$ of the fish were missed entirely, we get the results presented in Table 18.

The results for 11 September suggested that even more fish used multiple overflows on this day than had on other September days we tagged fish (we originally analyzed these data to see how the individual transceivers were performing so it was easy to continue analyzing them for this comparison). These results supported the observations of Stansell and other biologists.

Table 16.

\begin{tabular}{lccc}
\hline \multicolumn{4}{c}{ Data for Fish migrating on 11 September 2001 } \\
\hline Number of Weirs & Fish (n) & Number of Weirs & Fish (\%) \\
\hline 0 & 0 & 0 & 0.0 \\
1 & 6 & 1 & 9.8 \\
2 & 6 & 2 & 9.8 \\
3 & 5 & 3 & 8.2 \\
4 & 4 & 4 & 6.6 \\
5 & 4 & 5 & 6.6 \\
6 & 5 & 6 & 8.2 \\
7 & 4 & 7 & 6.6 \\
8 & 27 & 8 & 44.3 \\
Down & 0 & & \\
Total & 61 & Total & 100 \\
\hline
\end{tabular}




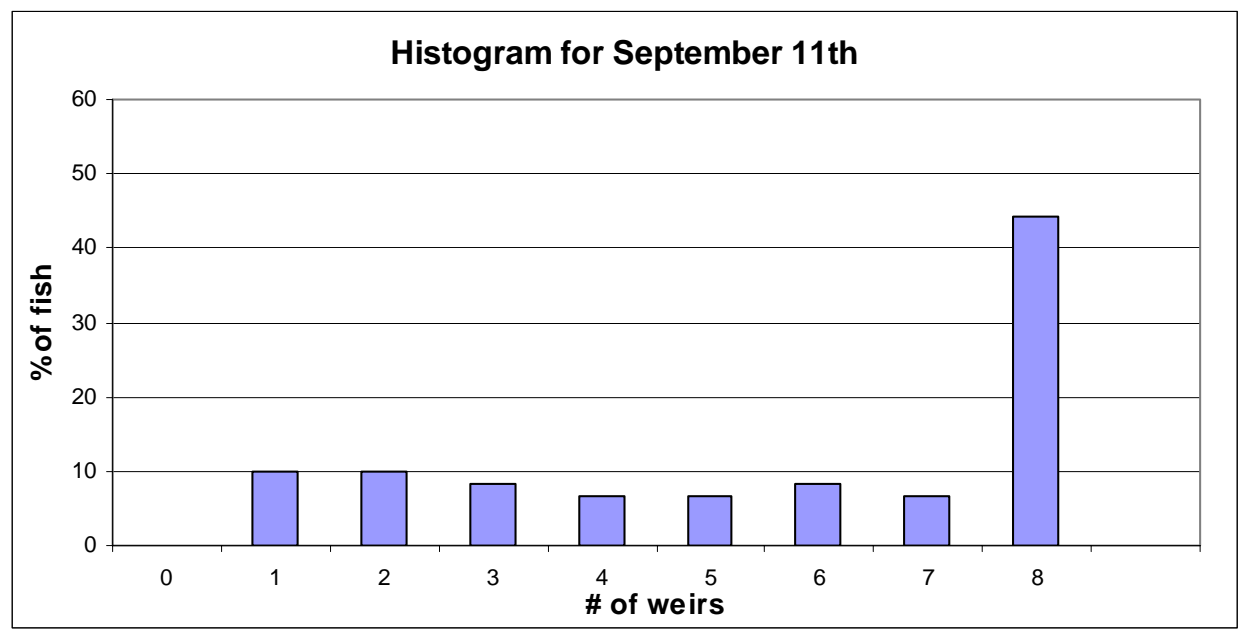

Figure 10.

Table 17.

\begin{tabular}{lc}
\hline Date & Fish using only 1-3 weirs (\%) \\
\hline April & 3.5 \\
June & 15.3 \\
11 Sep & 27.8 \\
late Sep & 13.1 \\
\hline
\end{tabular}

Table 18.

Manipulated Data for Fish migrating on 11 September 2001

\begin{tabular}{lccc} 
Number of Weirs & Fish (n) & Number of Weirs & Fish (\%) \\
\hline 0 & 6 & 0 & 9.0 \\
1 & 6 & 1 & 9.0 \\
2 & 6 & 2 & 9.0 \\
3 & 5 & 3 & 7.5 \\
4 & 4 & 4 & 6.0 \\
5 & 4 & 5 & 6.0 \\
6 & 5 & 6 & 7.5 \\
7 & 4 & 7 & 6.0 \\
8 & 27 & 8 & 40.3 \\
Down & 0 & & \\
Total & 67 & Total & 100 \\
\hline
\end{tabular}


These data showing the high percentages of fish that were recorded on only 1-3 weirs strengthen the conclusion reached by the University of Washington statisticians that the assumption of weir independence is being violated; in other words, fish that use an overflow at one weir are more apt to use an overflow at the next and subsequent weirs (Appendix C). Unless statisticians can incorporate this violation of weir independence into their models, the models will continue to overestimate the overall ladder efficiency. The spring data were re-evaluated using a robust estimator that more closely agreed with the empirical data. We never received the analysis of fall data from the University of Washington.

Conclusions--Results for 2001 suggest that fish behavior, run time, and species are large factors in determining reading efficiency for the entire ladder. Even during the massive return for the spring chinook salmon, we only missed 3.2\% of the study fish. However, the results also suggest that covering 8 weirs may not be sufficient during the summer and fall. It looks like we may be closer to a $90 \%$ reading efficiency level during these times. Actually, we need to take the time to analyze the data to determine on a per species basis what the overall reading efficiencies were for the three tagging periods. It may be necessary to either increase the number of weirs installed with orifice detectors, to start work to develop a system for detecting fish in the vertical slots or counting windows where all of the fish pass through, or to reconsider overflow detection on some weirs.

These data suggest that the assumption of weir independence is being violated, as fish that use an overflow at one weir are more apt to use an overflow at the next and subsequent weirs, especially during the fall run. Spreading out the weirs may be a better approach, and some ladders being installed with orifice detectors this winter will be using a more spread out design because of structural constraints. Knowing the number of fish not detected is critical for accurately estimating reading efficiencies for the entire ladder. Statistical models that rely solely on fish detected in the ladder appear to overestimate the overall ladder efficiency. University of Washington is trying to determine how best to modify their model. Anyway, to help in further development of the model and to learn more about how fish behavior will impact our installations, we plan on tagging more fish next year in the Washington Shore Ladder at Bonneville Dam. 


\section{Analysis of the Data by Species}

Our tagging plan for 2001 was based on three sources of information: anecdotal evidence (reports and numerous discussions with researchers who work with adult salmonids), video results by the Corps, and results generated from tagging done the previous year (during evaluation of the PIT-tag equipment in the exit ladder of the Adult Fish Facility). As indicated by the analysis above, one objective was to determine if tag-reading efficiencies were different for various run times-focusing on chinook salmon.

Nothing in these references had suggested the degree of overflow use that we recorded this year. Based on anecdotal information and previous video data, we thought we had installed enough weirs and had tagged enough fish to get a snapshot of how effective the PIT-tag equipment was during the main spring and fall runs. Fish density was most likely a factor in causing the higher than expected use of the overflows-at the peak of this fall run, there were 60,000 fish/d transiting Bonneville Dam and there were $27,000 / \mathrm{d}$ at the spring peak compared to 10 -year averages of $11,700 / \mathrm{d}$ and 2,500/d for the fall and spring peaks respectively (these figures combine the totals for chinook adults, chinook jacks, steelhead, and coho). ${ }^{1}$

Because of the large runs this year, we were able to tag many more fish in 2001 than we had the previous year. However we now know that if we are to obtain species-specific information on steelhead and coho salmon, we will need to tag even more fish next year. We did limit the number of tagging days this year because of the extensive time required to analyze videotapes. Next year, we will not be videotaping and will therefore have more time to tag additional fish.

Based on Corps video results from previous years, NMFS was most concerned with the use of overflows by fall chinook salmon; thus we made certain to tag enough of these fish to have confidence in the results (Stansell et al. 2000, Stansell and Beck 2001). However, even for this population, results next year may be different from this year: these results are snapshots-they may only apply to BWSL for 2001. Only time and more tagging will give us knowledge about which trends observed this year are consistent from year to year.

As in the above run-time analyzes, in the following tables and histograms, 0 indicates that a fish was not read on any of the 12 weirs, the 1 to 8 categories represent

\footnotetext{
1 These return numbers and others used in this document are from the DART website.
} 
the number of upper weirs that a fish was read on, and "down” indicates the fish was only read on the lower weirs at BWSL.

Spring chinook salmon--A total of 303 spring chinook salmon were PIT-tagged at the AFF on April 11, 16, 17, 18, 24 and 25 April 2001 (see Table 5). Table 19 and Figure 11 depict the numbers and percentages of fish read on the various numbers of weirs for the two salmonid populations tagged in April.

Even during the massive 2001 return for the spring chinook salmon, most of this population used the orifices as almost $80 \%$ were recorded on all 8 weirs (Table 19 and Figure 11). In fact, we basically reached the $95 \%$ level with 4 weirs installed (Table 20). Furthermore, we missed reading only $2.6 \%$ of all spring chinook (Table 19 ).

Steelhead in April--We only tagged 13 steelhead in April, which greatly impacted the reading efficiency estimate (see Table 5). If we had detected 12 fish instead of 11 fish, the overall ladder efficiency would have increased to $92.3 \%$ from $84.6 \%$. The steelhead appeared to use the overflows more than the spring chinook salmon as only $38.5 \%$ used all eight weirs and furthermore, $30.8 \%$ of them were recorded using only 1 , 2, or 3 weirs out of the 8 possible compared to $1.6 \%$ for the spring chinook salmon (Table 19). It may be that these early-run steelhead were reacting to the large run of spring chinook salmon that were predominately using the orifices. Basically, we need to tag more steelhead to be able to reach any conclusions. To complicate the issue, steelhead migrating in April may be either A-run or B-run steelhead as some B-run steelhead hold up below Bonneville Dam during the winter and there may be a behavioral difference between the two runs. 
Table 19.

\begin{tabular}{lccccc}
\hline Number of & \multicolumn{5}{c}{ Data for fish tagged in April 2001 } \\
Weirs & $\begin{array}{c}\text { Chinook } \\
\text { (n) }\end{array}$ & $\begin{array}{c}\text { Steelhead } \\
(\mathrm{n})\end{array}$ & $\begin{array}{c}\text { Number of } \\
\text { Weirs }\end{array}$ & $\begin{array}{c}\text { Chinook } \\
(\%)\end{array}$ & $\begin{array}{c}\text { Steelhead } \\
(\%)\end{array}$ \\
\hline 0 & 8 & 2 & 0 & 2.6 & 15.4 \\
1 & 2 & 2 & 1 & 0.7 & 15.4 \\
2 & 4 & 2 & 2 & 1.3 & 15.4 \\
3 & 1 & 0 & 3 & 0.3 & 0.0 \\
4 & 3 & 0 & 4 & 1.0 & 0.0 \\
5 & 4 & 1 & 5 & 1.3 & 7.7 \\
6 & 12 & 0 & 6 & 4.0 & 0.0 \\
7 & 20 & 1 & 7 & 6.6 & 7.7 \\
8 & 239 & 5 & 8 & 78.9 & 38.5 \\
Down & 10 & 0 & Down & 3.3 & 0.0 \\
Total & 303 & 13 & & & \\
\hline
\end{tabular}

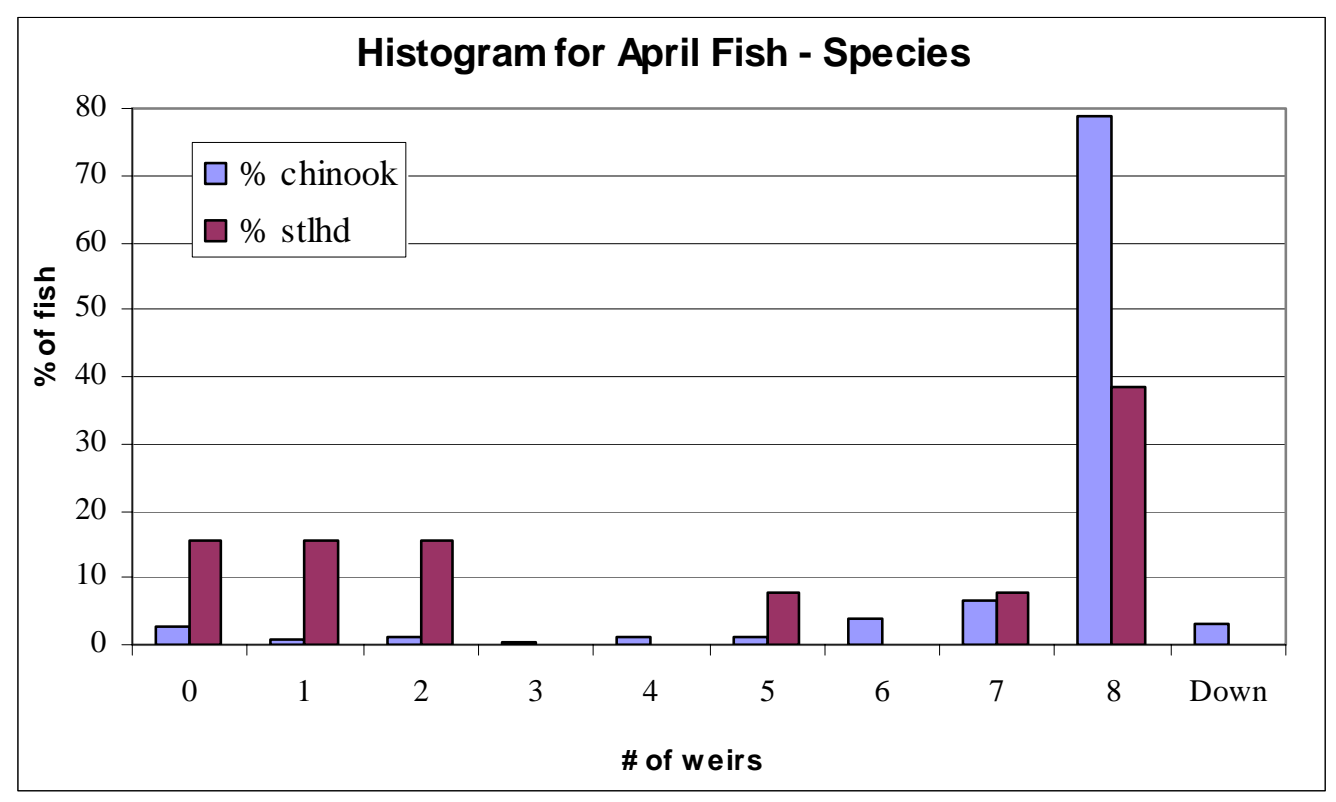

Figure 11. 
Table 20.

\begin{tabular}{lcccccc}
\hline & \multicolumn{6}{c}{ RE for different number of consecutive weirs (\%) } \\
& 4 & 5 & 6 & 7 & 8 & Fish* (n) \\
\hline Chinook & 94.5 & 95.5 & 95.9 & 96.6 & 97.2 & 290 \\
Steelhead & 61.5 & 69.2 & 69.2 & 84.6 & 84.6 & 13 \\
& & & & & & \\
Combined & 93.1 & 94.4 & 94.7 & 96.0 & 96.7 & 303 \\
\hline
\end{tabular}

* Only used fish that ascended the ladder on day tagged for this analysis.

Summer chinook salmon and Steelhead in June--On 13 June, 36 summer chinook salmon and 16 steelhead were PIT tagged (see Table 9).

The low number of fish tagged again significantly reduced the strength of any conclusions. The results suggested that summer chinook salmon primarily used the orifices, as over $70 \%$ of the fish were recorded using all eight weirs (Table 21 and Figure 12). Steelhead appeared to use the overflows more than chinook salmon: only $31.3 \%$ of steelhead used all eight weirs. These behavioral observations are strengthened by the number of each population only recorded using 1, 2, or 3 of the 8 weirs: these values were $31.3 \%$ for the steelhead and $8.4 \%$ for the summer chinook salmon.

It looks like the 8-weir interrogation system would probably be sufficient for the summer chinook salmon (Table 22). We tagged too few steelhead to feel comfortable reaching any conclusions, though the general fish behavior appeared similar during the April and June tagging (both of these tagging periods were before the peak of the steelhead A run that occurs in August). 
Table 21.

\begin{tabular}{lccccc}
\hline Number of & \multicolumn{5}{c}{ Data for fish tagged in June 2001 } \\
Weirs & $\begin{array}{c}\text { Chinook } \\
\text { Steelhead }\end{array}$ & $\begin{array}{c}\text { Number of } \\
(\mathrm{n})\end{array}$ & $\begin{array}{c}\text { Chinook } \\
(\%)\end{array}$ & $\begin{array}{c}\text { Steelhead } \\
(\%)\end{array}$ \\
\hline 0 & 2 & 4 & 0 & 5.6 & 25.0 \\
1 & 1 & 1 & 1 & 2.8 & 6.3 \\
2 & 2 & 2 & 2 & 5.6 & 12.5 \\
3 & 0 & 2 & 3 & 0.0 & 12.5 \\
4 & 0 & 0 & 4 & 0.0 & 0.0 \\
5 & 1 & 0 & 5 & 2.8 & 0.0 \\
6 & 1 & 2 & 6 & 2.8 & 12.5 \\
7 & 3 & 0 & 7 & 8.3 & 0.0 \\
8 & 26 & 5 & 8 & 72.2 & 31.3 \\
Down & 0 & 0 & Down & 0.0 & 0.0 \\
Total & 36 & 16 & & & \\
\hline
\end{tabular}

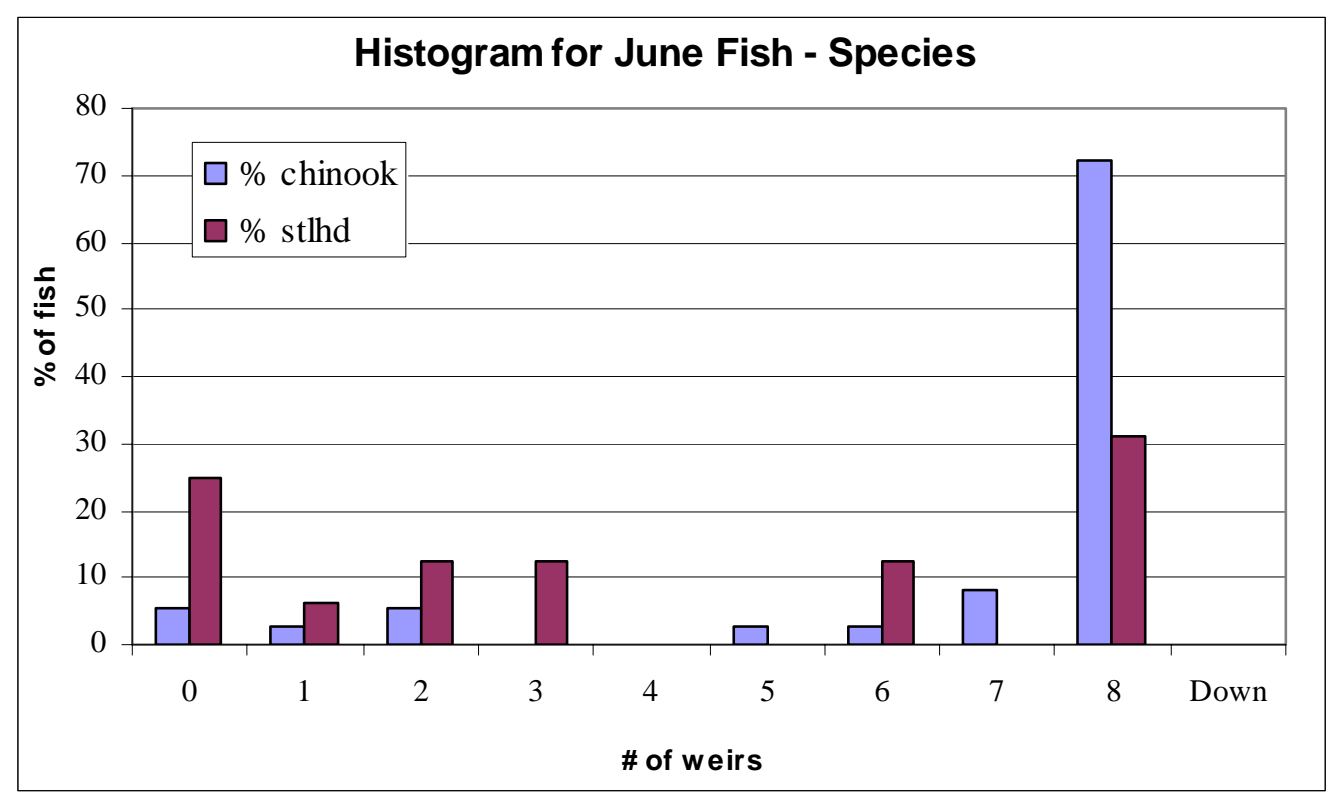

Figure 12. 
Table 22.

\begin{tabular}{lrrrrrl}
\hline & \multicolumn{7}{c}{ RE for different number of consecutive weirs (\%) } \\
& 4 & 5 & 6 & 7 & 8 & Fish* (n) \\
\hline Chinook & 86.1 & 86.1 & 88.9 & 91.7 & 94.4 & 36 \\
Steelhead & 50.0 & 50.0 & 56.3 & 75.0 & 75.0 & 16 \\
& 75.0 & 75.0 & 78.8 & 86.5 & 88.5 & 52 \\
\hline
\end{tabular}

* Only used fish that ascended the ladder on day tagged for this analysis.

Fall chinook salmon--During September, we tagged 158 fall chinook salmon (Table 13). The fall chinook salmon used the overflows more than the spring and summer chinook salmon as less than $50 \%$ were recorded on all 8 weirs (Table 23) compared to $70+\%$ for the previous two chinook runs (Tables 19 and 21). Furthermore, $15.2 \%$ of the fall chinook salmon were recorded using 1, 2, or 3 weirs out of the 8 possible compared to 2.3 and $8.4 \%$ for spring and summer chinook salmon respectively. Historical anecdotal evidence and the video data collected by the Corps in 1999 and 2000 also suggested that the fall chinook salmon used the overflows more than spring and summer chinook salmon (Stansell et al. 2000, Stansell and Beck 2001). It appears that with the 8 -weir interrogations system, we may be closer to a $90 \%$ reading efficiency than the $95 \%$ goal (Table 24). The $90 \%$ level is probably sufficient for the researchers conducting the transportation/survival studies, but might not be adequate for studies planned to investigate conversion rates between dams.

Steelhead in September--In September, we tagged 88 steelhead trout (Table 13). During late September, we were tagging near the end of the steelhead B run. At this time, the results suggest that these B-run steelhead may use the overflows less than their spring-early summer A-run cohorts. The September results showed $78 \%$ of the steelhead used the orifices for 6-8 weirs compared to around $45 \%$ for the early run steelhead (Table 23 and Figure 13). Of course, these B-run fish may have been reacting to the other fish in the ladder-maybe as more coho and fall chinook salmon used the overflows, then the steelhead used the orifices. We will tag more steelhead next year, but are comfortable with using the 88 fish to suggest that it appears that the 8-weir interrogation system would be sufficient for monitoring late-run steelhead as $95 \%$ of them would have been read even if only 6 consecutive weirs been installed (Table 24).

Coho salmon--In September, we tagged 31 coho salmon (Table 13). We tagged too few coho salmon to reach any strong conclusions, but when these results were 
combined with the results for coho analyzed for 11 September, the same trends were apparent. It appears that coho salmon use the overflows more than fall chinook salmon (only $22.6 \%$ of them were detected on all eight weirs) and that their overall ladder reading efficiency is probably in the $75-80 \%$ range with the 8-weir interrogation system (Tables 23 and 24). In other words, far below the 95\% goal (although coho were never mentioned specifically when this goal was discussed). This may not be surprising considering that coho salmon are surface-oriented fish. The large return may also have been a factor as this year's coho run was 8 times the 10-year average and 20 times the numbers at the peak of the run $(15,000-20,000$ vs. $800-1,000 / d)$.

Table 23.

\begin{tabular}{lccccccc}
\hline \multicolumn{7}{c}{ Data for fish tagged in September 2001 } \\
$\begin{array}{lccccc}\text { Number of } \\
\text { Weirs }\end{array}$ & $\begin{array}{c}\text { Chinook } \\
(\mathrm{n})\end{array}$ & $\begin{array}{c}\text { Steelhead } \\
(\mathrm{n})\end{array}$ & $\begin{array}{c}\text { Coho } \\
(\mathrm{n})\end{array}$ & $\begin{array}{c}\text { Number of } \\
\text { Chinook }\end{array}$ & $\begin{array}{c}\text { Steelhead } \\
(\%)\end{array}$ & $\begin{array}{c}\text { Coho } \\
(\%)\end{array}$ & $(\%)$ \\
\hline 0 & 15 & 4 & 7 & 0 & 9.5 & 4.5 & 22.6 \\
1 & 7 & 2 & 2 & 1 & 4.4 & 2.3 & 6.5 \\
2 & 6 & 4 & 1 & 2 & 3.8 & 4.5 & 3.2 \\
3 & 11 & 2 & 1 & 3 & 7.0 & 2.3 & 3.2 \\
4 & 7 & 1 & 3 & 4 & 4.4 & 1.1 & 9.7 \\
5 & 8 & 3 & 2 & 5 & 5.1 & 3.4 & 6.5 \\
6 & 12 & 3 & 2 & 6 & 7.6 & 3.4 & 6.5 \\
7 & 16 & 5 & 6 & 7 & 10.1 & 5.7 & 19.4 \\
8 & 74 & 61 & 7 & 8 & 46.8 & 69.3 & 22.6 \\
Down & 2 & 3 & 0 & Down & 1.3 & 3.4 & 0.0 \\
Total & 158 & 88 & 31 & & & & \\
\hline
\end{tabular}




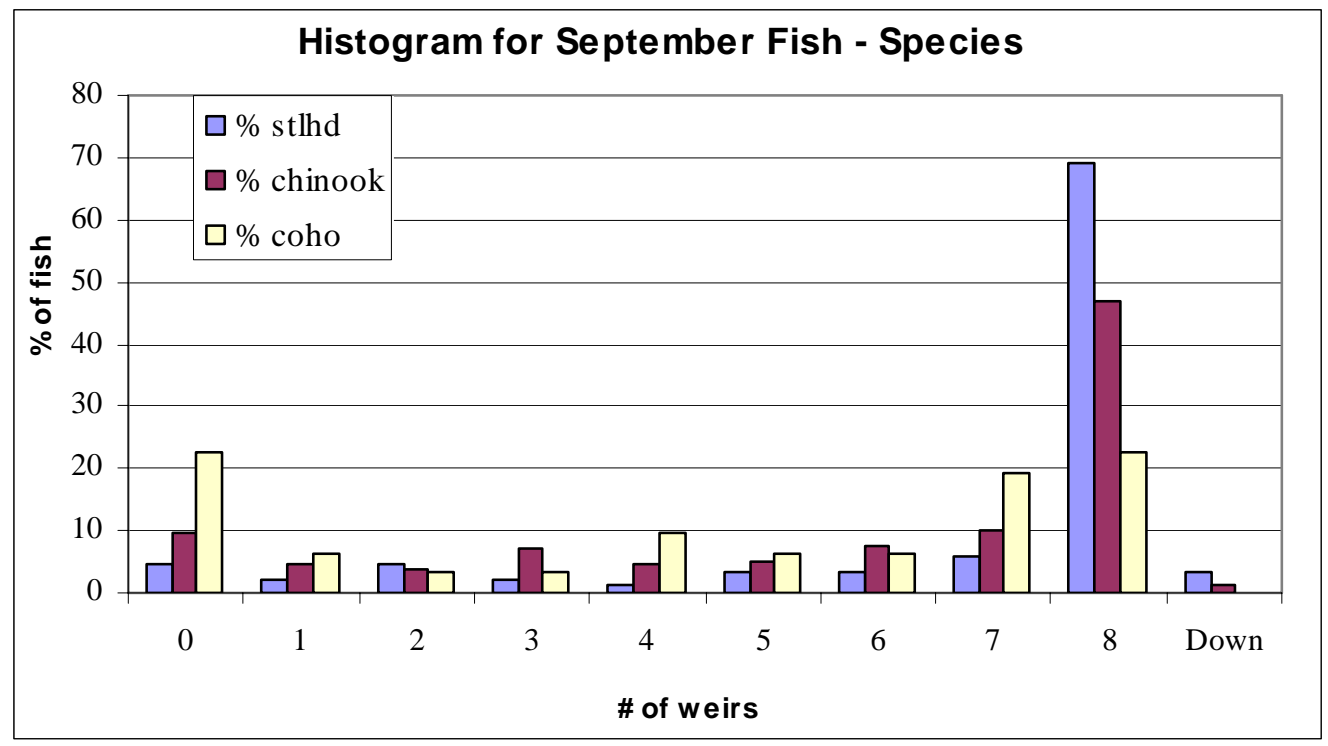

Figure 13.

Table 24.

RE for different number of consecutive weirs (\%)

\begin{tabular}{lrrrrrr} 
& 4 & 5 & 6 & 7 & 8 & Fish*(n) \\
\hline Fall chinook & 76.8 & 83.2 & 87.7 & 89.0 & 90.3 & 155 \\
Steelhead & 88.3 & 88.3 & 94.8 & 94.8 & 94.8 & 77 \\
Coho & 62.1 & 72.4 & 75.9 & 75.9 & 75.9 & 29 \\
Combined & 78.5 & 83.5 & 88.5 & 89.3 & 90.0 & 261 \\
\hline
\end{tabular}

* Only used fish that ascended the ladder on day tagged for this analysis.

Overall Observations--Besides the obvious need to tag more fish to get the species specific information, we are concerned about two findings suggested by the fish tests:

- $\quad$ The apparent $90 \%$ reading efficiency level for the fall chinook salmon

- $\quad$ The apparent $75-80 \%$ reading efficiency level for coho salmon

Do these reading efficiency levels that fall below the 95\% objective impact the ability of the fisheries community to meet its obligations outlined in the NMFS Biological Opinion for operating the FCRPS? Below we discuss these results in terms of this question and present possible next steps. 


\section{Status of PIT-Tag Detection of Adult Salmonids in Fish Ladders at the End of 2001 and Possible Next Steps}

The results of our analysis of the data on a per-species basis suggested several things. One that we need to tag more fish in general to get more statistical precision (Figure 14) and see if the trends we found this year are consistent in subsequent years. Please keep in mind that these results may only apply to the BWSL for 2001 (i.e., the data are only snapshots in time) and fish behavior may be site specific. We also want to tag fish next year because at this time the statistical models are overestimating the reading efficiency of a ladder, and except for BWSL, the models are our only real option for evaluating fish ladders. By tagging more fish, we can help improve these models.

Figure 14 suggests that not much is gained with tagging more than 200 spring chinook salmon as the reading efficiency values started to level off; that asymptotic value was reached at closer to 75 for the fall chinook salmon. These results suggest that for other species in the future we should try to tag at least 100 fish for each species and 200 if possible. Figure 14 also suggests that low numbers of fish tend to underestimate the true efficiency of the interrogation system. Data from the other species also indicate the effect of tagging low numbers-for example, with steelhead in spring, had we detected one more fish, reading efficiency would have increased from 84.6 to $92.3 \%$. Therefore, next year, we plan to tag more fish and cover more of the run time.

The results from the fall tagging suggested two important trends. One is that the reading efficiency for the fall chinook salmon may be closer to $90 \%$ with the 8 weirs installed in BWSL. The other trend is that reading efficiency appears to be in the 75-80\% range for coho salmon. Although these results are below our targeted goal of 95\%, they may be quite acceptable for helping researchers that are conducting current projects. For example, NMFS researchers indicate that the $90 \%$ level would be acceptable for their transportation/survival studies. We have asked NMFS Regional Office and have received permission to tag all coho next year, which will help us significantly in reaching our tagging goal. As an aside, we have not tagged any sockeye salmon and therefore we have no idea how effective the 8-weir interrogation system would be for them.

Again, we want to emphasize that we are reading lower than expected not because the PIT-tag equipment is missing too many fish (individual orifices have reading efficiencies of $99+\%$ - Stansell and Beck 2002), but because the fish are choosing to use the overflows more than the fisheries biologists expected. Therefore, we are not reading $95 \%$ for all of the species all of the time. Of course, we had some great returns this year, which may have influenced fish behavior in the ladder. Certainly, the biologists working 

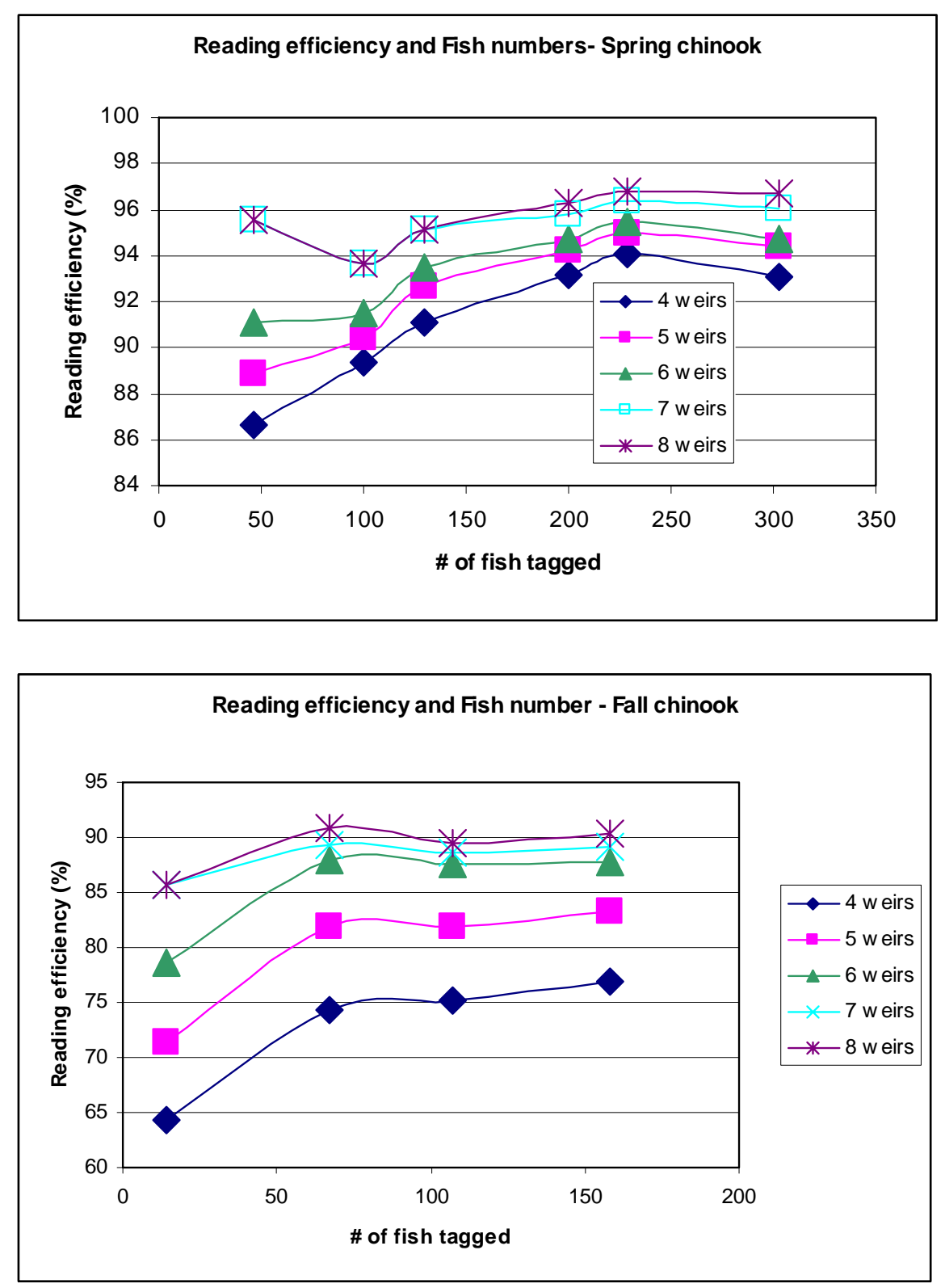

Figure 14. Figures show the relationship between numbers of chinook salmon tagged and precision of reading efficiency values for different number of weirs. The data displayed in the top figure are from the spring chinook salmon data collected during April 2001 and data displayed in the bottom figure are from the fall chinook salmon data collected during September 2001. 
at Bonneville indicated that they were seeing more use of the overflows this fall than they could recall having seen before.

What this indicates to us is that we are still learning about fish behavior in ladders and suggests that the 8-weir interrogation systems being proposed for the fish ladders at Bonneville and McNary Dams might not be the final products installed; however, they are probably adequate for helping the researchers complete their current set of projects. They may not be sufficient for conducting studies examining conversion rates between dams-on the other hand, they may be.

We only have data (and somewhat insufficient data at that) for one ladder for one year. Furthermore, this may have been an atypical year as fish numbers at Bonneville Dam were very high:

- $\quad$ The spring chinook run was 6 times the 10 -year average and 10 times the density at the peak of the run $(25,000 / \mathrm{d}$ vs. $2,500 / \mathrm{d})$

- The fall chinook run was double the 10-year average and 3 times the density at the peak of the run $(25,000 / \mathrm{d}$ vs. $8,000 / \mathrm{d})$

- $\quad$ The steelhead run was around 3 times the 10 -year average for both fish number and density at the peak

- The coho run was 8 times the 10-year average and 20 times the density at the peak $(15,000-20,000 / d$ vs. $8000-1,000 / d)$

- Even shad numbers were the highest for the past 10 years

Furthermore, Bonneville Dam normally has 2-4 times as many fish and 2-4 times the density of fish going over it than McNary Dam. Thus, there may be less use of overflows at McNary Dam because the fish density is lower-on the other hand, the two fish ladders at McNary Dam have full-overflow designs compared to the partial overflow design for the BWSL, which may affect fish behavior. Cascades Island Ladder is also a full overflow design (actually, each fish ladder is unique and may influence fish behavior).

Our point here is that we think it is too early to judge whether the 8-weir interrogation systems planned for Bonneville and McNary Dams will be sufficient by themselves to answer all of the management and biological issues raised in the Biological Opinion.

However, it may be time for the fisheries community to decide whether to stand pat and wait to see how effective the interrogation systems perform next year or whether 
it is time to put some effort toward research and development to increase the reading efficiency of a ladder or the dam as a whole. It may be that we need site-specific solutions because Bonneville Dam is unique with its high fish numbers and densities or we may need more general solutions. We have thought of several possible ways to proceed if steps need to be taken to increase overall reading efficiencies:

1) wait and see how effective are the installed systems (determine if results are unique to BWSL in 2001);

2) install more orifice detectors;

3) develop and install overflow detectors;

4) develop and install detectors at the counting windows;

5) develop and install detectors for the vertical slots;

6) create choke points within the ladder in which interrogation equipment could be installed; and

7) install a combination of the above options for site-specific solution.

None of these options is different from those discussed 4-5 years ago when this subject of detecting salmonids in fish ladders was first broached; however, PIT-tag technology has significantly improved since that time and it may now be possible to succeed in interrogating salmonids in these alternative sites. For one, in the laboratory, we can detect tags in the center of 48-inch antennas because of significant improvements made to the transceiver model FS1001 that was installed throughout the Columbia River Basin in 2000 for interrogating juvenile salmonids.

The original "enhanced performance" transceiver, model FS1001A, was the model installed at BWSL. Even since that installation, Digital Angel has added the capacity to include a $24 \mathrm{~V}$ power supply unit instead of a $12 \mathrm{~V}$ power supply, which allows the transceiver to work better with large antennas (e.g., the 48-inch antennas and the 2' x 6' antennas being used in small-stream interrogation systems).

Another significant improvement is the "super" ISO tag, which provides better read performance overall than the current tag especially under electronically noisy conditions. This tag, however, will not be available until late this year or next and has not been evaluated in the field (plus adults returning with it will not be in the system for a few years). There are obviously outer limits, but development has pushed PIT-tag technology to work in new areas (e.g., small streams and full-flow bypass systems). More development is planned-Digital Angel is starting to work with the fisheries community on a modular design for future transceivers that would include a faster processor and the ability to handle multiple analog boards. 
We thought it would be useful to outline the pros and cons of each of the above options. We may not list everything, but hopefully enough will be included to help with the discussion planned for 30 October.

\section{Install more orifice detectors in additional weirs}

Pros:

- Technology has been proven effective (individual orifices are $99+\%$ effective)

- Could be added to currently planned systems (i.e., use most of the same infrastructure)

- No more money needed for new R\&D efforts

- No hydraulic modeling by the Corps needs to be done
Cons:

- Unknown how to install so we get the fish who use $>8$ consecutive overflows (though a spread out design might be more effective and is favored by one NMFS statistician)

- No guarantees that all fish will pass through an orifice

\section{Develop and install overflow detectors}

Pros:

- Hydraulic modeling has been completed by the

Corps

- Not much R\&D effort would be needed to develop a system for partial overflows

- Could probably be added to currently planned infrastructures (e.g., PIT-tag rooms)
Cons:

- Until super tag is available in adult fish and maybe even then, we are unlikely to read all tags in fish using overflows when the ladder is in high-flow mode for assisting shad passage

- Interrogation systems for full overflows would require multiple antennas to cover the 20-25' spans. This would require developing the ability to multiplex these antennas and probably would have to wait for the next generation of transceivers (the modular design that could accommodate multiple analog boards).

- Would be quite costly to install for the number of weirs needed to incorporate a redundant system

- Not all fish use this passage route

- Antennas could not be accessed during the field season for maintenance

\section{Develop and install detectors at the counting windows}

Pros:

- All of the dams have counting windows

- All of the fish use this passage route (except those transiting the navigation locks)

- Many of the windows have relatively narrow pathways (e.g., McNary Dam has an 18" wide by 5' deep window)
Cons:

- Probably only room for 1-2 antennas with maybe a third at some locations - not much redundancy

- Because of the limited number of antennas, the desired overall increase in ladder reading efficiency may not be met

- At Bonneville, would not know which ladder the - Antennas could be accessed during the field season fish originally transited for maintenance
- At Bonneville, counting window size is 3' by 5' and so would require an antenna that is larger than we have currently tested successfully (in fact the upper cross beam would probably need to clear the water surface by 1-2', so the antenna would be quite 
large or require two antennas)

- Potentially there could be a negative human health factor with the electromagnetic fields generated with these large antennas

- Could increase the debris problem

\section{Develop and install detectors for the vertical slots}

\section{Pros: $\quad$ Cons:}

- All of the fish use this passage route (except those - Vertical slots are only present at Bonneville and transiting the navigation locks)

- Multiple slots so could easily install four or more redundant antenna systems

- Might be a good site-specific solution for Bonneville Dam

- Antennas could be accessed during the field season • Requires more system development work than for maintenance without the ladder needing to be some other options dewatered
Ice Harbor Dams

- Could increase the debris problem depending on design

- At Bonneville, would not know which ladder the fish originally transited

\section{Create choke points within the ladder in which to install interrogation equipment}

An additional option would be to create choke points within the ladder in which interrogation equipment could be installed. For example, on the Washington side at Bonneville Dam, the fish transit through a long channel before exiting into the forebay. This channel is about $15 \mathrm{ft}$ across and maybe the Corps could install a long slot like the counting window that would be narrow enough to use present technology or install a weir in there with orifices.

Another example was mentioned above--maybe the counting windows can be extended before they flare out so that additional antennas could be installed to get the necessary redundancy to reach the $95 \%$ reading efficiency goal.

\section{Install a combination of the above options}

It may be that we need site-specific solutions and therefore that a combination of the above options is the only way to successfully increase the overall reading efficiency for specific species or runs. Some of the options listed above would require changes to fish ladders - we need to learn from the Corps and NMFS Regional Office what are acceptable changes. For example, can two antennas be installed in a counting window or a vertical slot that would create a cross beam in the middle of these spaces (the cross beams would increase the chances of catching debris)? If so, then current technology could be applied to these locations without as much development work. Hopefully this 
has helped the reader understand better what we learned during 2001 and what our options are for 2002 and beyond.

\section{Evaluation of Alternative Direct Methods}

The use of direct evaluation for detection systems requires that all tagged fish pass through the interrogation system. This can be problematic for adult fish systems because newly tagged adults released into a fish ladder below an interrogation system could elect to descend rather than ascend the ladder. For these fish, it would be impossible to determine whether they had ascended without being detected or avoided the interrogation system by descending and exiting the ladder.

To use the direct method in the fish ladders to be newly outfitted for 2002, fish would need to be captured, anesthetized, tagged, held until recovery, transported and then released at some point between weirs having PIT-tag interrogation antennas. In 2001, we evaluated this method by releasing eight fish in the middle of the eight upper weirs in BWSL. Results suggested that the behavior of these fish would not be representative of river-run fish volitionally ascending a fish ladder; thus information produced using this method could be suspect. For this reason, we are apprehensive about using this approach unless results from the alternative approaches fail to provide adequate information.

Other alternative direct methods that will be used in 2002 include use of adult salmonids that are double tagged by University of Idaho with radio tags and PIT tags. The University of Idaho releases most of their study fish below Bonneville Dam. This alternative is preferred because radiotelemetry data could be used to confirm fish passage up individual ladders. This would permit a direct comparison.

A second method is to utilize PIT-tagged fish that have been detected upstream (mostly at Lower Granite or Wells Dam) and determine whether they were detected at downstream dams. Obviously with this approach, we would not know whether undetected fish had avoided detection by using weir overflows or by passing the dam via the navigation lock. However, this approach would yield information on the effectiveness of detection systems installed at dams (i.e., overall reading efficiency of the dam). 


\section{Evaluation of Interrogation Systems for Adult Salmonids at Bonneville and McNary Dam}

During 2002, we analyzed performance of the PIT-tag interrogations systems installed at Bonneville and McNary Dams and submitted two reports to BPA (Downing and Prentice 2003; Appendix B). These covered:

- Comparison between the counting window and orifice-based interrogation systems installed in the McNary Oregon Ladder

- Determination of reading efficiencies for tagged salmonids in the BWSL

- Determination of reading efficiencies for salmonids double tagged with radio and PIT tags

- $\quad$ Performance of orifice antennas containing moisture

- $\quad$ Orifice passage behavior in fish ladders at Bonneville and McNary Dams 


\section{EMI-MONITORING STATIONS}

\section{Introduction}

During the development tests at the AFF in the spring of 2000, RF noise was observed at levels high enough to interfere with the detection of PIT tags by the transceiver systems (Downing et al. 2001). Both natural and man-made sources of EMI were recorded; both at levels that prevented PIT tags from being detected. NMFS and its contractors then did studies to design shielding that could reduce the effects of known sources of EMI. Two types of RF shields were designed: continuous (electrically shorted) and gapped (electrically unshorted).

During these tests with known sources of EMI, the shorted shield protected better against the magnetic ( $\mathrm{H}$-field) component of the noise and the unshorted shield protected better against the electric (E-field) component. Since both components of electromagnetic fields are present when RF noise is present, it was unknown which shield would do better in the "real world" at the dams. At Bonneville Dam, the motor controllers for the screen cleaners in Powerhouse II were the only identified source of noise, so tests were run in September 2000 with the 3-sweeper cycle left on continuously. We released some tagged fish during this time and found that with this type of noise, the shorted shield performed better: no fish were missed using the shorted shield, while approximately two-thirds of the fish went undetected using the unshorted shield (Downing et al. 2001).

The experience at the AFF made it apparent that it would be prudent to monitor future installation sites for 1 year in advance of the scheduled installation in order to identify sources of EMI in time to eliminate them before evaluations. This would also permit multiple locations within a ladder to be monitored for determining which would be the preferred location for the installation of the production system. During FY01, EMI was monitored in the fish ladders at Bonneville and McNary Dams. 


\section{Activities}

Two methods were used to monitor EMI sources in 2001: actual interrogation units installed into the orifices themselves at Bonneville and McNary Dams and an interrogation unit placed on the powerhouse deck near the top of the McNary Washington Ladder. Both approaches rely on clean power and good grounding systems to be effective, and both are effective at identifying the presence of significant levels of noise that traveled through the air, like the noise generated by motor controllers at Bonneville Dam. However, only the in-ladder approach would be able to identify noise traveling through the reinforcement bar in the ladder.

Since we did not know what type of EMI might be present at McNary Dam (i.e., $\mathrm{H}$-field or E-field), to test which shield design was better at this dam, we installed both unshorted and shorted shields into one location in the McNary Oregon Ladder. Each EMI-monitoring station had an RF shield, antenna housing, antenna cable and grounding lines, Destron-Technologies FS1001A transceiver, and a computer for recording noise data. The original plan called for two locations in each ladder at McNary Dam to be monitored, but the Corps needed to water up the dewatered Washington Ladder before in-ladder work could be done there.

The transceivers were set up to report the average and peak RF noise levels that had occurred during the previous $2 \mathrm{~min}$. Temperature and antenna current values were also collected every $4 \mathrm{~h}$. During the year, the EMI-monitoring stations were checked weekly to confirm normal operation, and data files were collected every two weeks. PSMFC helped out with the maintenance and collection of files at McNary Dam.

NMFS was tasked with analyzing the data, and we graphed the daily data from every interrogation unit. This permitted us to quickly identify problems and to monitor their duration. The 2-min scale enabled us to determine how quickly changes occurred and if there were patterns to the changes (e.g., noise that occurred for 6 min every $4 \mathrm{~h}$ or noise that increased as temperatures inside the transceivers increased during the afternoons).

When average noise levels are above 15\% with the FS1001A transceiver, PIT tags are sometimes not detected. Since EMI is generated in waves, noise levels are not constant, and because it only takes 31 milliseconds to decode a PIT tag, it is still possible sometimes to read a tag under noisy conditions. We initiated this monitoring plan to ensure that there were no long periods of time at any of the sites when the ability to decode PIT tags would be significantly impacted. If persistent high levels or a pattern 
were identified at a site, then the general plan was that the next step would be to try to identify the source(s) or see what could be done to reduce the impact on the interrogation system. If needed, an EMI survey would be conducted to help identify the source(s).

Monitoring was continued over the whole season because it might be that something in the vicinity that caused interference was only active during 2 weeks every year. For example, if such interference were to occur during the peak of the fall run, then it would significantly impact PIT-tag data collection efforts.

\section{Results}

During 2001, NMFS installed and maintained six EMI-monitoring stations at Bonneville and McNary Dams. The monitoring results for each station are presented separately.

\section{McNary Oregon Ladder}

The three orifice antennas were installed into this ladder in January 2001, and monitoring began on 11 April when the transceivers and laptops were installed. EMI-monitoring sites were located in the middle and upper sections of the ladder (Weirs 279 and 328). Continuous shorted and gapped unshorted shields were installed into the middle site. The upper site had a shorted shield.

For the EMI-monitoring site located at Weir 279, the orifice antenna with the continuous shorted shield was much quieter than the orifice antenna with the gapped unshorted shield (Fig. 15). The average noise level was steady at 2-3\% for the continuous-shielded antenna while it was mostly in the $15-20 \%$ range for the gapped-shielded antenna. The average noise levels for the gapped-shielded antenna also bounced around more and the peak RF noise levels were much higher; mostly around the $70 \%$ range while they were closer to $10 \%$ for the shorted shield antenna. The shorted-shielded antenna in Weir 279 was quieter than the shorted-shielded antenna in Weir 328 whose average was about 8\% (Fig. 15).

Finding a functional ground for this upper location had been difficult because there was no place on the backfilled hillside to drive a ground rod (we ended up tying into the electrical ground at the bottom of the hill); we recognized that this contributed to the higher peak noise that was observed at this site. Although the early monitoring results demonstrated that both sites would have been acceptable locations for the 

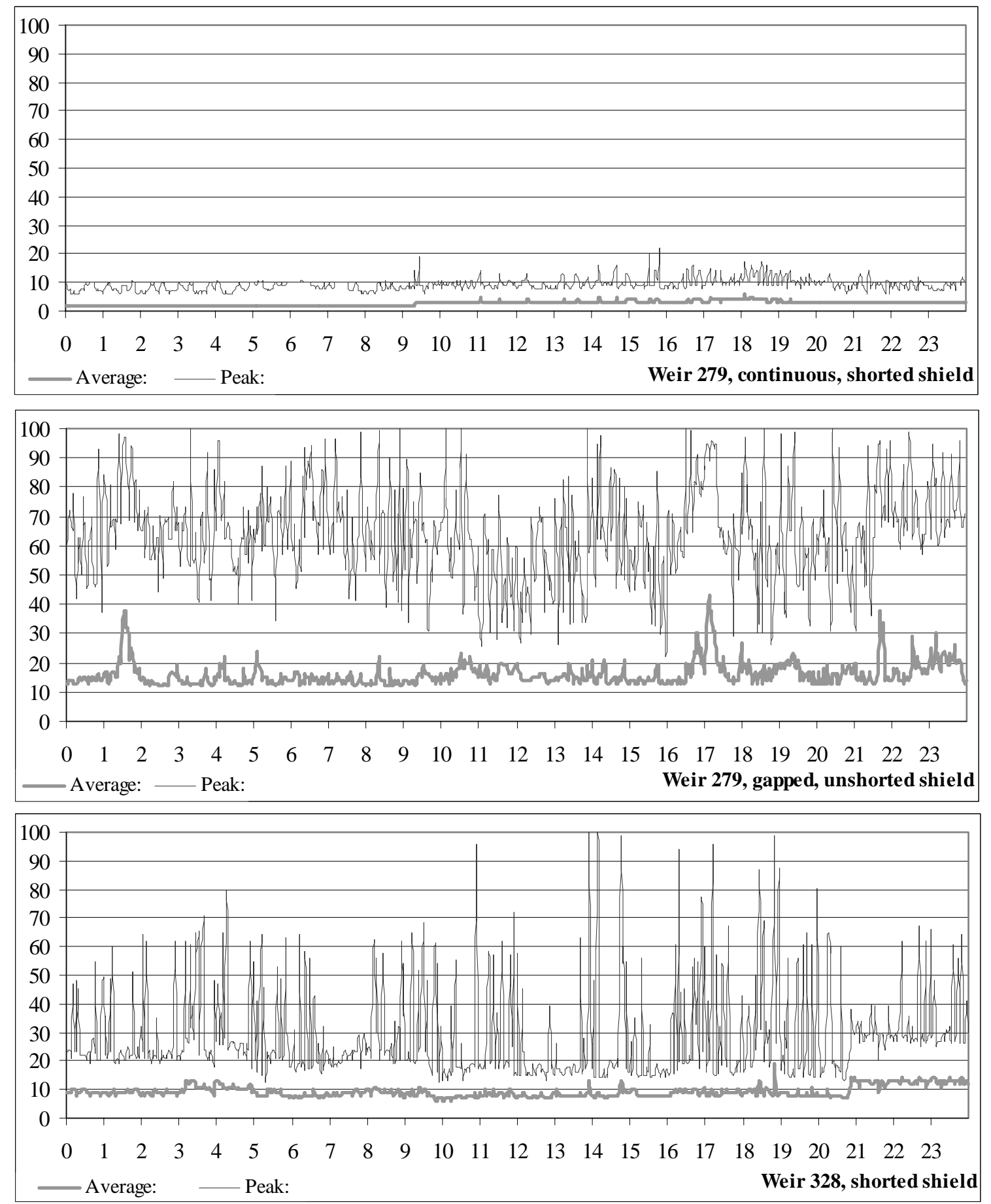

Figure 15. Hourly average and peak noise levels (percentages) on 17 April 2001 for the 3 antennas installed in McNary Oregon Ladder. Top--antenna in Weir 279 with continuous shorted shield; middle--antenna in Weir 279 with gapped unshorted shield; bottom--antenna in Weir 328 with shorted shield. 
production system, since the middle ladder section was the preferred location based on PSMFC and Corps input, we stopped monitoring the upper section at the end of May.

Monitoring of the middle section continued until the middle of October. During the summer, the peak EMI noise levels would rise slightly when the transceiver temperatures rose above $60^{\circ} \mathrm{C}$ during the afternoon (Fig. 16). However, over the 6 months of monitoring, there were no prolonged EMI levels observed that caused concern that there would be problems when a full production system was installed.

We did have a few down times when power was lost to the computer because of other work in the area by the Corps. Unfortunately, laptop computers need to be rebooted manually when power is restored, and we were not always informed when Corps personnel shut off the power. After one power outage, 2 weeks of data were lost before PSMFC went to collect the data files and found the computers off.

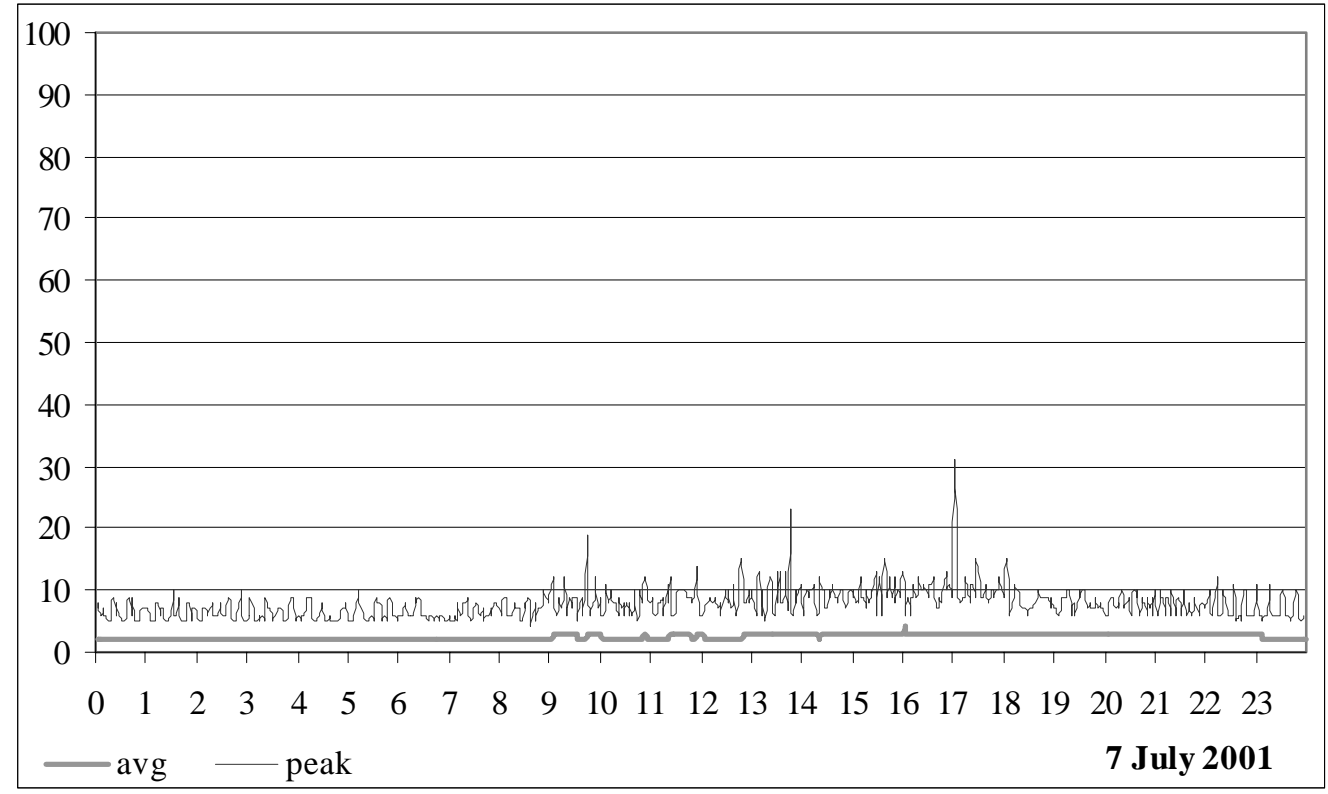

Figure 16. Hourly average and peak noise levels (percentages) on 7 July 2001 for the antenna with the continuous shield located in Weir 279 at McNary Oregon Ladder. The graph shows a slight increase in peak noise levels as the transceiver temperatures rose above $60^{\circ} \mathrm{C}$ during the afternoon. 


\section{McNary Washington Ladder}

No work was done at this site until mid June because the Corps was unable to provide a power source on the middle deck level underneath the fish ladder. Since we had been unable to install orifice antennas into this ladder to collect EMI data for this ladder, we hired a contractor, Northwest EMC, to conduct an EMF survey and we installed an orifice antenna inside of a shield on the upper powerhouse deck near the top of the fish ladder where power was available.

Ambient EMF measurements made by Northwest EMC on the upper powerhouse deck showed a strong signal at $101 \mathrm{kHz}$, but this frequency does not interfere with PIT-tag detection at $134.2 \mathrm{kHz}$. Measurements were also made while the navigation lock opened and the bridge was raised and lowered; these actions did not interfere with the transceiver. Northwest EMC also made ambient measurements on the middle deck level, which had been designated as the preferred location for the production system because this site would provide more protection from the weather, especially the sun that can quickly heat up a transceiver in this dry dessert climate.

The ambient EMF measurements indicated it was slightly quieter on the lower deck than the upper deck. However, these survey results do not reveal noise that in the future system would be generated on power lines, ground wires, or radiated through the rebar grid. Furthermore, the survey only monitored ambient noise sources that were present during the $2 \mathrm{~d}$ the contractor was on site.

Therefore to monitor the ambient noise for a longer time period, we used an orifice antenna installed on the upper powerhouse deck. The transceiver and computer for this setup were placed in a nearby room where they were protected from the high heat

present on the deck. We collected the ambient noise data from mid June to the middle of October. In general, the average noise levels were below $10 \%$ and then rose to slightly above $10 \%$ in the afternoon and evening (because the transceivers remained around $50^{\circ} \mathrm{C}$ all day, we assume this increase was due to a peak load effect being generated by the nearby high voltage lines; Fig. 17). Starting in the middle of September, there was no longer a peak demand, and consequently the average noise levels remained low throughout the day (Fig. 17). 

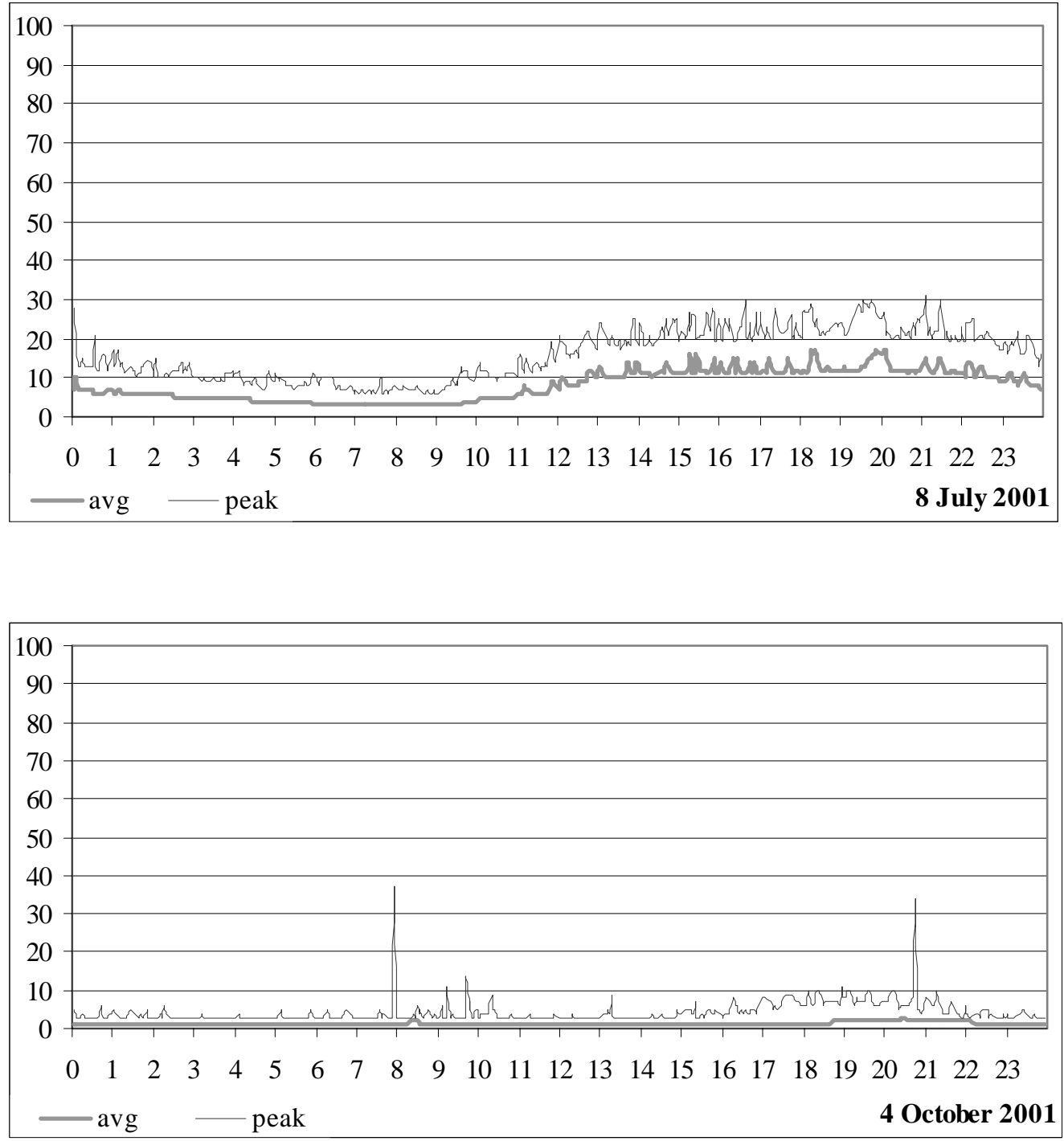

Figure 17. Daily graphs for 8 July (top) and 4 October 2001 (bottom)of the average and peak noise levels (percentages) for the antenna with the continuous shield located on the powerhouse deck of McNary Washington Ladder. The summer graph shows an increase in average and peak noise levels during the afternoon and evening. 
Periodically, peaks did occur that would have impacted the ability of transceivers to detect PIT tags during the time we monitored; however, there was no set pattern, and the peaks normally lasted less than 15 min. We did not observe any RF noise that would have prevented PIT tags from being detected by an interrogation system in this ladder for long periods of time. However, since we were unable to monitor EMF noise that radiated through the rebar grid or power lines, we cannot be as confident of these results as we are of those from other sites.

\section{Cascades Island Ladder at Bonneville Dam}

For this EMI-monitoring site, we utilized an orifice antenna that had been installed in January 2000 (Weir 54). Monitoring began on 4 April 2001 when the transceiver and laptop computer were installed. In general, average noise levels were low at 5-8\% over the year (Fig. 18). The peak RF noise levels were also mostly low, but there were days when over most of the day, there were spiky patterns with maximum levels in the 20-40\% range (e.g., middle graph in Fig. 18). However, because the average noise levels remained low, the transceiver was still able to detect PIT tags. Monitoring through the end of October did not show any EMI patterns that raised concerns about proceeding with the installation of a production system.

\section{Bradford Island Ladder at Bonneville Dam-A Branch}

An orifice antenna (with a continuous shorted shield) was installed during December 2000 and January 2001 into Weir 48. Monitoring began on 4 April when the transceiver and computer were installed and stopped at the end of November. The pattern for this interrogation unit was very consistent over the whole monitoring season (Fig. 19). The average noise levels were mostly below $10 \%$ and the peak level had a spiky pattern with maximum levels in the $10-40 \%$ range. We attributed the spiky pattern at this site and others to be due to the fact we had to use standard ground rods as grounds while a permanent site would be able to connect to the hydroelectric facility's ground. Monitoring over the whole season did not show any EMI patterns that raised concerns about proceeding with the installation of a production system. 


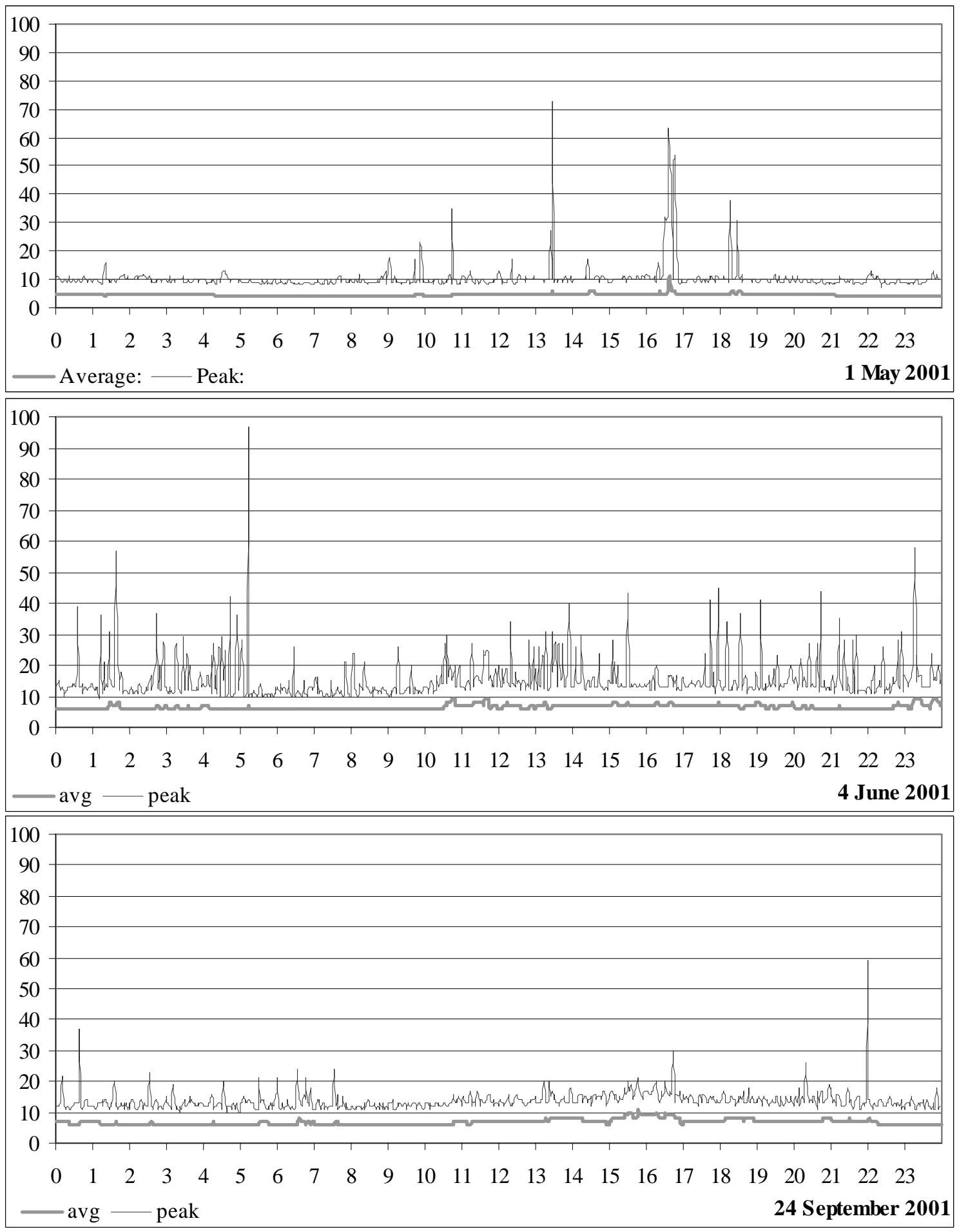

Figure 18. Daily graphs for 1 May (top), 4 June (middle), and 24 September 2001 (bottom) of the average and peak noise levels (percentages) for the orifice antenna located at Bonneville Cascades Island Ladder. 

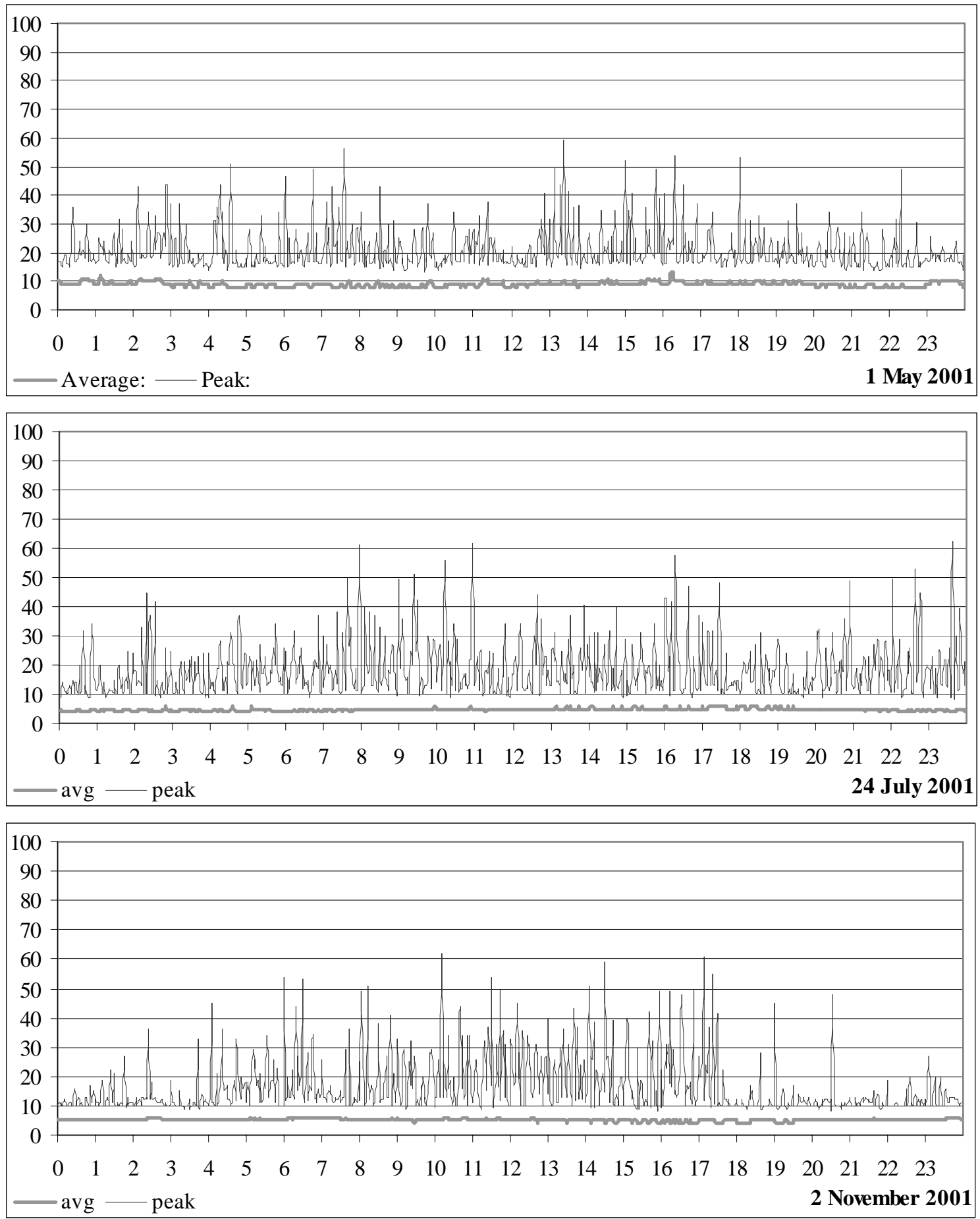

Figure 19. Daily graphs for 1 May (top), 24 July (middle), and 2 November 2001 (bottom) of the average and peak noise levels (percentages) for the orifice antenna with the continuous shield located at Bonneville Bradford A-Branch Ladder. 


\section{Bradford Island Ladder at Bonneville Dam-B Branch}

An orifice antenna (with a continuous shorted shield) was installed during December 2000 and January 2001 into Weir 49. Monitoring began on 4 April when the transceiver and computer were installed and stopped at the end of November. The noise pattern for this orifice antenna was unstable from the beginning, with average noise levels varying greatly over some days during the first month of monitoring (Fig. 20). We attributed this instability to the power source: an extension cord plugged into a trailer used by the Corps Field Fisheries Unit (the Corps had installed a power line to the A-branch location).

Unfortunately, the noise pattern worsened significantly on 12 May (Fig. 21), when peak values rose to $100 \%$ for long periods of each day, and average values increased to over $20 \%$. Electromagnetic noise is intermittent since it travels in waves; thus some tags can still be detected even when average noise over $2 \mathrm{~min}$ is above $20 \%$. Indeed, a few tags were detected on 12 May during the lower noise periods. Like the A-branch unit, the B-branch unit would read each fish 11-12 times when tags were detected (i.e., we did not see a pattern of fewer reads per fish during this noisy period; although other tagged fish were undoubtedly missed). These read-per-fish results also showed that electromagnetic noise was less constant than in the high noise situation of Antenna 9B in the Bonneville Washington Shore Ladder, where the number of reads per fish was significantly reduced relative to neighboring orifice antennas (see Fig. 29 and Table 25).

NMFS started an investigation to identify the source of EMI at this site. When the ground for the shield was switched from a grounding rod to the electrical system ground, the noise level dropped significantly. Destron Technologies helped in the investigation by bringing a spare transceiver. When the group was removing the transceiver to replace it with another one, they discovered that there were two loose screws inside that normally helped to hold the back plane on securely. When these screws were tightened, average noise dropped to below $10 \%$, and when they were loosened again, noise increased to above $20 \%$.

The conclusion was that loose screws allowed wind and rain to cause vibration in the transceiver box, and these vibrations caused internal noise. These changes eliminated the extreme conditions that had initiated on 12 May; however, because of the power source, this site continued to be noisier than any of the other sites. Typically, average noise levels would be high for several hours during 1-2 $\mathrm{d}$ and then return to a lower level (Figs. 22-23). We concluded that a cleaner power source would stabilize noise at this site; therefore, there was no reason not to proceed with installation of a production site. 

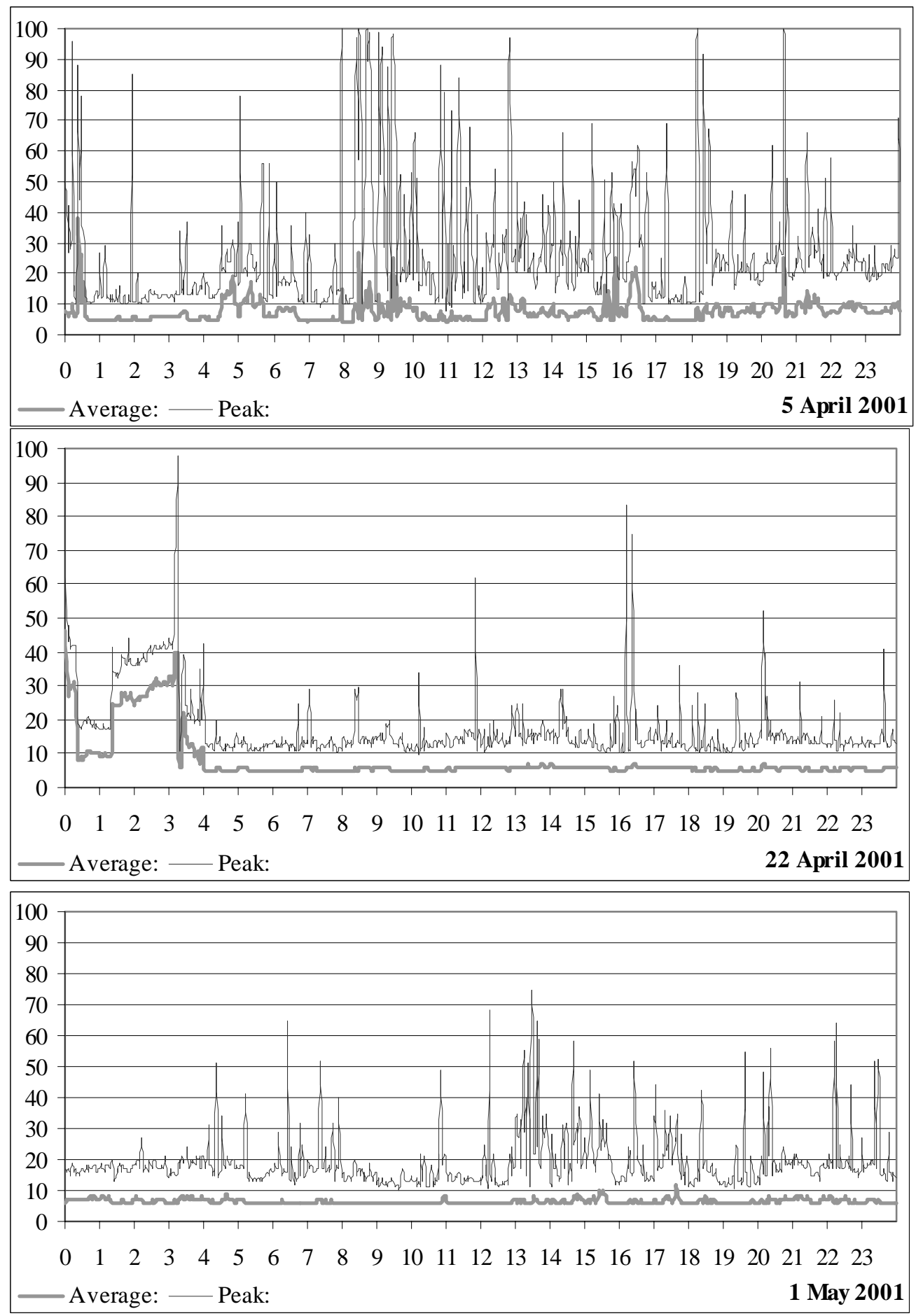

Figure 20. Daily graphs for 5 April (top), 22 April (middle), and 1 May 2001 (bottom) of the average and peak noise levels (percentages) for the orifice antenna with the continuous shield located at Bonneville Bradford B-Branch Ladder. 


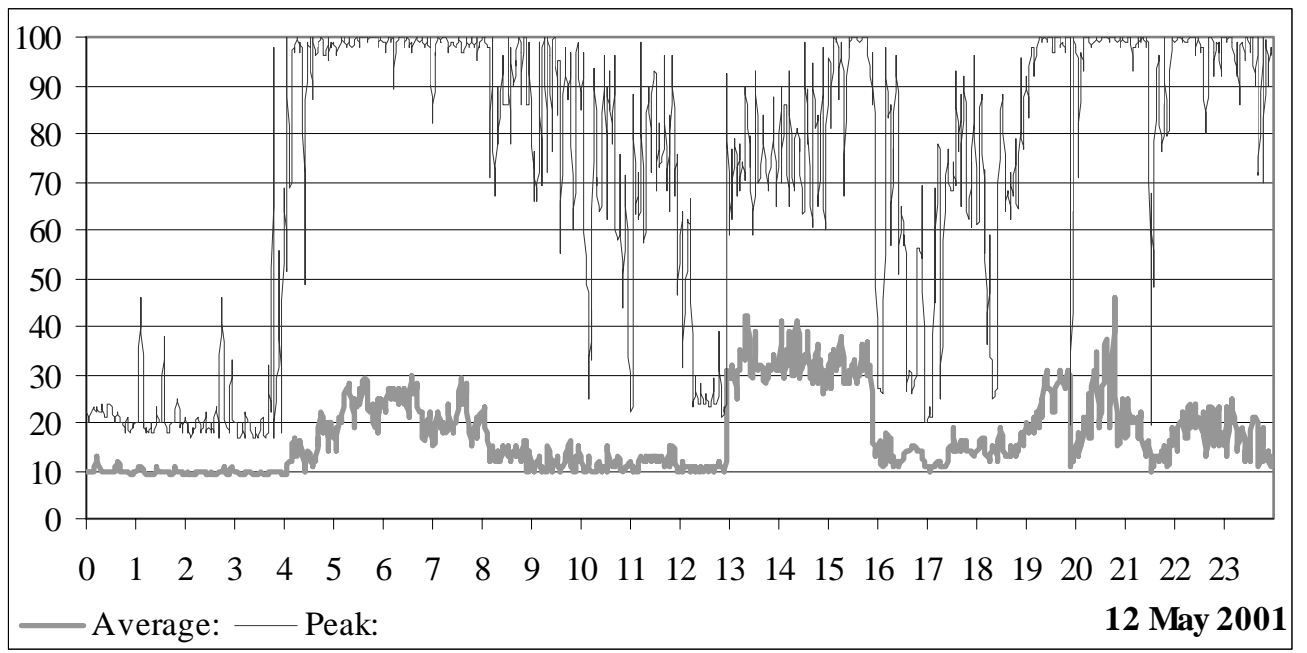

Figure 21. Daily graph for 12 May 2001 of the average and peak noise levels (percentages) for the antenna with the continuous shield located at Bonneville Bradford B-Branch Ladder. 

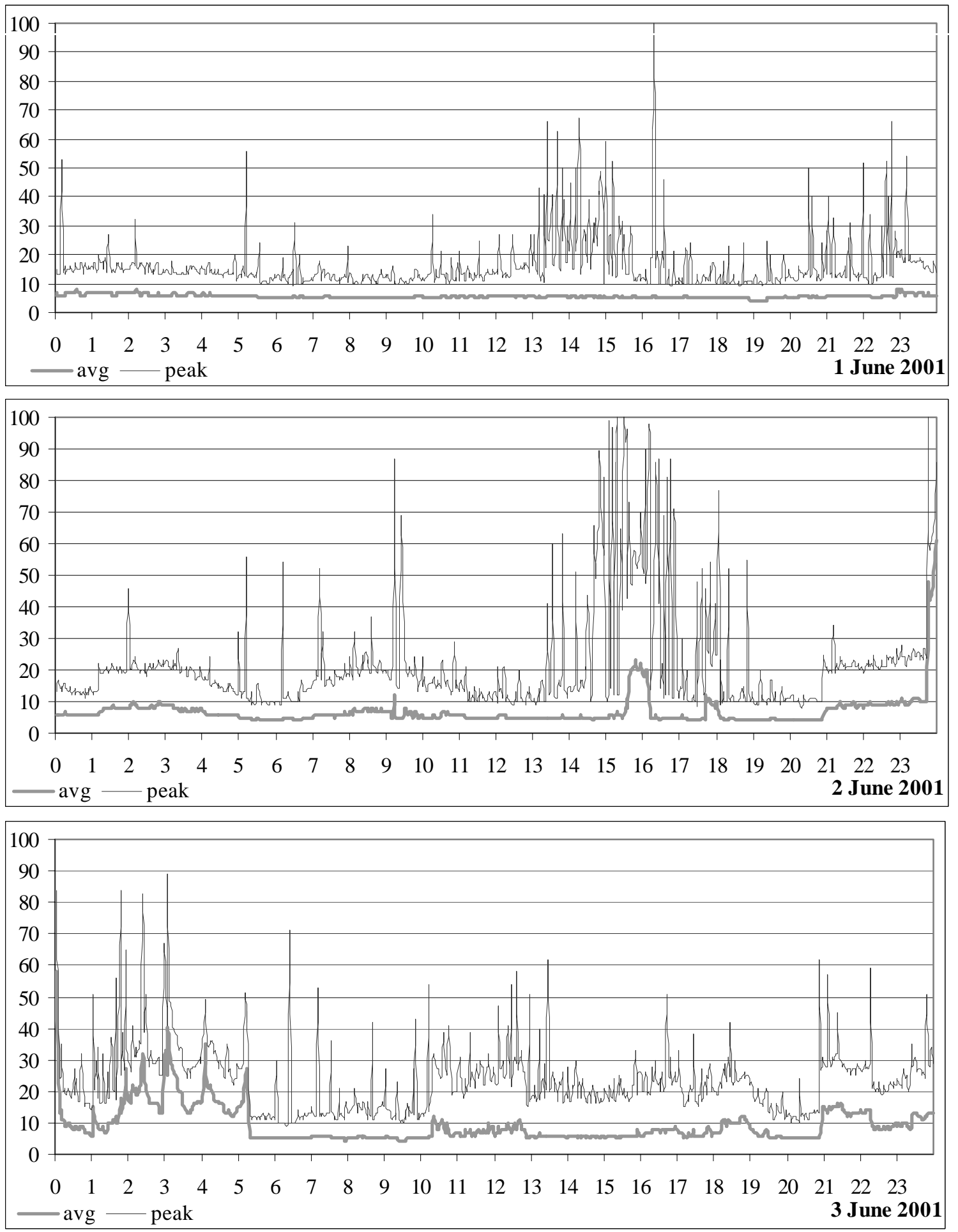

Figure 22. Daily graphs for 1 June (top), 2 June (middle), and 3 June 2001 (bottom) of the average and peak noise levels (percentages) for the antenna with the continuous shield located at Bonneville Bradford B-Branch Ladder. 

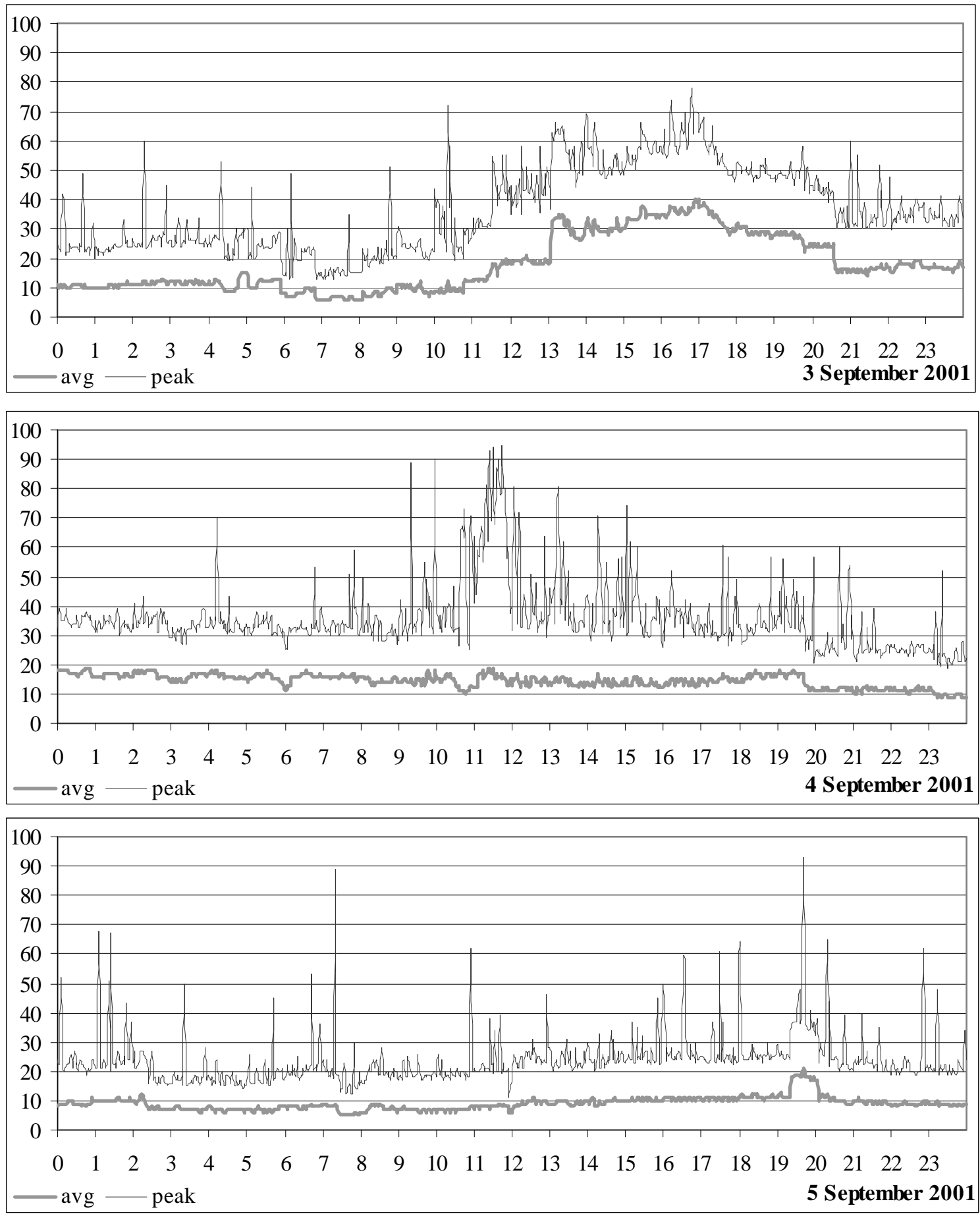

Figure 23. Daily graphs for 3 September (top), 4 September (middle), and 5 September 2001 (bottom) of the average and peak noise levels (percentages) for the antenna with the continuous shield located at Bonneville Bradford B-Branch Ladder. 


\section{Bonneville Washington Shore Ladder}

Although BWSL was not an official EMI-monitoring site, we did collect noise data there over the entire year. Since there were 24 orifice antennas installed, monitoring this site gave us information on the variation that could be observed among units installed 3-100 $\mathrm{m}$ apart. This site also had the best ground system and cleanest power of all of the sites and we wanted to confirm that these made a difference. Furthermore, this site gave us the potential for investigating whether there was a correlation in the noise levels for an interrogation unit and how it performed (i.e., average number of reads per fish).

Variation between units--We present the noise data for the 16 orifice antennas in the upper section of the fish ladder (the orifice antennas installed into Weirs 52-59) for three dates (12 April, 29 July, and 1 October) over the 2001 season to show the variation between individual interrogation units on daily basis and to show how individual units changed over time (Figs. 24-29). In general, the pattern for each individual unit remained consistent over the entire year. Furthermore, with the better ground and power conditions, most antennas had average noise levels below 10\% (even below 5\% in half of orifice antennas) and peak noise levels between 10 and 20\%. With noise patterns like these, they should have been able to detected tagged fish easily.

All eight of the orifice antennas in the lower section had average noise levels that were below 5\% until Antenna DB changed in the middle of July and so we only present that unit's noise graph for the three dates (Fig. 29). When the fish ladder was dewatered in December 2002, it was determined that the conduit used to help connect the antenna cable to the antenna housing for Antenna DB had broken. A broken conduit would probably have caused the antenna cable to vibrate as it moved with the water, which would have increased noise levels similar to what happened when the back plane screws for the transceiver became loose.

The noise data for 12 April are presented to show how the antennas were performing at the beginning of the year. This date was also picked because it was before the filter was installed on the motor controllers for the screen cleaners; therefore, one can see the impact operating the screen cleaners in Powerhouse II had on some of the orifice antennas, but not all (Figs. 24-29). Antennas 2A, 7A, and 9A distinctly showed that the screen cleaners were operated three times that day (approximately 0500, 0600, and 1900). Antenna 9B also showed the screen cleaners, but it is harder to distinguish on its graph because its normal noise levels were so high. Its noise levels were so high because it has a high-voltage line installed directly beneath it. Antennas 3A, 3B, 5B, 6B, 7B, 8A, and $8 \mathrm{~B}$ showed noise from the motor controllers to a lesser extent, but this noise was not 
Figure 24. Daily noise graphs showing the average and peak levels (percentages) for Antennas 2A (top), 2B (middle), and 3A for 12 April, 29 July, and 1 October 2001.

April
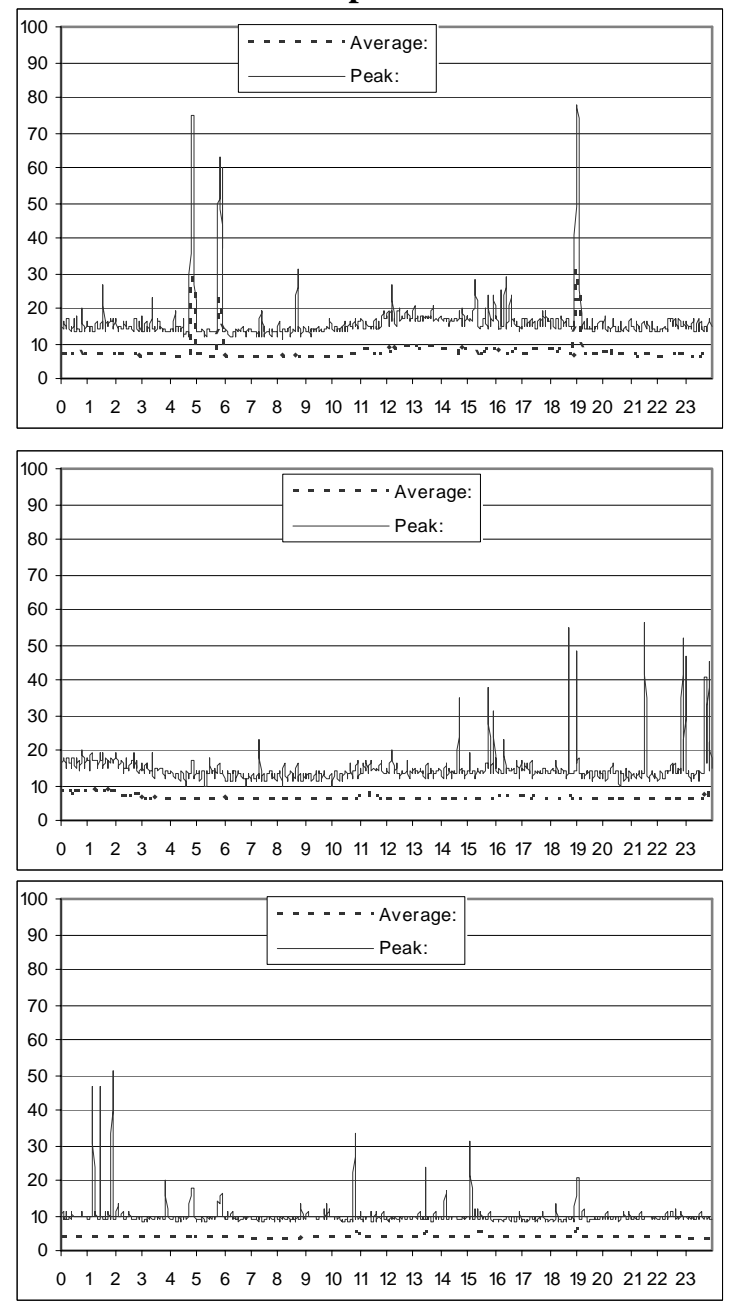

July
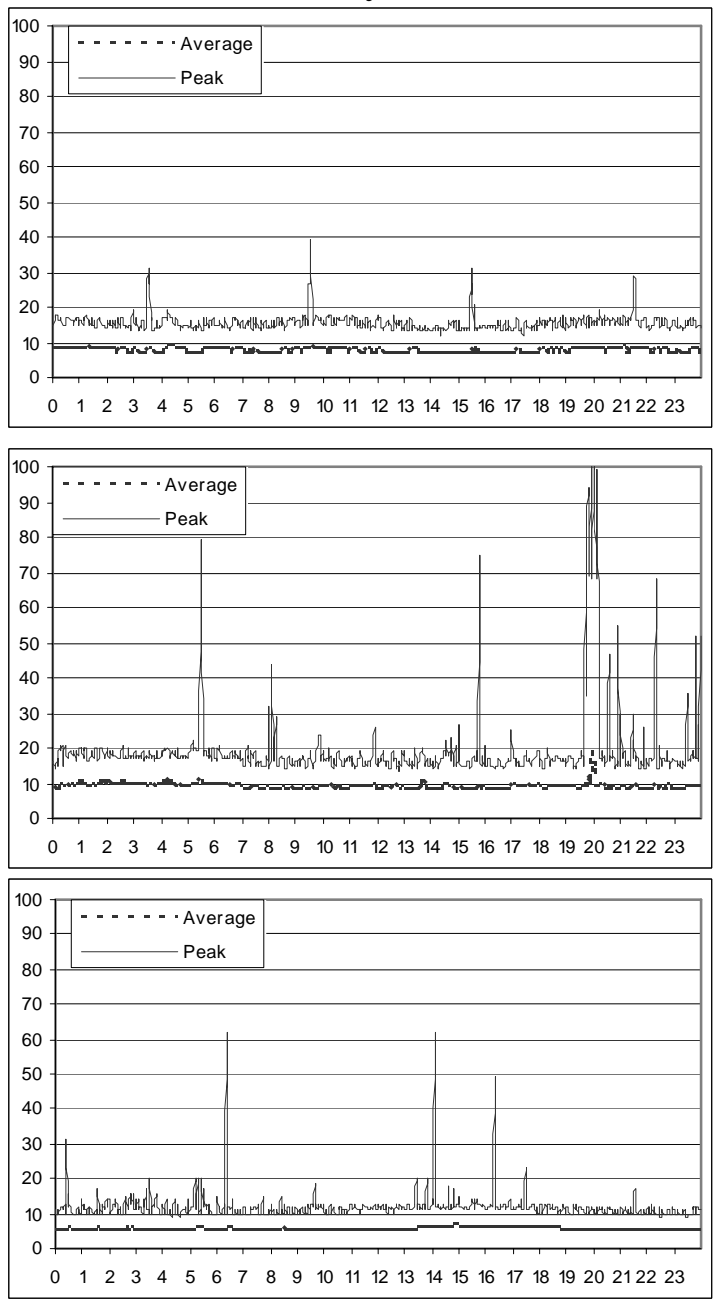

\section{October}
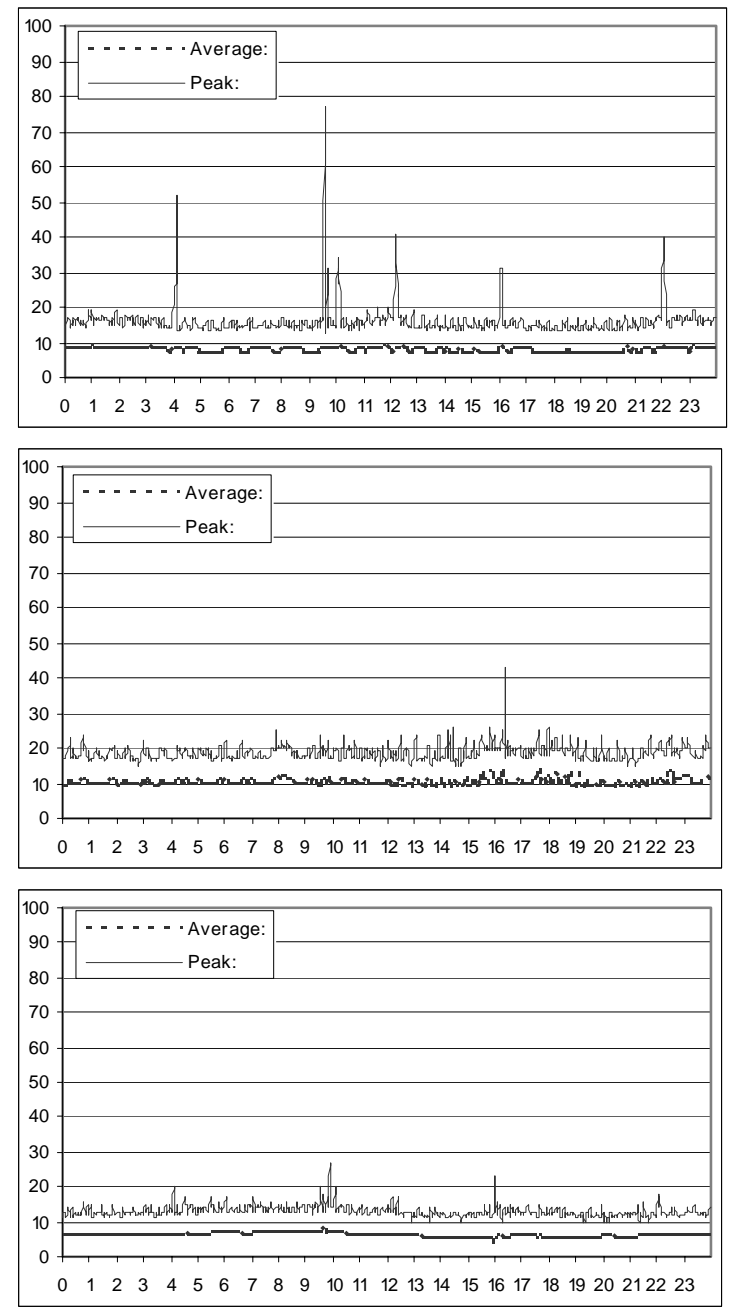
Figure 25. Daily noise graphs showing the average and peak levels (percentages) for Antennas 3B (top), 4A (middle), 4B (bottom) for 12 April, 29 July, and 1 October 2001.

April
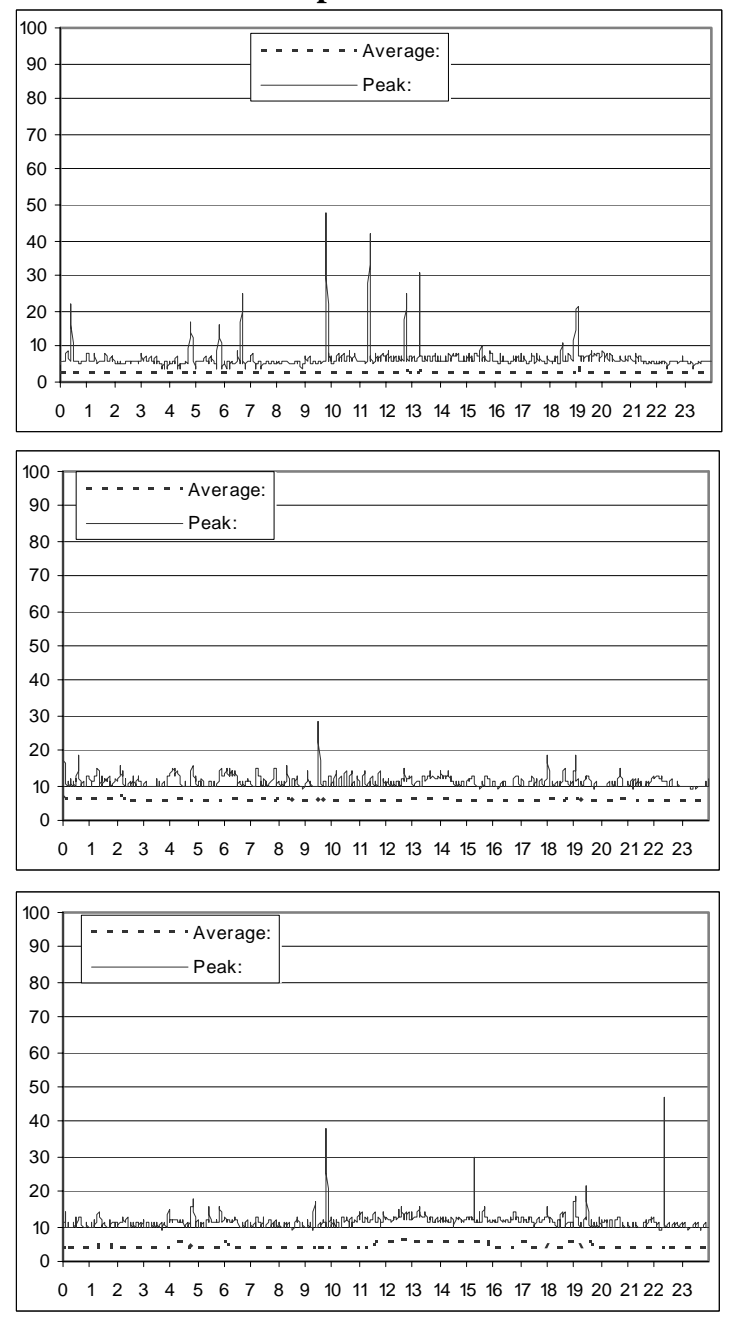

July
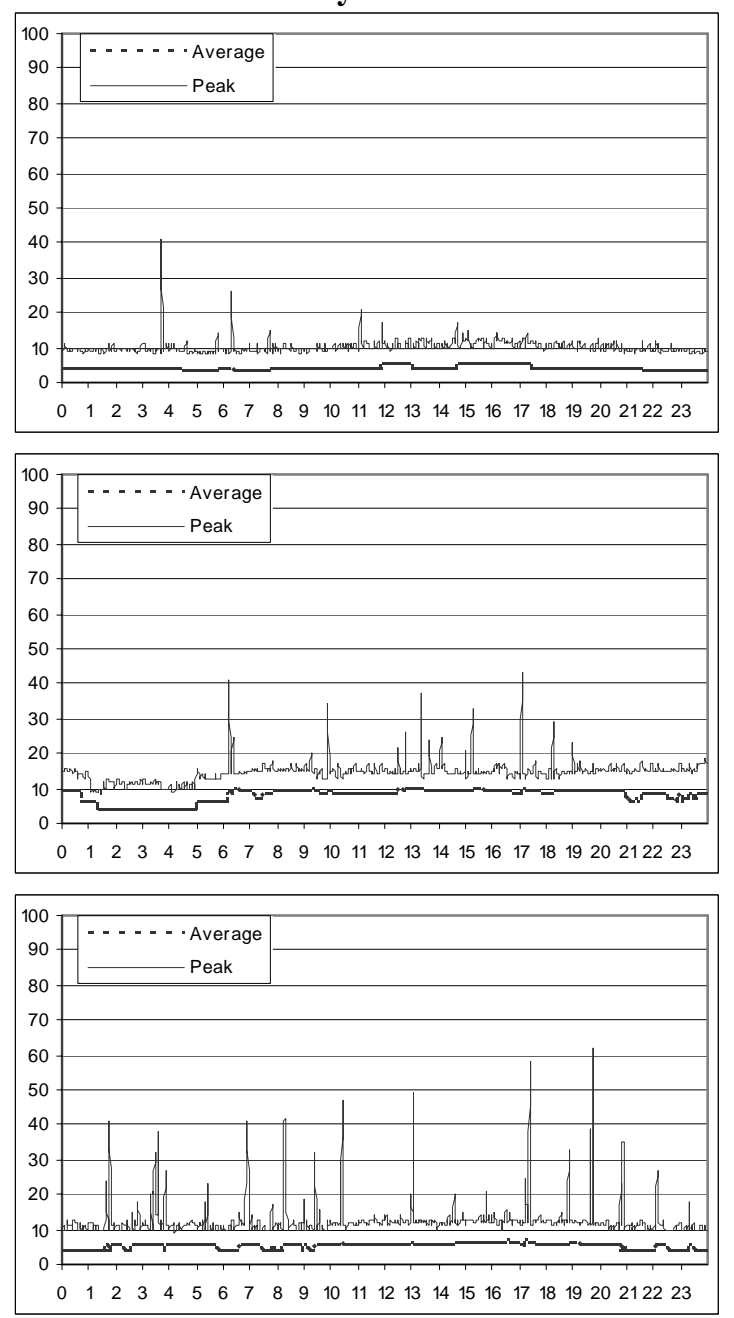

October
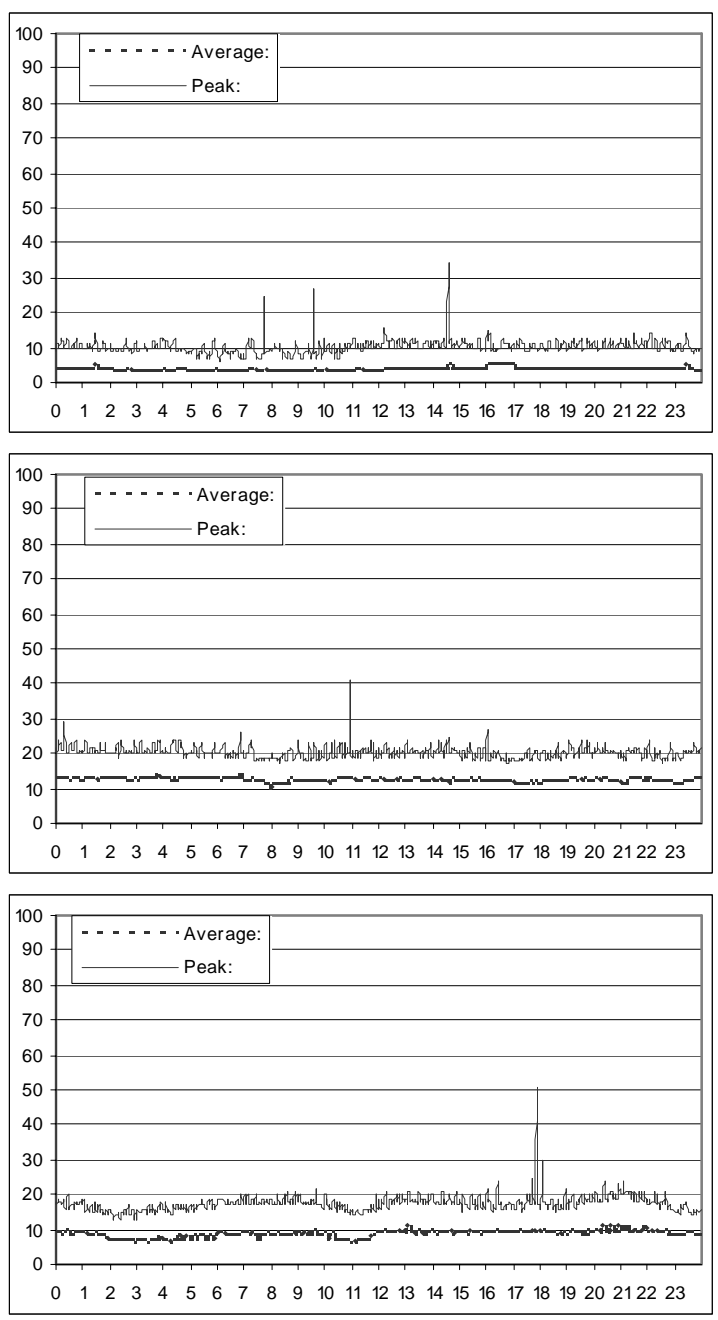
Figure 26. Daily noise graphs showing the average and peak levels (percentages) for Antennas 5A (top), 5B (middle), 6A (bottom) for 12 April, 29 July, and 1 October 2001.

\section{April}
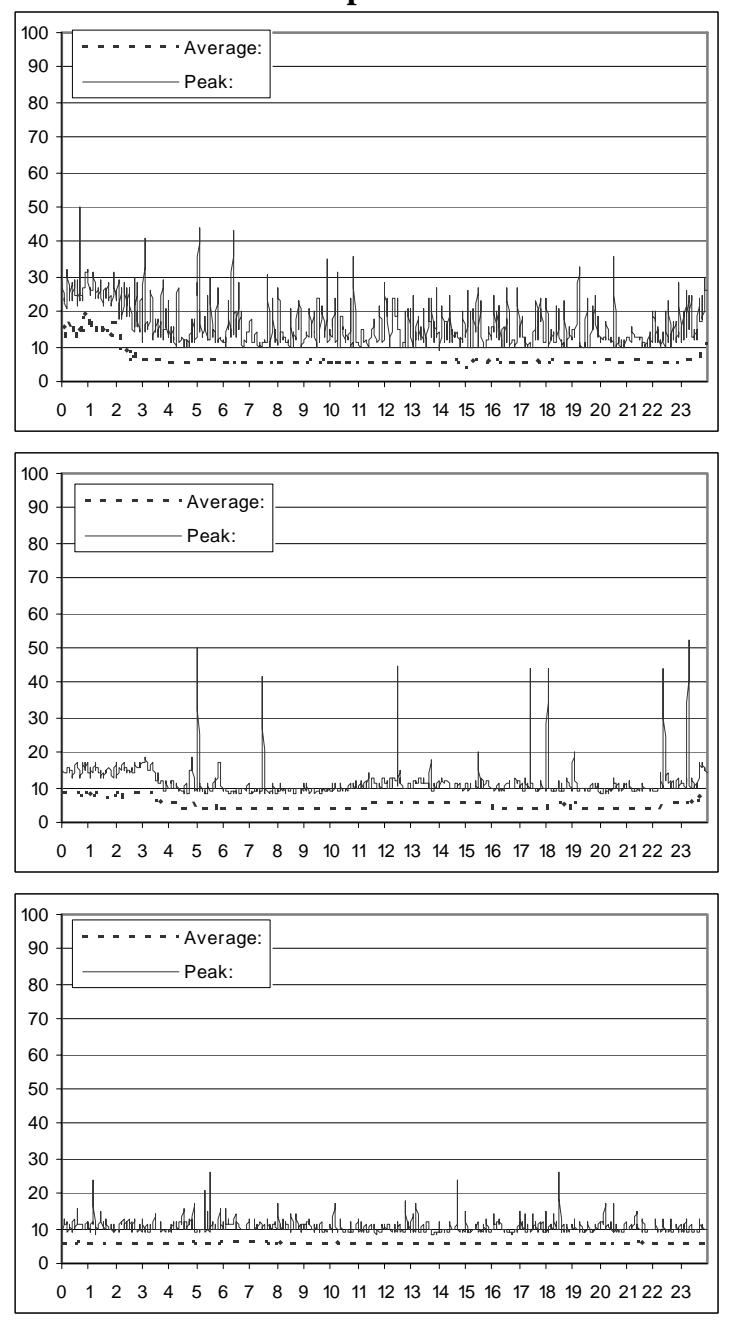

July
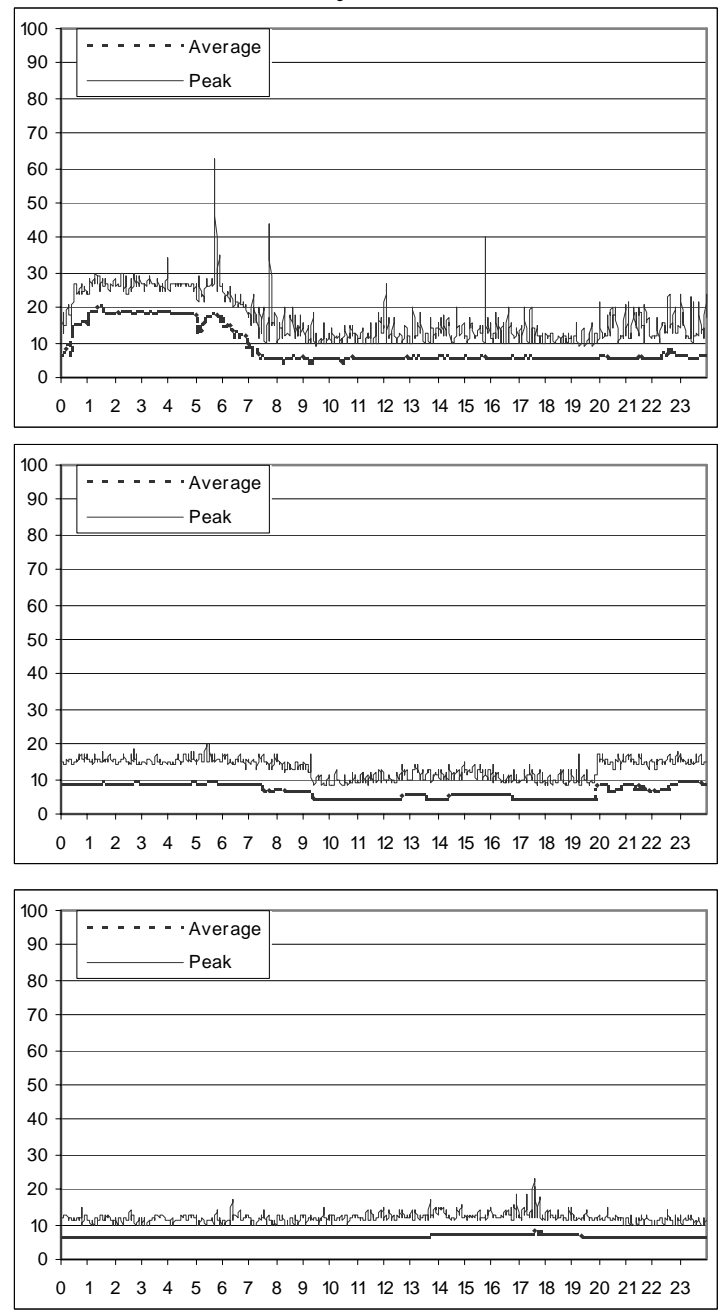

October
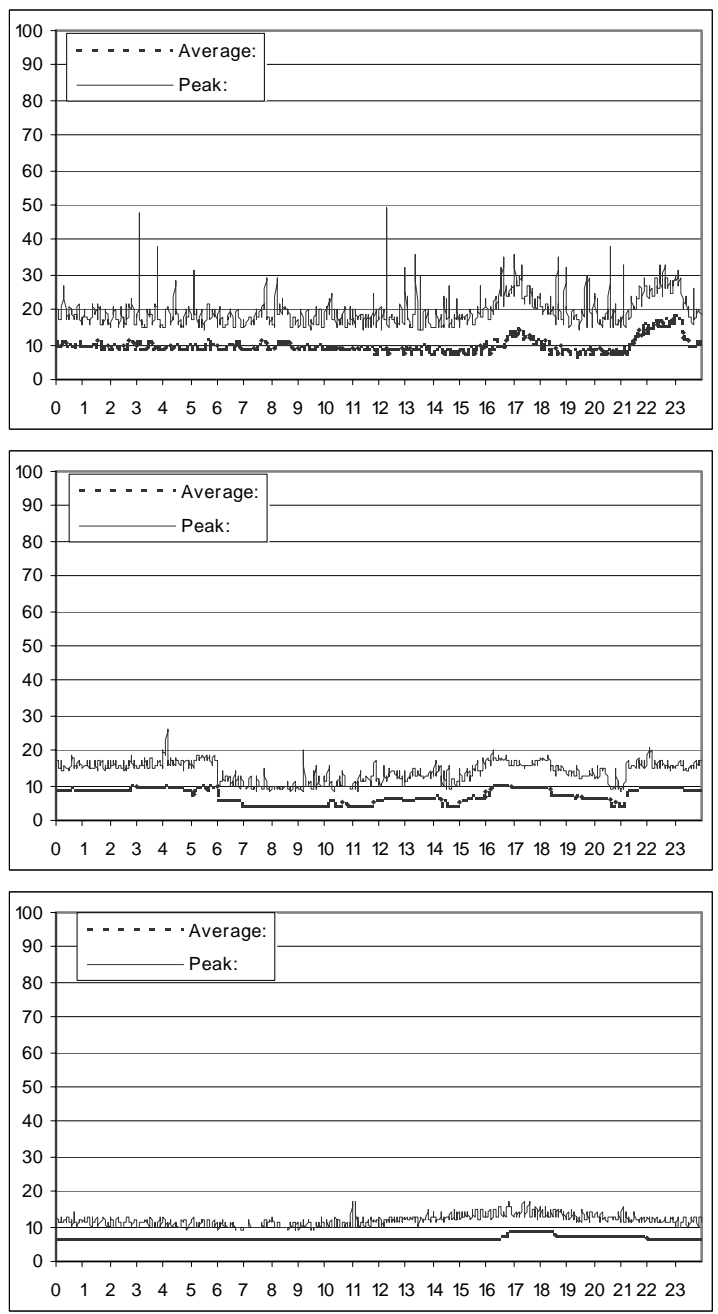
Figure 27. Daily noise graphs showing the average and peak levels (percentages) for Antennas 6B (top), 7A (middle), 7B (bottom) for 12 April, 29 July, and 1 October 2001.

\section{April}
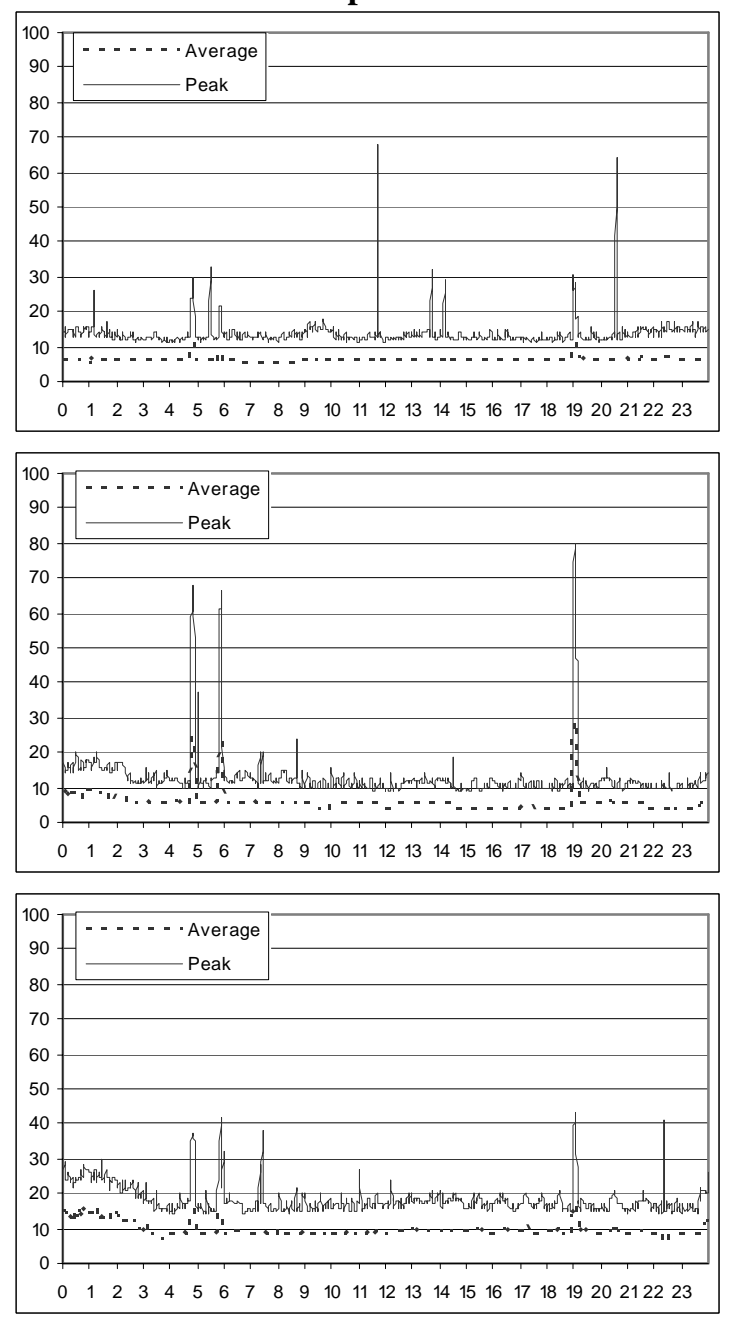

July
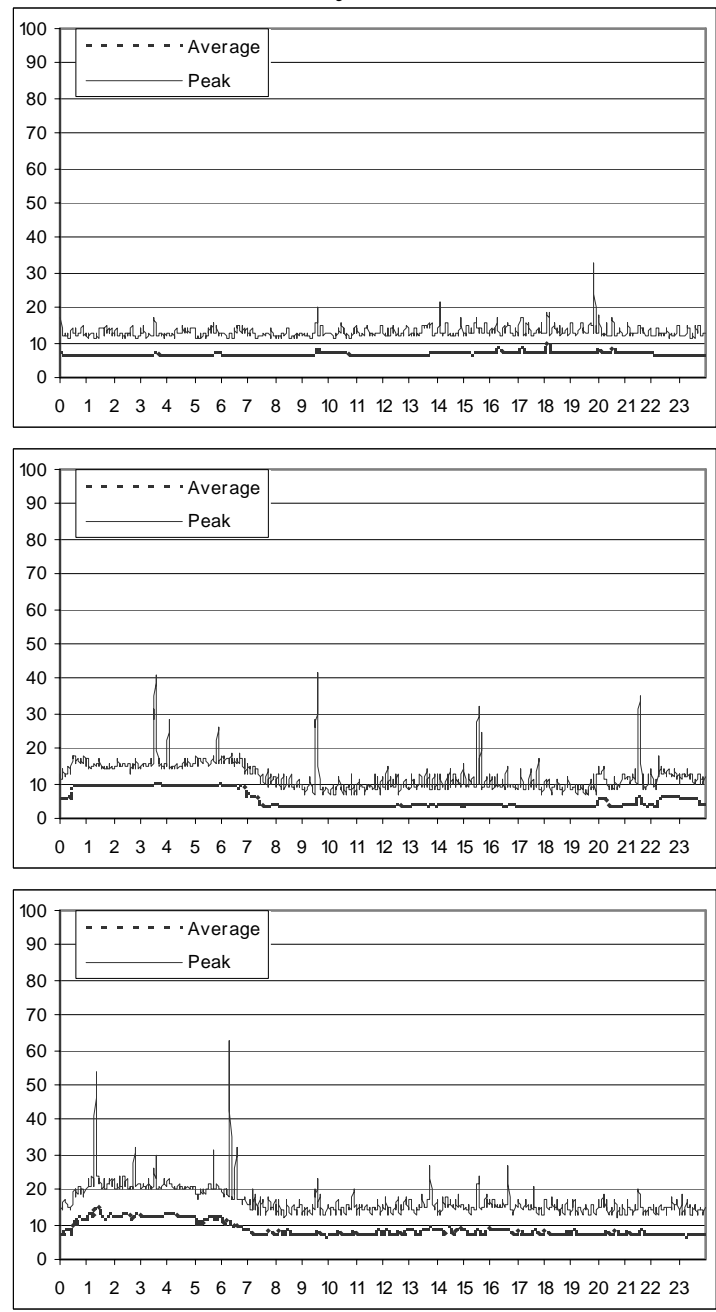

October
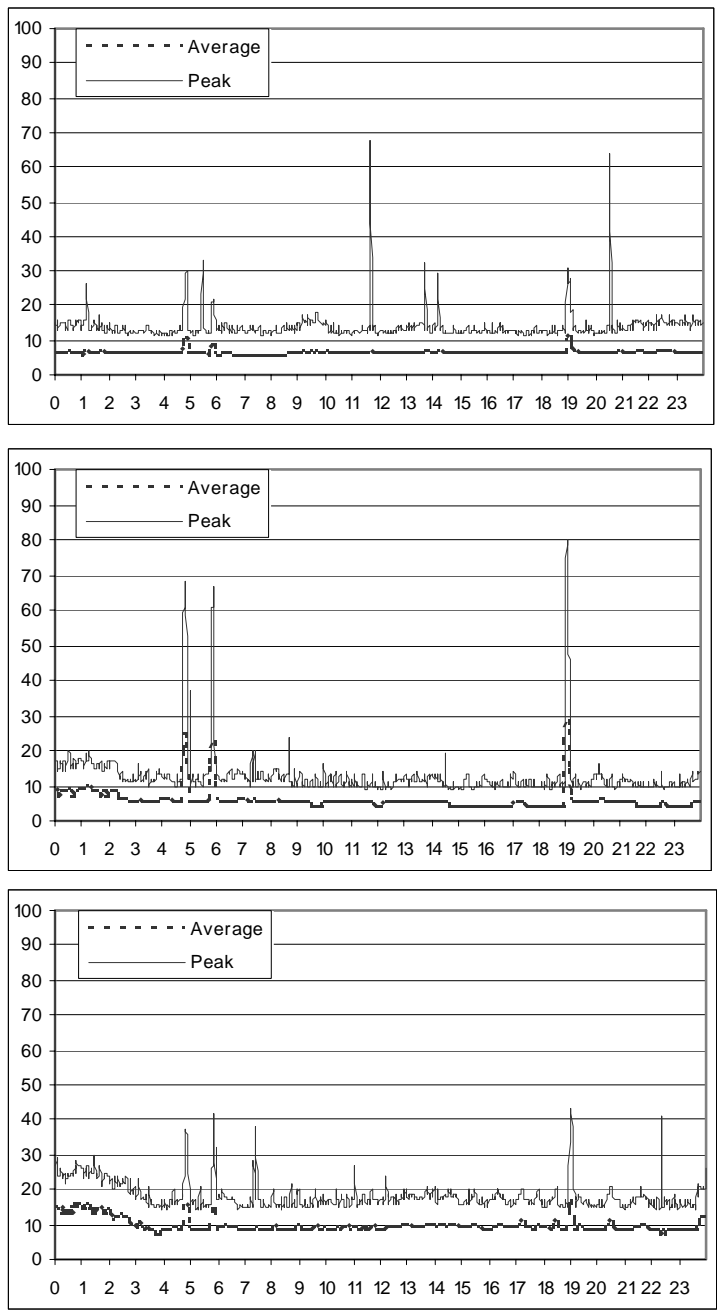
Figure 28. Daily noise graphs showing the average and peak levels (percentages) for Antennas 8A (top), 8B (middle), 9A (bottom) for 12 April, 29 July, and 1 October 2001.

\section{April}
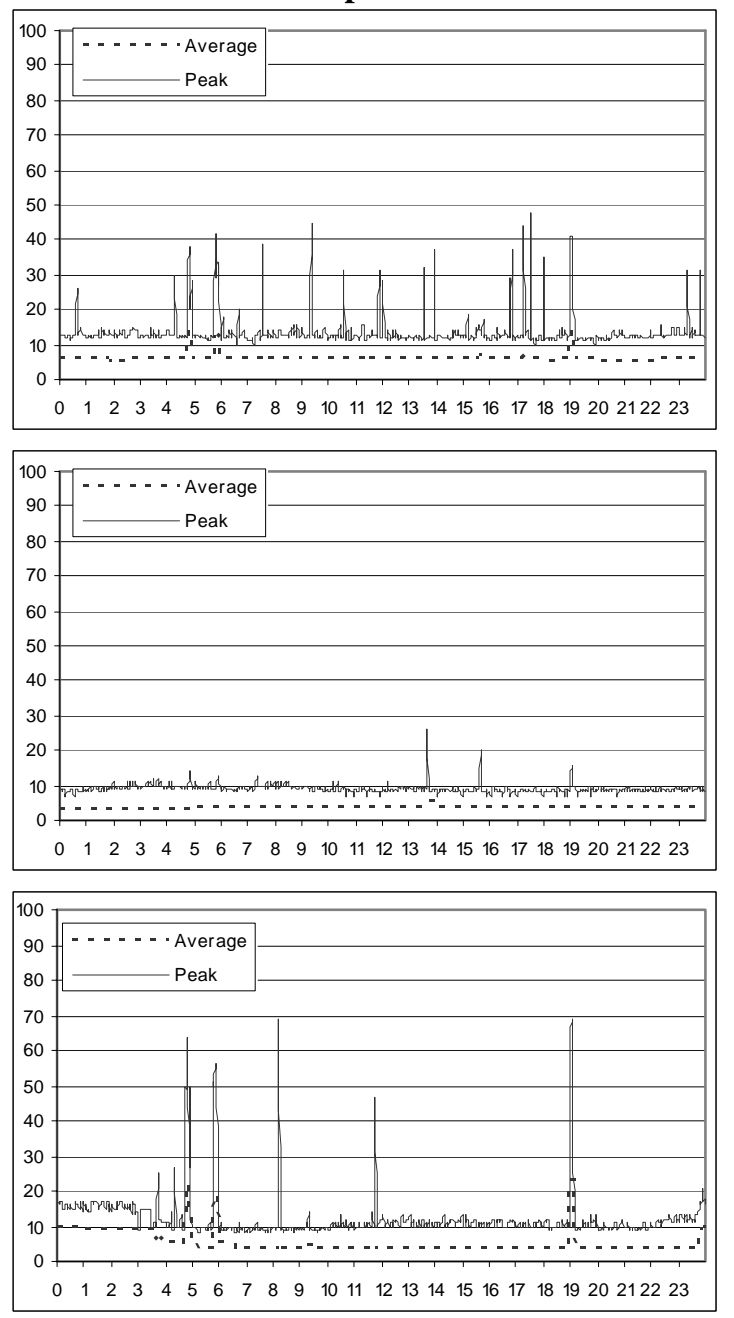

July
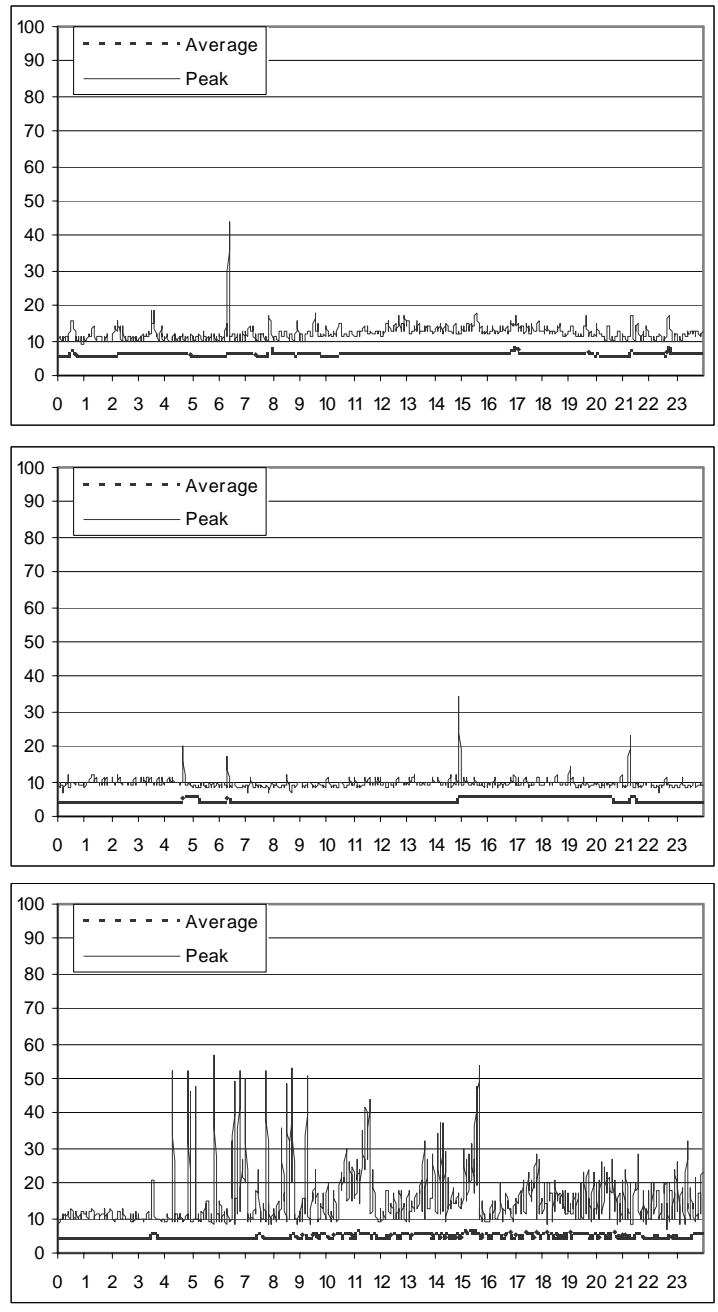

\section{October}
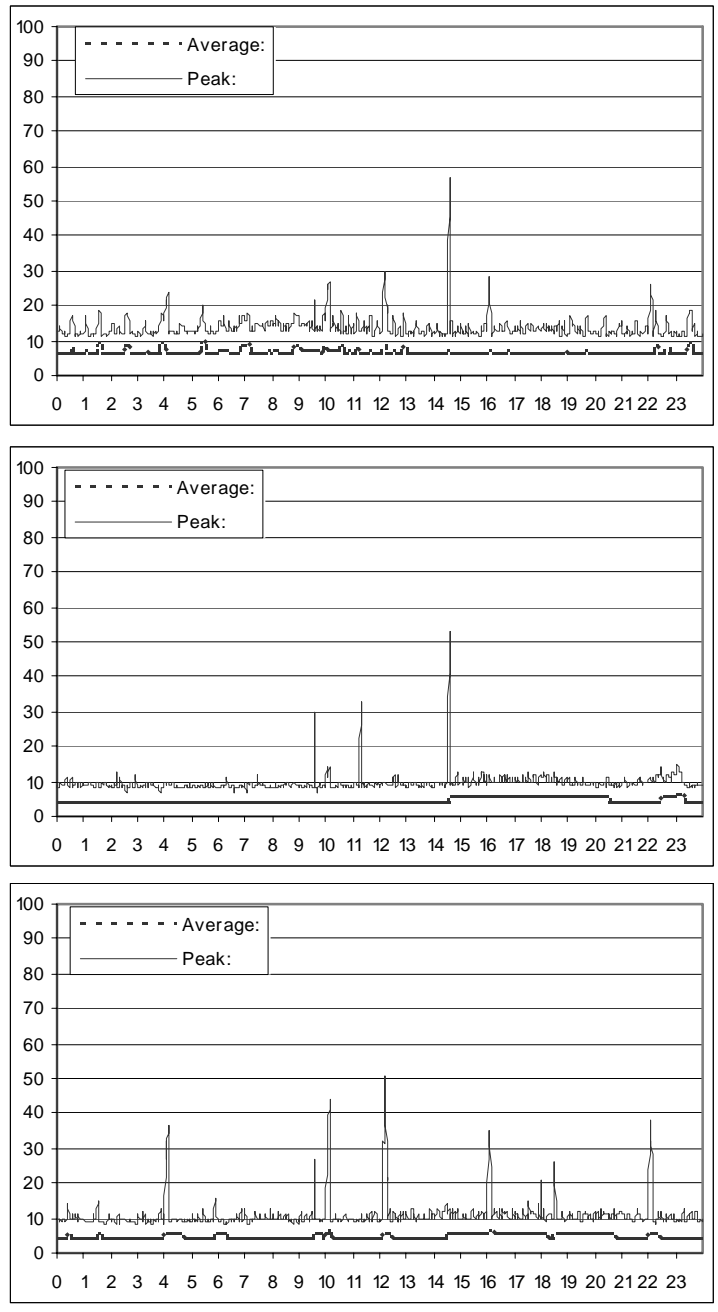
Figure 29. Daily noise graphs showing the average and peak levels (percentages) for Antennas 9B (top), DB (bottom) for 12 April, 29 July, and 1 October 2001.

April
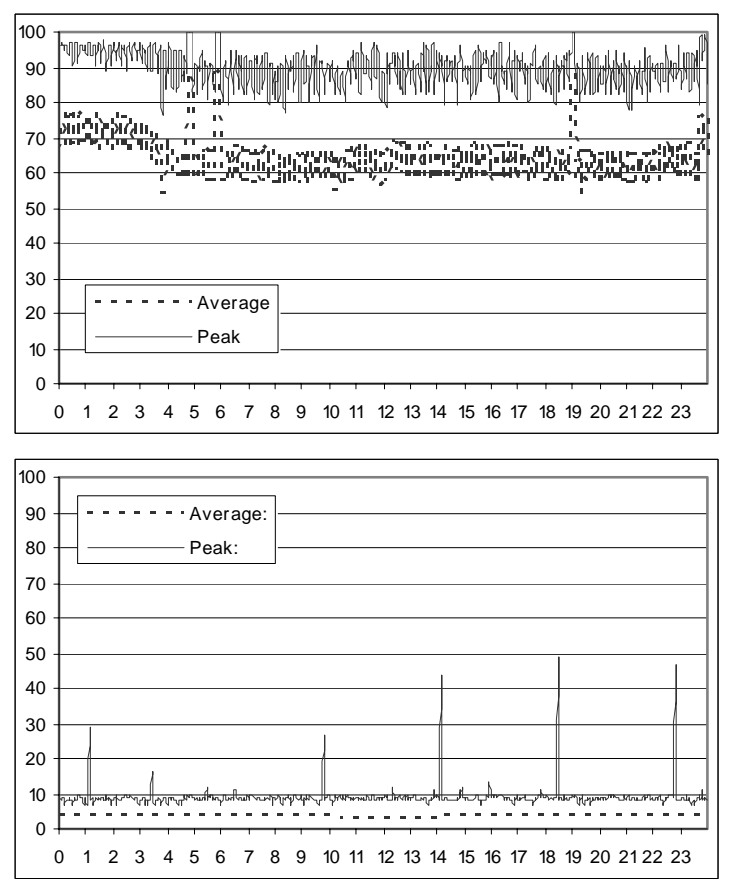

July
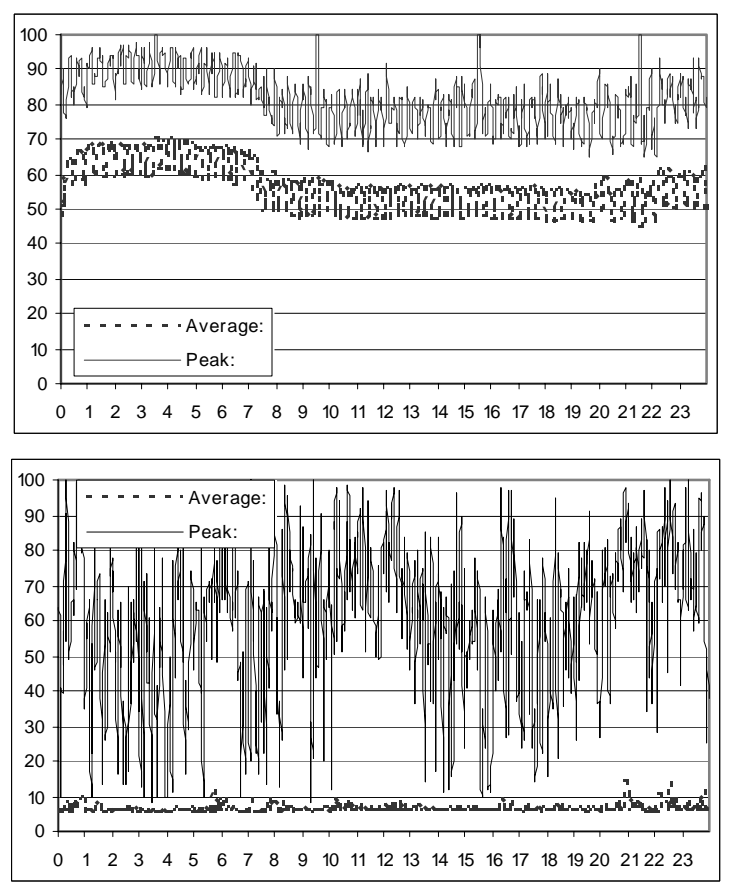

October
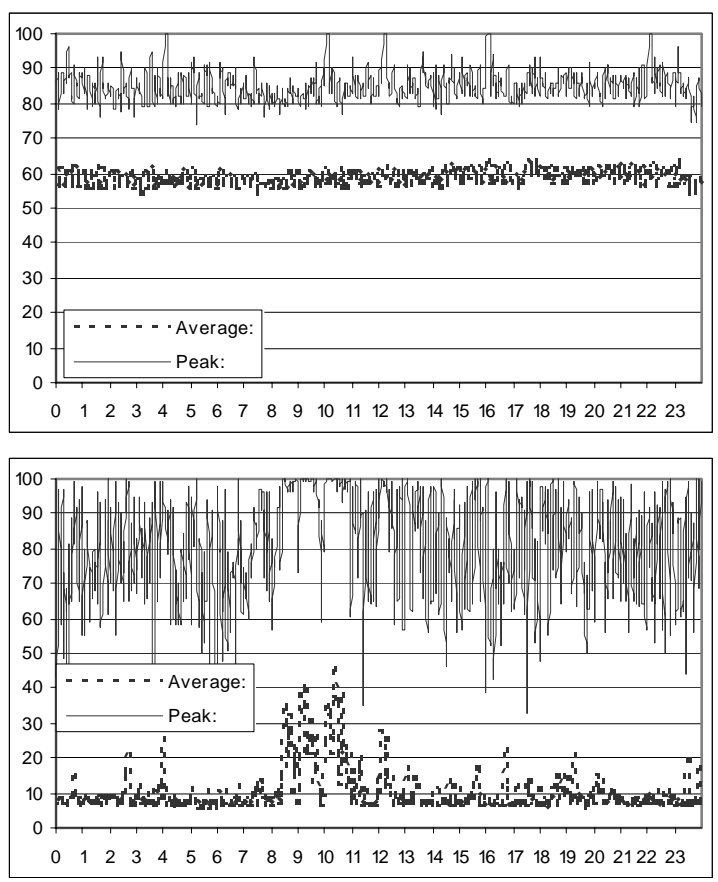
detectable in the remaining antennas (2B, 4A, 4B, 5A, 6A).

The noise data for 29 July (chosen at random to represent the middle of the year) showed that the screen cleaners were run four times that day (approximately 0330, 0930, 1530, and 2130; Figs. 24-29). Even after the filters were added to the motor controllers for the screen cleaners, one can still see the noise spikes caused by the motor controllers clearly on the graphs for Antennas 2A and 7A and to a lesser extent in the graph for Antenna 9B. However, unlike in early April, the spikes were associated only with peak noise levels and not average levels (thus, PIT tag detection would not be impacted).

Graphs for the other antennas did not show any noise being generated by the motor controllers. Graphs for three antennas (5A, 7A, and 7B) were similar and show a higher average noise level from 0030 to 0630. Antenna 9B also showed this increase. The cause of this increase is unknown. Otherwise, Antennas 9A and DB have more spiked patterns than they did in April. Antenna 9A showed this slightly noisier pattern for around $10 \mathrm{~d}$; its transceiver was then adjusted, and noise returned to a steadier pattern.

Noise data for 1 October (chosen at random to represent the end of the year) showed that the screen cleaners were run four times that day (approximately 0400, 1000, 1600, and 2200; Figs. 24-29). As in the graphs for July, one can clearly see peaks for the motor controllers in Antennas 2A, 7A, 9A, and to a lesser extent in Antenna 9B. Also as in July, the graphs for Antennas 5A, 7A, and 7B were similar: all showed the same increase in average and peak noise levels from 2130 to 2330.

By reviewing the graphs for the individual antennas for the three dates, one notices that the general pattern for each antenna was basically the same over the year. Another observation worth noting is that Antennas 9B, DB, and 5A were the only antennas that had average noise levels that exceeded $15 \%$ for more than a few minutes.

Noise and fish detection--The noise data for 12 April were also presented because this was $1 \mathrm{~d}$ after we tagged and released fish into the fish ladder for the first time; therefore, we could use the data from these fish to determine if there was a correlation between how well a unit detected fish and its noise levels. Except for Antennas 9B and 8B, all of the orifice antennas read tagged fish more than 15 times per fish (Table 25). Surprisingly, despite having an average noise level consistently above 60, Antenna 9B still detected some tags. However it did miss some tagged fish and definitely read each fish fewer times than the other interrogation units on 11 April. Antenna 8B had the second lowest median number of reads per fish at 13.0 reads, but it was one of the quietest units (Figs. 24-29). Only 5 fish used this orifice on 11 April; when more fish used this orifice for fish tagged on 16, 17, and 18 April, the median value 
rose to 17.0 reads per fish.

As with the April data, noise levels on 29 July and 1 October did not appear to correlate well with median values for reads per fish (Table 26). Antenna 4A, which had started reading tags half as well as most of the other orifice antennas in June, was still basically quiet. Although noisier than it had been in April, it still had average noise levels below $10 \%$ (Fig. 25). We unsuccessfully tried several ways to fix the problem at Antenna 4A (e.g., we exchanged analog boards and whole transceivers), but were unable to remedy the situation or identify the cause.

Table 25. Median number of reads per fish for some orifice antennas in the Bonneville Washington Shore Ladder on 11 April 2001. No study fish used Antenna DB on this date.

\begin{tabular}{lcccccccccccccccc}
\hline \multicolumn{11}{c}{ Antenna } \\
\hline 2A & $2 \mathrm{~B}$ & $3 \mathrm{~A}$ & 3B & $4 \mathrm{~A}$ & $4 \mathrm{~B}$ & $5 \mathrm{~A}$ & $5 \mathrm{~B}$ & $6 \mathrm{~A}$ & $6 \mathrm{~B}$ & $7 \mathrm{~A}$ & $7 \mathrm{~B}$ & $8 \mathrm{~A}$ & $8 \mathrm{~B}$ & $9 \mathrm{~A}$ & $9 \mathrm{~B}$ & $\mathrm{DB}$ \\
16.0 & 20.0 & 17.0 & 21.0 & 18.0 & 19.5 & 18.0 & 16.0 & 18.0 & 15.5 & 18.0 & 17.0 & 18.0 & 13.0 & 17.0 & 7.0 & NA \\
\hline
\end{tabular}

Table 26. Median number of reads per fish for some orifice antennas in the Bonneville Washington Shore Ladder on 29 July 2001 and for fish tagged on 25 and 26 September 2001.

\begin{tabular}{|c|c|c|c|c|c|c|c|c|c|c|c|c|c|c|c|c|c|}
\hline \multirow[b]{3}{*}{ July } & \multicolumn{17}{|c|}{ Antenna } \\
\hline & $2 \mathrm{~A}$ & $2 \mathrm{~B}$ & $3 \mathrm{~A}$ & 3B & $4 \mathrm{~A}$ & $4 \mathrm{~B}$ & $5 \mathrm{~A}$ & $5 B$ & $6 \mathrm{~A}$ & $6 B$ & $7 \mathrm{~A}$ & $7 \mathrm{~B}$ & $8 \mathrm{~A}$ & $8 B$ & $9 \mathrm{~A}$ & $9 \mathrm{~B}$ & DB \\
\hline & 14.5 & 12.0 & 13.0 & 14.5 & 6.5 & 15.0 & 15.0 & 15.0 & 15.0 & 13.0 & 14.0 & 12.0 & 15.0 & 15.0 & 12.5 & 6.0 & 14.0 \\
\hline Sept & 11.0 & 13.0 & 12.0 & 13.0 & 7.0 & 13.0 & 13.5 & 15.0 & 13.0 & 14.0 & 12.0 & 14.0 & 12.0 & 14.0 & 13.0 & 4.0 & NA \\
\hline
\end{tabular}

The problem observed with Antenna 4A was gone by the start of 2002 after maintenance on all interrogation units was performed during the dewatered period. For each interrogation unit during the dewatered period, the antenna cable connectors were cleaned and coated with silicon, the timer test tags and their cables were removed, permanent sleeves were applied to the transceiver end of the antenna cables, and PSMFC installed virtual test tags into the transceivers. We will never know which action or combination of actions fixed the problem. 


\section{Conclusions and Recommendations}

From the results of the EMI-monitoring stations and the 24 orifice antennas installed into the Bonneville Washington Shore Ladder, NMFS concluded that the in-ladder approach was an effective tool for monitoring EMF at future sites. Although orifice antennas are more costly to install, the data produced are reliable predictors of future performance.

The experience of PSMFC at Wells Dam during fall 2001 confirmed this conclusion. They used an in-air monitoring system and found that its observations did not cross-reference very well with observations from antennas installed into the ladder. The in-air monitoring indicated some spikes lasted 1-2 min, but when the orifice antennas were initially installed, they displayed high noise almost all of the time (this noise was being generated through the rebar structure) while other orifice antennas were quiet. They were able to reduce the impact of the noise by offsetting the affected antennas farther from the wall than had been originally planned.

In the best of worlds, EMI-monitoring equipment would be installed in the locations of future antennas within a ladder, since this approach has been shown to be the best predictor of EMI problems. As such, this approach reduces the risk associated with an installation. However, we do recognize that knowledge gained from multiple installations has given Destron Technologies, PSMFC, ourselves, and others the technical solutions to overcome most EMI problems encountered during production installations. Therefore from a time and cost standpoint, the most practical approach to determining if an EMI problem exists is to install monitoring equipment as near to the locations of interest as possible. Since EMI problems can occur periodically, it is important that monitoring be conducted over the entire fish migration season and not just for a few days. 


\section{INSTALLATION, EVALUATION, AND MAINTENANCE OF THE ISO-BASED FLAT-PLATE SYSTEM FOR JUVENILE FISH}

\section{Introduction}

The NMFS research and development team developed and installed a $400-\mathrm{kHz}$ flat-plate (pass-by) PIT-tag interrogation system for juvenile salmon in the downstream migrant (DSM) channel of Bonneville Dam Powerhouse I in 1996 (Nunnallee et al. 1998). This site is designated BVX in the PTAGIS database. The continued reliable operation of this system is essential to meet informational needs of fisheries investigators and managers in the CRB.

Therefore, like the rest of the PIT-tag equipment at the juvenile fish facilities, the $400-\mathrm{kHz}$ flat-plate system was replaced with an ISO-based system in time for the 2000 smolt migration (Downing et al. 2000, 2001). Unlike the other juvenile fish facilities, this flat-plate system utilized a transceiver developed and produced by Patten Engineering because the Destron-Technologies FS1001 transceiver system could not produce the necessary field with the larger antennas located at this site.

The 134.2-kHz, flat-plate interrogation system with the Patten-Engineering transceivers used two antenna housings that each contained two overlapping antennas (coils). The antennas were positioned to minimize cross coupling and interference. Each antenna was connected to a transceiver. The antenna housings lay perpendicular to flow, one upstream of the other, and are attached to the top of the sampling trap. Fish passing down stream over the flat-plate system would pass over a minimum of two antennas.

To be effective, the ISO-based system needed to match or surpass the results for the $400-\mathrm{kHz}$ system $\left(10-\mathrm{cm}\right.$ reading range for tag angles up to $45^{\circ}$ and reading efficiencies of $95 \%$ for the entire system). To determine tag-reading efficiencies, NMFS conducts fish tests where juvenile salmonids are released one at a time into the DSM channel about $20 \mathrm{~m}$ upstream from the flat-plate system (Prentice et al. 1998, 1999). The fish generally pass over the interrogation system within 2 min from the time of release. 


\section{FY01 and FY02 Activities}

During FY01, NMFS made some firmware changes in the Patten-Engineering transceiver so that the data-collection program MINIMON could be utilize by PSMFC. NMFS re-installed the transceivers in March. At that time the system was tested for functionality and read-range performance. On 9 April 2001, NMFS conducted fish tests using 257 hatchery chinook salmon (mean fork length $69.6 \mathrm{~mm}$ ) and 253 hatchery steelhead (mean fork length $187.5 \mathrm{~mm}$ ). Overall tag-reading efficiencies for all four antennas combined were 97.7 and $96.8 \%$ for chinook salmon and steelhead respectively.

These results were similar to those obtained in 2000 when 99 and $95 \%$ reading efficiencies were obtained for the juvenile chinook salmon and steelhead respectively (Downing et al. 2001). Thus, there does appear to be some species-specific behavior to explain the lower reading efficiencies observed for the steelhead.

Because this site uses a different transceiver than the rest of the juvenile fish facilities, NMFS has been in charge of operating and maintaining the system (these efforts are coordinated with the Corps and PSMFC). To ensure reliable system operation, we conducted routine inspections and maintenance on the flat-plate system. These efforts included tag-reading tests using tagged drones that were conducted by NMFS and facility personnel.

Typically, the results of the daily tagged-drone tests were near $100 \%$, although results did vary depending on the person conducting the tests. In spite of the variability in results, the tagged-drone tests have remained a valuable indicator of overall operational status, especially when low numbers of tagged fish are present. These tests indicated that performance of one antenna dropped drastically on one occasion in 2001. The connector plug to the antenna was removed, cleaned, and then reinserted, which resulted in the antenna returning to its original operating efficiency of near $100 \%$.

During the 2001 juvenile migration season, no PIT-tag data were lost because of electronic component failure; however, mechanical problems were encountered. About mid-way through the migration season, problems started to occur with the pneumatic lift system that raises the flat-plate antenna array when fish are being subsampled. On a number of occasions the lift could not be made to operate, which meant no subsample could be taken.

Temporary fixes were made periodically, and PSMFC and NMFS continued to operate the lift system in spite of its mechanical problem until the end of the field season. 
Due to low water flows in the Columbia River and personnel shortage, BVX was closed for the year on 2 August 2001, which was 6-8 weeks earlier than normal. At the end of September, the entire sampling system was removed by NMFS, including the flat-plate antennas, so that the lift system could be redesigned and fabricated before the next juvenile migration.

NMFS installed the newly designed lift system and re-installed the Patten-Engineering transceivers in March 2002. Since tag-reading performance had been consistent for the previous 2 years, the fish tests were omitted in 2002. As before, NMFS was in charge of operating and maintaining the system. Only minor electronic problems were encountered during the 2002 field season; however, the Corps had several problems in June and July with flow control in the DSM channel. The channel was flooded several times and had erratic flows at other times.

One of the June floods caused the plastic cover on the flat-plate to buckle and separate from the upstream edge. Fixing this resulted in the site being shut down for $1.5 \mathrm{~h}$. Also, because the trap was raised whenever water flow was erratic, the site was down for several days in July when the Corps was unavailable to fix a flow problem.

\section{Conclusions and Recommendations}

Since construction of the juvenile fish collection and sampling facility for Bonneville Dam Powerhouse I is not yet scheduled, a flat-plate system will continue to be needed in this facility. Therefore, NMFS recommends that the current setup be converted to a system based on equipment manufactured by Destron Technologies for 2003. This would allow the responsibility of operation and maintenance to be transferred from NMFS to PSMFC and the effort could be coordinated with the need to replace the original temporary sample box, which was designed in 1996 to operate for only 2 to 3 years.

The transceiver model (FS1001A) developed by Destron Technologies for interrogating salmonids in fish ladders could easily be adapted for use at this site; the resulting system should perform comparably to the current system, which uses Patten Engineering equipment. This conversion will require that the antenna system be changed as well, but the converted system will be one that PSMFC is familiar with and thus can maintain. These steps will allow the continued flow of high-quality data from this site, as required by the fisheries community. Because this site is no longer experimental, we suggest its site code should be changed to B1J in the PTAGIS database. We also recommend that fish tests be conducted on the converted system in 2003. 


\section{DEVELOPMENT AND EVALUATION OF AN IN-STREAM INTERROGATION SYSTEM}

\section{Introduction}

Many juvenile salmon are presently being captured, PIT tagged, and released in small streams, in part to determine the effectiveness of stock restoration efforts. Currently, the only means of obtaining movement information on these tagged fish is to recapture them or wait until they pass a dam or trap that includes a PIT-tag interrogation system. These methods provide valuable information, but leave large voids in our understanding of fish biology and ecology.

With the development of in-stream PIT-tag interrogation systems, a number of studies could be designed to address questions without additional fish handling such as, What is the in-stream survival for a specific stream reach? What type of stream environment is best suited for a particular species or life stage? When do fish begin to migrate from that stream? In-stream interrogation systems can also be used to collect data on adult salmonids and can be used in a laboratory or controlled environment (e.g., behavior study channels).

NMFS examined a basic prototype model of an in-stream interrogation system for small streams in 2000. The objective of the test was to determine proof of concept and to identify areas where additional work was required before the technology could be made available to end users. Both juvenile and adult PIT-tagged salmon were successfully interrogated in a trial conducted in an artificial stream channel at NMFS Manchester Research Station. Results were encouraging and did show proof of concept. In addition, the Manchester tests defined the subsystems required for a complete in-stream interrogation system. These include the transceiver and antenna systems (antenna housing and coil assembly); alternative power system; data capture, storage, and communications package; and secure equipment enclosures.

The ultimate goal of this development project is to develop a "stand alone" in-stream interrogation system (i.e., system that could be located in a remote area without access to the power grid). For equipment to operate in remote locations, a reliable and electronically quiet DC power source must be identified. We believe this is the most challenging task for this work element. At this time, a hybrid power system is visualized that consists of a combination of batteries and an energy regeneration system. 
Four potential alternative power sources for remote locations are solar, hydro, wind, and chemical (e.g., fuel cell). There are pros and cons associated with each alternative power source. For instance, solar power is limited by exposure and sunlight availability and hydropower by water velocity, depth, and debris load. We are getting assistance from BPA and other power-system experts to determine the best solutions under different study conditions.

\section{FY01 and FY02 Activities}

After hearing of the success at Manchester and that of other investigators working on in-stream PIT-tag interrogation systems, PIT-tag users from within NMFS and from a number of other agencies expressed an interest in and need for these systems. Among these were personnel from the U.S. Geological Survey (USGS) Columbia River Research Laboratory at Cook, WA. In FY01, we began a cooperative study with USGS to evaluate antenna and extended-range transceiver technology in a small stream with a system they could use to collect PIT-tag data for their ongoing BPA-funded stream ecosystem study.

In August 2001, we installed a prototype in-stream interrogation system near the mouth of Rattlesnake Creek, a tributary of the White Salmon River in Washington State. The in-stream system at Rattlesnake Creek was installed on private property after a cooperative agreement was established and state and federal permits were obtained. Electrical power, fiber-optic communication cables, and a stainless-steel enclosure for the transceivers were installed streamside (Fig. 30).

The data-collecting computer was installed in the workshop of the property owner. One reason that this site was chosen as the first field installation of an in-stream interrogation system was because it had access to grid-supported power (we did not have an alternative DC power system designed in 2001 and needed to focus on other subsystems without this confounding factor). Under the cooperative agreement, USGS was responsible for PIT-tagging fish, data collection, and system inspection, and NMFS was responsible for maintaining the site and installing any new equipment for evaluation.

In 2002, we established two additional test sites in Valley Creek near Stanley, Idaho. The Valley Creek location provided environmental and logistical challenges that dramatically differed from the Rattlesnake Creek site. For example, one test site did not have grid-supported power, and thus we are evaluating an alternative power system there. Like the Rattlesnake Creek site, Valley Creek is serving as both a place to evaluate technology and to collect biological data (Achord et al. 2004). 

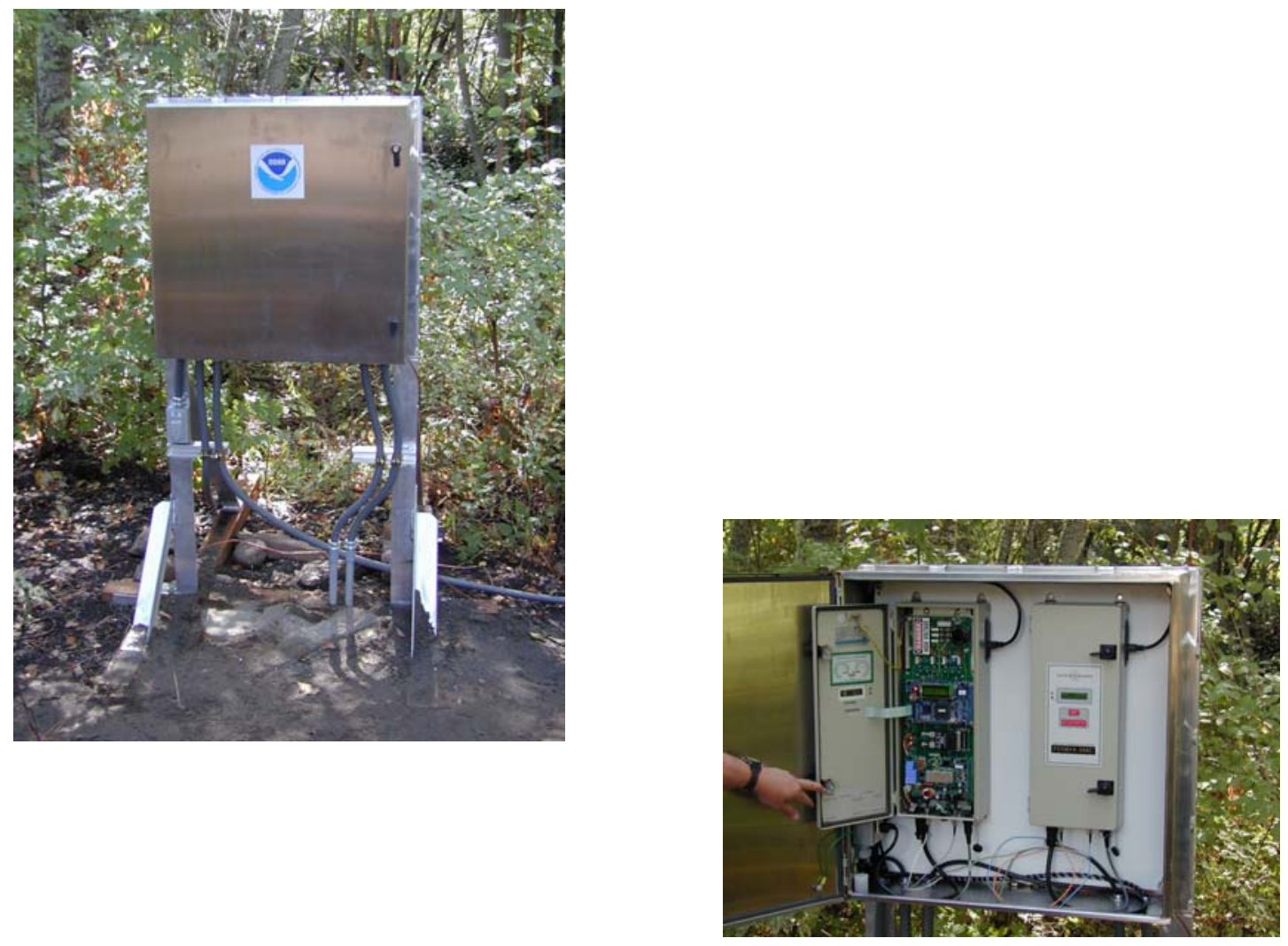

Figure 30. Enclosure box containing two transceivers that was installed streamside at Rattlesnake Creek. 


\section{Transceiver Systems}

RF noise--Initially at Rattlesnake Creek, 24V, AC-powered FS1001A transceivers manufactured by Destron Technologies were installed. The status reports generated by the transceivers indicated that RF noise levels varied significantly over time with no noticeable pattern. In fact, wide fluctuations were observed while standing in front of a transceiver; even within a 1-min interval, levels changed by 10-40\%.

The AC electrical ground to the transceivers was identified as one source of RF noise. At times, this noise source raised the RF noise level to a point that interfered with tag reading. In an effort to improve performance, NMFS contracted Destron Technologies to modify the FS1001A transceivers for DC operation. This modification significantly reduced the base noise levels, and read distances for both antennas were improved with the DC-powered transceivers. The vertical read distance for the pass-by antenna increased from $11.4 \mathrm{~cm}$ to $20.3 \mathrm{~cm}$, while the total read distance for the pass-through antenna increased from $45.7 \mathrm{~cm}$ to $61.0 \mathrm{~cm}$ (center measurement). The read distance values varied significantly (up to $8 \mathrm{~cm}$ ) depending on background EMI levels at the time of measuring.

Although switching to DC power eliminated the AC electrical ground noise, sporadic RF noise patterns continued because there are other unidentified EMI sources at this site (these have a larger impact at stream sites than at dam sites because unlike at the dams, these large antennas do not have RF shields). Further testing showed that the transceivers themselves generated some of the RF noise.

Internal transceiver heat--Another problem encountered at Rattlesnake Creek was internal heat buildup that resulted from operating the transceivers at between 6.0 and 6.2 amps. The high current levels were required to obtain sufficient read distances with the large antennas. At the fish ladder sites, the FS1001A transceivers operate at between 3.0 and 4.5 amps and thus normally operate at lower temperatures. The high temperatures caused some premature component failure and fluctuations in the tune of the antennas. To overcome this problem, we recommended to Destron Technologies that it consider installing more heat sinks in the transceiver to dissipate the heat or find a more efficient transceiver power source.

Auto-tuning and Multiplexing--During 2001 at the Rattlesnake Creek site, the status reports produced by the transceivers every $4 \mathrm{~h}$ revealed large variations in the tune of the antennas, current-amperage levels, and transceiver temperatures on both daily and seasonal time scales. These variations were caused by changing environmental parameters such as ambient temperatures, background RF-noise levels, water levels, and 
stream flow conditions (some stream changes caused vibration in the antennas, which detuned the antennas). As a way to deal with the impact of environmental parameters on system tune, it was recommended that Destron Technologies design an auto-tune component for its FS1001A transceiver.

NMFS hosted a 2-day workshop for biologists interested in small-stream research in December 2001 (FY02). The objective of the workshop was to give an update on the development of in-stream interrogation systems to the fisheries community and to determine end-users needs. An extensive survey was distributed at the workshop, and its results indicated that one goal shared by many biologists was to interrogate streams that were 25-50 m wide. Currently, the only way to accomplish this would be to have multiple antennas spanning the stream. The only technological solution presently available to handle multiple antennas spanning a stream would be for these antennas to be multiplexed so that they would not interfere with each other (in this approach only one antenna is active at a time). The ability to multiplex antennas is not possible with the current transceiver.

For FY02, NMFS contracted Destron Technologies to develop an add-on box that would house the electronic components needed to permit a single transceiver to control up to six antennas through multiplexing. If successful, multiplexing antennas would enable the number of transceivers required for a site to be dramatically reduced. Besides reducing the cost of an in-stream system, this approach would also significantly reduce power requirements, which is a critical factor for successfully developing stand-alone power systems for remote locations.

After getting the information from the survey, NMFS contracted Destron Technologies to develop add-on components to perform the auto-tune and multiplexing functions. Destron Technologies made a number of hardware and software changes to their FS1001A 24-V DC transceiver to add these functions. Some of the initial hardware changes to the transceiver included:

1) Adding a real time clock for stand-alone operation

2) Enabling the dynamic auto-tuning capacitance to range between 10,000 pf and 120,000 pf

3) Redesigning the analog card receiver to provide fast antenna switching time

4) Incorporating a power MOSFET (MOS stands for metal-oxide-semiconductor and FET stands for field-effect transistor) switch design into the tuning capacitor switches. 
Software changes were also made to the existing FS1001A firmware to enable self-tuning for each antenna based on antenna current amplitude, antenna current phase, and read sensitivity; to add dynamic tuning based on antenna current phase for each active antenna; to enhance real time clock support; and to expand the functionality of the maintenance port.

During FY02, Destron Technologies tested in the laboratory some prototype auto-tuning and antenna-switching (multiplexing) components for its FS1001A transceiver. In early FY03, Destron Technologies and NMFS will test the first prototypes for these interim components at NMFS Pasco Research Station. The Pasco Research Station has a stream whose water level can be adjusted, which allows the auto-tuning capability to be evaluated under different conditions over a short time. The stream will also enable the multiplexing to be tested under field conditions.

\section{Antenna Systems}

To determine the direction of fish movement, two in-stream antennas were anchored $15 \mathrm{~m}$ apart in Rattlesnake Creek. The antennas were attached to the stream substrate using a combination of wedge anchors, eyebolts, and line. This setup also permitted two different antenna designs to be evaluated under various stream flow conditions. In FY01, pass-through and pass-by designs were evaluated at Rattlesnake Creek (Figs. 31-32). The two antennas installed in 2001 were designed and fabricated by Destron Technologies under a contract with NMFS. The antennas were housed in $10-\mathrm{cm}$ diameter PVC pipe arranged in rectangular shapes that measured $203 \mathrm{~cm}$ by $81 \mathrm{~cm}$ (external dimensions). As indicated above, there were no RF shields associated with these antennas.

The main advantages of the pass-through antenna design are that tagged fish swim through the antenna in the optimal orientation for detection and they swim through the largest section of the tag-energizing field. Consequently, these antennas have large read windows. The disadvantage is that it is possible for debris to collect on the antenna and cause it to break from its moorage or cause stream channel alteration. To try to reduce the damage that would occur were the antenna to be hit by large debris or if water pressure increased significantly, the stanchion holding the pass-through antenna in its vertical position was designed to break under heavy debris load. When the stanchion broke, an attached salvage line would only allow the antenna to float downstream a short distance where it could then be retrieved. In addition, the plug connecting the antenna to its antenna cable was not securely attached in order to expedite its separation from the antenna when the antenna broke loose. 


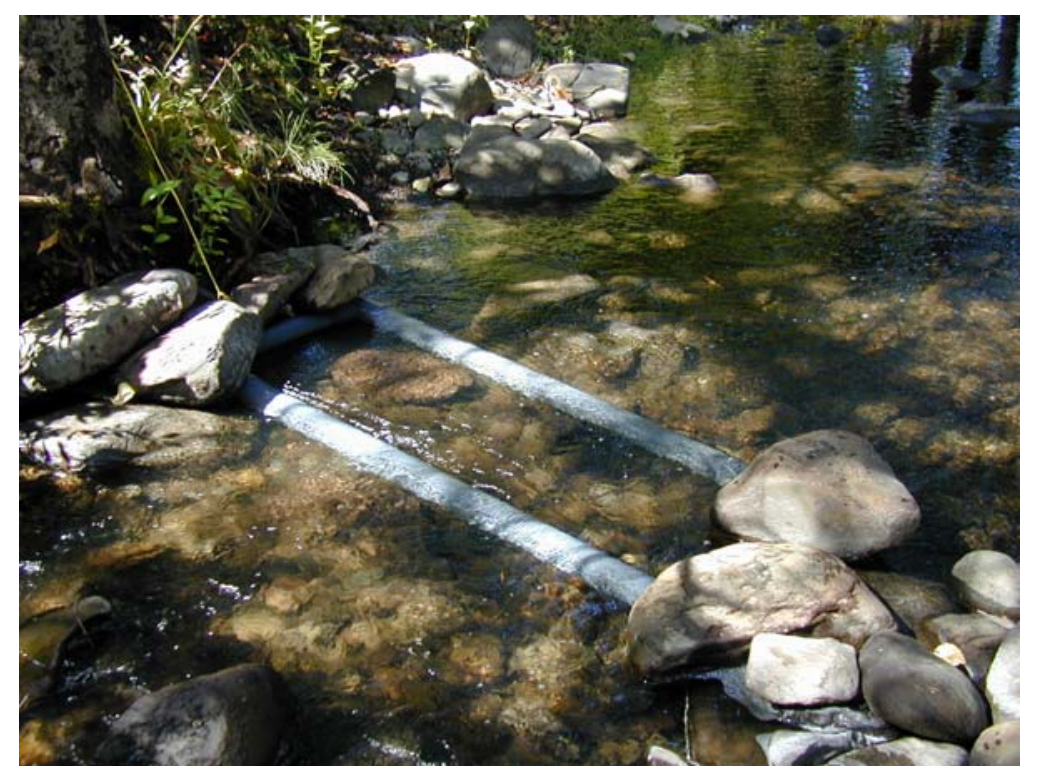

Figure 31. Photo of a pass-by antenna installed into Rattlesnake Creek.

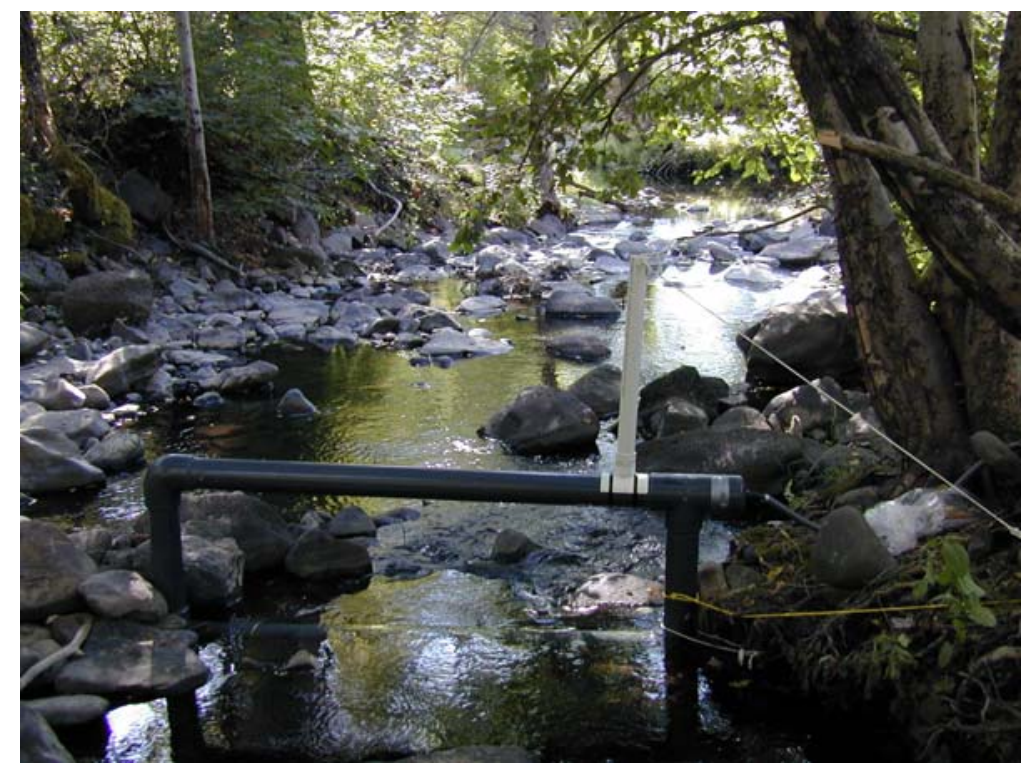

Figure 32. Photo of a pass-through PIT-tag antenna installed into Rattlesnake Creek. Note the stanchion mounted at the top of the antenna that is designed to break when heavy debris hits the antenna and the salvage line designed to help retrieve the loose antenna. 
The advantages of the pass-by antenna design are that antennas are below the water surface and they can be anchored tightly to the substrate of the stream. Both of these advantages reduce the likelihood that an antenna will be removed by high water or debris, since debris passes over the antenna. The main limitation of this design is that the tag-energizing field is small. Therefore, the effective read distances are much less (e.g., $15-20 \mathrm{~cm}$ ) than they are with pass-through designs (e.g., $\sim 61 \mathrm{~cm}$ read window in center of an antenna). Because of this limited read distance, some fish would be able to swim where they could avoid detection when stream levels rose. To maximize the effectiveness of this design at Rattlesnake Creek site, the pass-by antenna housing was deployed in a shallow water area.

Soon after the in-stream interrogation system was installed, PIT-tagged rainbow trout (Oncorhynchus mykiss) and cutthroat trout (O. clarki) were detected on both the pass-through and pass-by antennas. USGS have reported on the numbers of fish detected and when they were detected (Allen et. al 2003; Jezorek and Connolly 2003). The antennas did not appear to create a barrier to fish passage or to modify fish behavior. However, fish did take up residence near to or under the pass-by antenna. Its transceiver was subsequently set to record the same tag code again only after 1 min had elapsed. Even at this setting, there were numerous recordings of the same fish. No other problems occurred with the pass-by antenna in FY01.

In December 2001, debris during high-water conditions removed the pass-through antenna. The stanchion broke as designed and the antenna was recovered. However, the plug for the antenna cable was slightly damaged. The pass-by antenna housing design withstood the debris and bottom load impact during the high-water conditions. However, fish under these conditions may have avoided detection by passing too far above the antenna.

Therefore in FY02, we investigated a pivoting "hybrid" antenna design that incorporated both pass-by and pass-through features (Fig. 33). In this design, only the upstream portion of the antenna is anchored to the stream substrate via pivots attached on each end of the antenna. This leaves the downstream end floating free, which enables the antenna to adjust to different stream flow conditions. The buoyancy of the downstream end is adjusted so that it lies just underwater; this feature expedites the passage of surface debris past the antenna. The degree of submergence was adjusted by using a lead weight attached to the downstream member of the antenna. With the hybrid design, effective read distance varies with water depth because changes in depth alter the angle of the antenna and thus the orientation of fish passing through the antenna. 

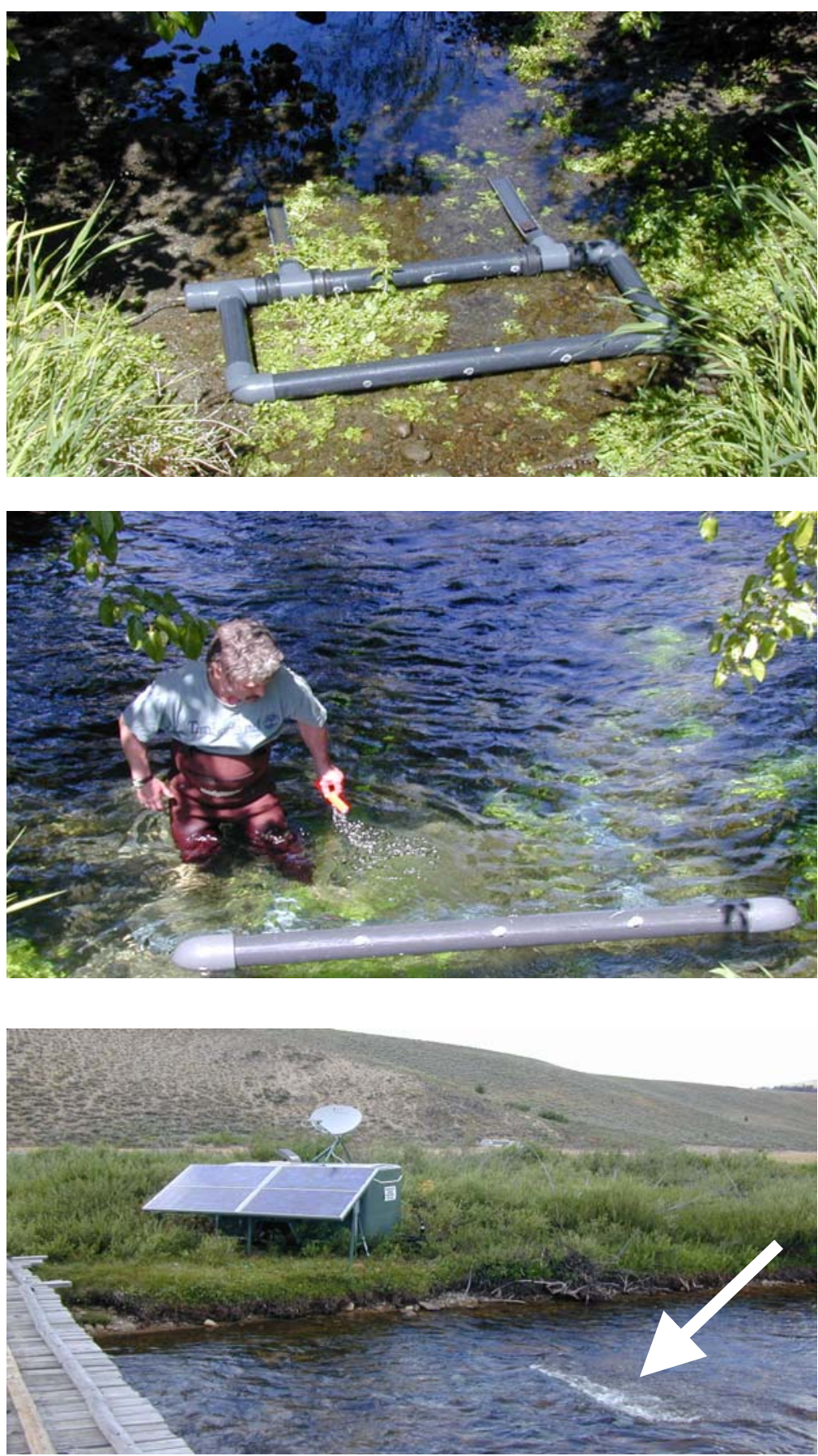

Figure 33. The hybrid PIT-tag antenna under low (top), medium (middle), and high (bottom) water conditions. Low and medium water photos were taken while the antenna was being developed in a stream near Pasco, WA; high water photo shows the antenna operating in Valley Creek, ID. 
However, the overall read distance of the hybrid was significantly better than that of the pass-by design because the fish swam through the antenna (i.e., the hybrid had a read window that varied between 15 to $60 \mathrm{~cm}$ while the pass-by had a more constant read window of $15-20 \mathrm{~cm}$ ). To evaluate this design, we installed the hybrid antenna where the pass-through antenna had been located in June 2002. This antenna functioned without problems during the reporting period and detected several PIT-tagged fish that the pass-by antenna did not detect. Similar hybrid antennas were installed at both interrogation sites in Valley Creek near Stanley, Idaho.

In FY01 and FY02, 24-m long cables were used to connect the transceivers and antennas. The cables were attached directly to the antennas using waterproof plugs. After building several more antennas, we realized that it would be better to have the connection farther away from the antenna so that the connector could be lifted out of the water for inspection, servicing, and reconnection without the need to detach the antenna from the substrate. Therefore, we changed the cable connector design for future antennas to include a pigtail that measured 2-3 meters from the antenna.

\section{Power Systems}

In 2001, we examined fuel cell technology with the assistance of BPA personnel. We had hoped that a demonstration project using this technology could be arranged in 2001. However, after several months of negotiations and testing, the conclusion was that the technology, even though very promising, was too expensive and unreliable at this time for in-stream applications. Therefore in FY02, we contracted power system experts from the Washington State University Energy Program (WSUEP) to design and assemble a power system using a combination of batteries, solar panels, and a propane generator (Fig. 34). This system was installed at the Valley Creek site that was not connected to grid-supported power in September 2002 (Achord et al. 2004).

Mounted on the outside of a trailer housing system components were four 150-watt solar panels, a satellite dish used to send data files and to monitor whether the system was operating, a 284-L propane tank, and a propane-operated generator (Fig. 34). Within the trailer the following electronics were housed: four 12V DC 110 amp-hour glass-mat storage batteries that were connected to provide $24 \mathrm{~V}$ power (the batteries were placed in a shielded box to prevent them from interfering with the other electronics); one 24V DC-powered FS1000A transceiver; a notebook computer; a two-way satellite communication system; a power inverter; DC power disconnect and breaker panel; generator relay; and data control board. 

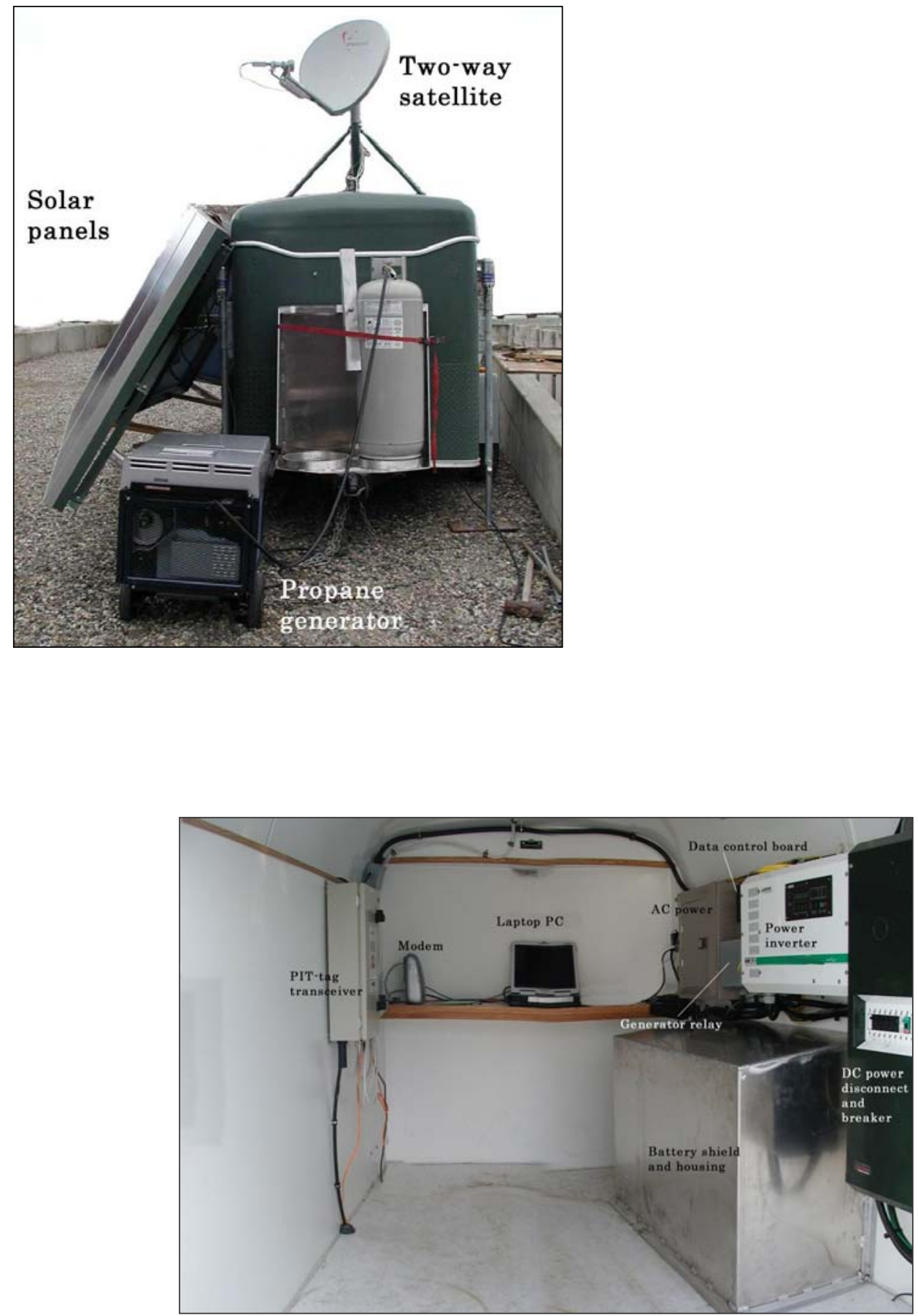

Figure 34. Outside and inside views of the PIT-tag equipment trailer that show the equipment for power management and communications. 
In designing the stand-alone DC power system, we had to take into account that we wanted the system to operate continuously. We estimated that it would take approximately five amps of power at 24 volts to operate the entire system during peak load. Of this power load, the transceiver itself only uses two amps, the rest being for the support equipment (e.g., computer, communications, battery charging, etc.). The battery bank by itself was sized to supply about $35 \mathrm{~h}$ of operation ( $40 \%$ battery draw down) under ideal operating conditions prior to requiring full recharge. We will report on how well this stand-alone power-system design functioned in Valley Creek in the FY03 annual report.

\section{Conclusions and Recommendations}

During FY01 and FY02, significant progress was made on the development of in-stream interrogation systems in the areas of antenna design, installation techniques, and power system design for remote locations. Three types of antennas are now available for use (pass-by, pass through, and a hybrid design). A technique of securing the antennas was developed for streams with large rock substrates. A stand-alone power system consisting of batteries, solar panels, and a propane generator was designed and installed at a small stream location in Idaho. The system is presently under evaluation.

Progress still needs to be made with the antenna systems. We recommend more research be done to find designs or solutions that will reduce or eliminate the EMI problems that are often encountered with the large unshielded antennas.

If an in-stream interrogation system can be developed that includes the ability to auto-tune and to multiplex multiple antennas, it could be used for year-round monitoring

of fish movements. This type of in-stream interrogation system would help us determine seasonal habitat use and connectivity of stream ecosystems which would in turn help in the restoration efforts for threatened and endangered stocks. During FY02, Destron Technologies started developing auto-tuning and multiplexing components. These add-on components will be tested in FY03. 


\section{INFORMATION TRANSFER, TECHNICAL REVIEWS, AND TECHNICAL SUPPORT}

During FY01 and FY02, NMFS continued active collaboration with other agencies on PIT-tag related matters such as facility designs to accommodate PIT-tag systems, PIT-tag system maintenance, assistance in using prototype equipment and the MULTIMON computer program, and information transfer. Because NMFS personnel designed or co-developed many of the present PIT-tag system components, they are an important resource for providing technical support and training to ensure the reliable operation of PIT-tag technology throughout the CRB. They also provided assistance in adapting PIT-tag technology for investigations into new areas. Activities that NMFS was involved in during the 2000-2002 reporting period are listed below.

- Provided assistance to PSMFC regarding the repair of PIT-tag interrogation systems, use and repair of ancillary equipment such as fish diversion gates, and setting up MULTIMON at CRB dams.

- Assisted investigators from several fisheries agencies in setting up the MULTIMON program to accommodate their separation-by-code requirements.

- Provided information on the CRB PIT-tag system to several national and international investigators. For example, we consulted with investigators from the Swedish Water Power Board, the Vindelälven Fishery Advisory Board, and The Swedish University of Agricultural Sciences who viewed fish passage structures and PIT-tag facilities at select sites within the Columbia River Basin. The group is addressing Atlantic salmon and sea trout fish passage issues on the river Umeälven located near Umea, Sweden.

- Assisted investigators from several fisheries agencies regarding the feasibility of applying in-stream interrogation systems to their research projects.

- Designed ISO-based equipment and improved the design for the towed-trawl detection system used in the Columbia River estuary. In addition we added to this system the capability of including GPS location in detection records collected by MULTIMON. 
- Helped set up an interrogation system in the artificial stream test facility at NMFS Manchester Research Station.

- Participated in the 2001 Manchester Street Festival held in Kitsap County by providing demonstrations of PIT-tag equipment used in the CRB. This was a community outreach effort to help highlight NMFS activities.

- Participated in the $70^{\text {th }}$ Anniversary Celebration of the Northwest Fisheries Science Center by providing demonstrations of PIT-tag equipment used in the CRB. This was a community outreach effort to help highlight NMFS activities.

- Interfaced with University Washington statisticians to help them apply their model to the test fish tagged in the evaluation of the orifice-based system installed in BWSL.

- Contributed articles to the PSMFC Newsletter to give updates on the development of the orifice-based interrogation system. 


\section{ACKNOWLEDGMENTS}

Support for this research came from the region's electrical ratepayers through the Bonneville Power Administration. We are grateful to personnel from the Walla Walla and Portland Districts of the U.S. Army Corps of Engineers and to Pacific States Marine Fisheries Commission staff. Without their timely assistance, some of our field work could not have been completed. The Corps Fisheries Field Unit in particular did an excellent job in recording and analyzing all of the videotapes for the evaluation of the orifice-based interrogation system installed into the Bonneville Washington Shore Ladder.

We are also indebted to NMFS employees Richard Frazier, James Simonson, and William Wassard for their valuable assistance in our research efforts. We thank Lyle Gilbreath for tagging fish used in the studies at Bonneville Dam. In addition, we express our appreciation to personnel from the NMFS Pasco Mechanic Shop, and the technicians from the NMFS Sand Point Electronics Shop.

In addition, we thank personnel from the following organizations for assisting with our tagging efforts at the Adult Fish Facility at Bonneville Dam: Oregon Department of Fish and Wildlife, Washington State Department of Fish and Wildlife, CRITFC, and University of Idaho.

Finally, field evaluations of the in-stream interrogation technology could not have been done without the cooperation of local landowners. We thank George McKovich, Steve Stampfli, and Teresa Tietjen for their assistance. 


\section{REFERENCES}

Achord, S., R. A. McNatt, E. E. Hockersmith, B. P. Sandford, K. W. McIntyre, N. N. Paasch, J. G. Williams, and G. M. Matthews. 2004. Monitoring the migrations of wild Snake River spring/summer chinook salmon smolts, 2003. Report of the National Marine Fisheries Service to the Bonneville Power Administration, Portland, Oregon. Available www.efw.bpa.gov/cgi-bin/FW/publications.cgi (April 2004).

Allen, B.M., P.J. Connolly, and K. Martens. 2003. Characterization of flow, temperature, habitat conditions, and fish populations in the Rattlesnake Creek watershed. Pages A1-A65 in P.J. Connolly, editor. Assess current and potential salmonid production in Rattlesnake Creek associated with restoration efforts. Report of the U.S. Geological Survey to the Bonneville Power Administration, Portland, Oregon. Available www.efw.bpa.gov/cgi-bin/FW/ publications.cgi (April 2004).

Downing, S. L. and E. F. Prentice. 2003. Overview of the Performance of PIT-Tag Interrogation Systems for Adult Salmonids at Bonneville and McNary Dams, 2002. Report of the National Marine Fisheries Service to the Bonneville Power Administration. Available www.efw.bpa.gov/cgi-bin/FW/publications.cgi (April 2004).

Downing, S. L., E. F. Prentice, E. P. Nunnallee, B. W. Peterson, and B. F. Jonasson. 2000. A study to determine the biological feasibility of a new fish tagging system (1998-1999). Report of the National Marine Fisheries Service to the Bonneville Power Administration. Available www.efw.bpa.gov/cgi-bin/FW/publications.cgi (April 2004).

Downing, S. L., E. F. Prentice, E. P. Nunnallee, B. W. Peterson, and B. F. Jonasson. 2001. Development and Evaluation of Passive Integrated Transponder Tag Technology. Annual Report: 1999-2000. Report of the National Marine Fisheries Service to the Bonneville Power Administration. Available www.efw.bpa.gov/cgi-bin/FW/publications.cgi (April 2004). 
Jezorek, I.G., and P.J. Connolly. 2003. Instream PIT-tag detection system. Pages B1-B15 in P.J. Connolly, editor. Assess current and potential salmonid production in Rattlesnake Creek associated with restoration efforts. Report of the U.S. Geological Survey to the Bonneville Power Administration, Portland, Oregon. Available www.efw.bpa.gov/cgi-bin/FW/publications.cgi (April 2004).

NMFS (National Marine Fisheries Service). 1995a. Endangered Species Act--Section 7 consultation. Biological opinion. Reinitiation of consultation on 1994-1998 operation of the federal Columbia River power system and juvenile transportation program in 1995 and future years. Hydropower Division, NMFS Northwest Region, Portland. Available www.nwr.noaa.gov/1publcat/bo/1995/ 1995.html (April 2004).

NMFS (National Marine Fisheries Service). 1995b. Proposed recovery plan for Snake River salmon. Hydropower Program, NMFS Northwest Regional Office, Portland, OR.

NMFS (National Marine Fisheries Service). 1998. Endangered Species Act--Section 7 consultation. Steelhead supplemental biological opinion. Operation of the federal Columbia River power system including the smolt monitoring program and the juvenile fish transportation program: a supplement to the biological opinion signed on March 2, 1995 for the same projects. Hydropower Division, NMFS Northwest Region, Portland. Available www.nwr.noaa.gov/1publcat/bo/1998/ 1998.html (April 2004).

NMFS (National Marine Fisheries Service). 2000. Endangered Species Act--Section 7 consultation. Biological opinion. Reinitiation of consultation on operation of the Federal Columbia River power system, including the juvenile fish transportation program and 19 Bureau of Reclamation projects in the Columbia Basin. Available www.nwr.noaa.gov/1hydrop/hydroweb/docs/Final/ 2000Biop.html (April 2004).

Nunnallee, E. P., E. F. Prentice, B. F. Jonasson, and W. Patten. 1998. Evaluation of a flat-plate PIT-tag interrogation system at Bonneville Dam. Aquacult. Eng. 17:261-272. 
Prentice, E. F., S. L. Downing, E. P. Nunnallee, B. W. Peterson, and B. F. Jonasson. 1998. A study to determine the biological feasibility of a new fish tagging system, 1996-1997. Report of the National Marine Fisheries Service to the Bonneville Power Administration. Available http://www.efw.bpa.gov/cgibin/FW/publications.cgi (April 2004).

Prentice, E. F., S. L. Downing, E. P. Nunnallee, B. W. Peterson, and B. F. Jonasson. 1999. A study to determine the biological feasibility of a new fish tagging system, 1997-1998. Report of the National Marine Fisheries Service to the Bonneville Power Administration. Available http://www.efw.bpa.gov/cgibin/FW/publications.cgi (April 2004).

Stansell R.J., C.R. Sprague, and R.H. Wertheimer. 2000. Evaluation of prototype adult salmonid PIT-tag detector inserts with underwater video cameras at Cascades Island Fishway Bonneville Dam, 1999. Report of the U.S. Army Corps of Engineers to the Bonneville Power Administration, Portland.

Stansell R.J. and L. M. Beck. 2001. Evaluation of fish behavior passing weirs where adult PIT-tag detectors will be installed at Bonneville Dam, 2000. Report of the U.S. Army Corps of Engineers to the Bonneville Power Administration, Portland.

Stansell R.J. and L. M. Beck. 2002. Evaluation of fish behavior passing weirs where adult PIT-tag detectors are installed at Bonneville Dam, 2001. Report of the U.S. Army Corps of Engineers to the Bonneville Power Administration, Portland.

TATT (Transceiver-Antenna Technical Team). 2000. Report on the evaluation to select a PIT-tag transceiver system for orifices located in fish ladders: fish and laboratory tests. Report of the TATT to the Bonneville Power Administration, Portland, Oregon. 


\section{APPENDIX A: Analysis of Electrical Leakage from Underwater PIT-tag Antenna Housings}

\section{Electronic Analysis}

In December 2001, it was confirmed that water had leaked into some of the underwater PIT-tag orifice antenna housings in the Washington Shore Fish Ladder at Bonneville Dam (Appendix Figure A1). This raised concern regarding whether migrating salmonids and other fish could be physically damaged or modify their behavior (i.e., to avoid the orifices). The effects of electrical current on fish are well known for applications such as electrofishing and euthanization of excess hatchery fish. However, these applications utilize relatively high DC voltages (50-150 V), strong currents (at least $0.5 \mathrm{~A}$ ), and large electrified water volumes within which the fish must be positioned (several cubic feet between electrical terminals).

In contrast, the most common site of water leakage has been on the backside of the electrical connector of the antennas where the straight line current path between the two wetted connector pins is only about $5 \mathrm{~mm}$ (the connector pins are $2 \mathrm{~mm}$ or less in diameter). The construction of the antenna housing limits the nearest point of exposure of fish to this electrical current flow to no less than $10 \mathrm{~cm}$. Consequently, little electrification danger exists due to the very short, straight-line current path, the low voltage applied to the connector ( $20 \mathrm{~V}_{\mathrm{RMS}}$ ), the distance to nearest point of exposure, and the low conduction through the fresh water. Unlike salt water, fresh water has little conductivity.

To better understand how electrical current flows between two points, it is necessary to visualize all possible current paths. Electrical current, as is the case with flowing water, always seeks the path of least resistance. Thus, the majority of the current will flow along a path near a straight-line distance between two points, but there will always be resistance to current flow and some current will also flow through longer, parallel paths (Appendix Figure A2). However, the quantity of current flow is inversely related to resistance; therefore, if path "B" is twice the length of path "A," the amount of current that will flow along path "B" will be half that flowing along path "A."

Consequently, the voltage measured across a unit distance of path "B" will be half of that across the same distance along path "A." 


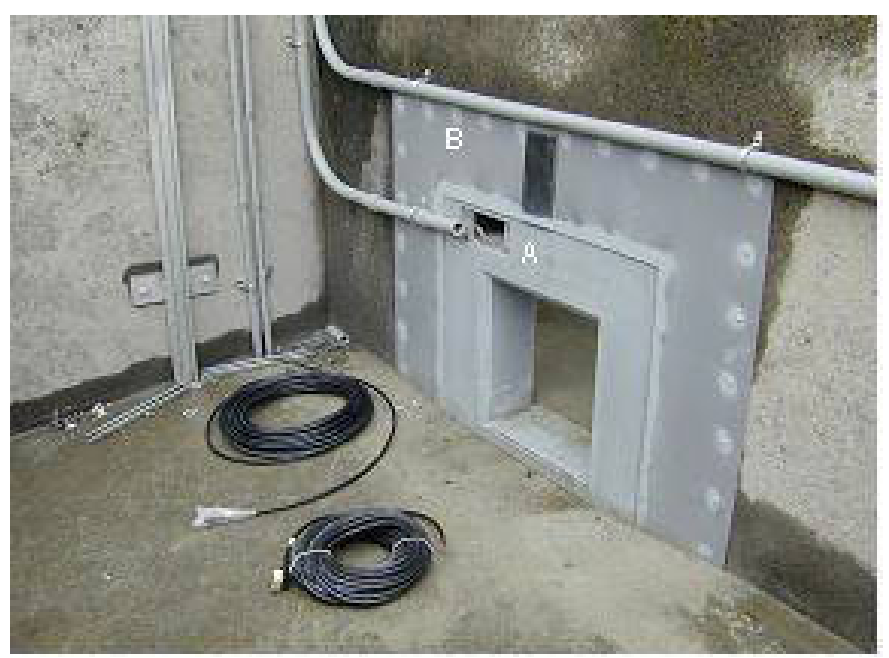

Appendix Figure A1. Photo taken during the installation of PIT-tag detection equipment into the Washington Shore Fish Ladder at Bonneville Dam. The antenna housing is labeled with the letter $\mathrm{A}$ at the approximate location of the connector inside the recessed access chamber. The aluminum shield is labeled with the letter B.

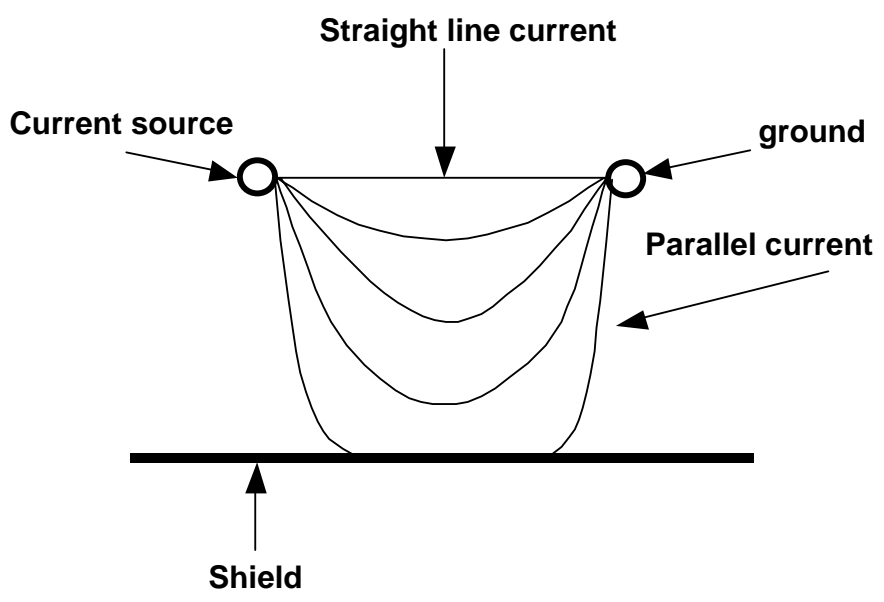

Appendix Figure A2. Schematic representation of parallel electrical current paths through water and the effect of the grounded aluminum shield. Note that the actual current paths will form a three-dimensional field, rather than two dimensions as depicted in the figure. 
Further, if some of the parallel current paths encounter a highly conductive path to ground, such as the aluminum shield installed with each antenna, much of the current will be shunted directly to ground. The total resistance between the wet connector pins (about $5 \mathrm{~mm}$ spacing) as measured in the field amounted to 5,000-10,000 ohms in the worst case. Because the resistance of the aluminum shield measures only a small fraction of an ohm for the same path distance, it provides a ready path to ground, and shunts away most of the leakage current.

Quantification of the actual amount of current that could flow through the body of a fish as it swims through an antenna orifice is difficult. It is also difficult to predict how the fish would react to that amount of current. However, some insight can be obtained if the problem is approached by first examining how much current can flow between the two wetted contacts on the back of an antenna connector, and then visualizing, as described above, the length of any parallel current paths that a fish could encounter. If it is assumed that the lowest resistance value measured across the antenna with the worst water leakage problem amounted to at least 5,000 ohms, then the greatest amount of current that could flow through all parallel paths combined would be:

$$
\begin{gathered}
\mathrm{I}_{(\text {amps })}=\mathrm{E}_{(\text {volts })} / \mathrm{R}_{(\text {Ohms })} \\
20 \mathrm{~V}_{\text {rms }} / 5,000_{\text {Ohms }}=0.004 \mathrm{~A}_{\text {rms }} \text { or } 4 \mathrm{~mA}_{\text {rms }}
\end{gathered}
$$

First, assume that most of this current flows through the straight-line distance ( $5 \mathrm{~mm}$ ) between connector pins. Further, assume that the nearest a fish can approach the wet connection is $10 \mathrm{~cm}$. The shortest parallel path would necessarily be at least 40 times longer $(20 \mathrm{~cm})$ than the straight path, so the amount of current flowing through that path could not be more than about $0.1 \mathrm{~mA}(4 \mathrm{~mA} / 40=0.1 \mathrm{~mA})$, or $100 \mu \mathrm{A}_{\mathrm{RMS}}$. Finally, the antenna shield is closer to the wet contacts than any fish is able to approach and thus will drain a significant amount of current in the field to ground. Therefore, the current that could flow through the body of a fish will be significantly reduced from $100 \mu A_{\text {RMs. }}$.

Mr. Yuri Smirnoff, Lead Electrical Engineer for Digital Angel (Destron Fearing), the manufacturer of the PIT-tag transceivers, used a different line of reasoning to reach the same conclusion; i.e., that there would not be a significant increase in the electrical field due to water leaking into the antenna housing. His comments are as follows:

1) Every degradation of insulation (caused by water leakage into an antenna) is going to reduce the $\mathrm{Q}$ of the antenna. The $\mathrm{Q}$ value of an antenna (a measure of efficiency) is the main factor in its ability to transfer power (electrical power to a magnetic field). 
2) Every change in the tuned circuit of the antenna will reduce the voltage across the antenna coil; when $\mathrm{Q}$ is reduced, then voltage will also be reduced. In the case where water has leaked into the capacitor chamber of an antenna, Q will approach zero as the resistance of the water short approaches zero, and all power will be contained within the shorted circuit; and therefore no power will be transferred to the magnetic field.

Much of the above reasoning is based on electrical theory, but it is also based on conservative estimates of the various parameters and a worst-case antenna failure. The only way to be more confident of the stated values would be to measure the actual current under field conditions. It would be impossible to make such measurements in the Washington Shore Ladder due to the rapid, high volume water flow, and limited accessibility.

In addition, if an antenna were energized, the electromagnetic field would produce a voltage on test probes that could not be distinguished from electrical leakage due to water inside the antenna, because the test probes would act as an antenna. It may be possible to try to simulate the system at the Pasco Research Station where a test facility has been constructed specifically for doing research on antenna design, but based on the above calculations, this effort does not seem necessary.

\section{Biological Information}

To try to gather biological evidence, we reviewed literature on the subject of using electrical fields as fish barriers, to count fish, to stun fish during electrofishing, or to euthanize fish. In each of these studies, the electrical fields tested were all different. Furthermore, because of different resistance, conductivity, and other study conditions (e.g., frequencies, units used to describe them, locations of exposure), it is impossible to know what field strength fish actually experienced in any of the studies.

However, in all cases, it appeared that the electric field strength that fish would be exposed to from our leaking antennas was orders of magnitude lower than what was purposefully used by these researchers. For example, where a graduated electric field was used to exclude coho from a hatchery, the fields used were $0.2-0.9 \mathrm{~V} / \mathrm{cm}$ while the strongest field that the fish would be exposed to with the worst leaking antenna would be significantly less than 0.001A. 
We also spoke with David Smith of Smith-Root, Inc. (SRI), a manufacturer of electrofishers and fisheries research equipment. He advised us that if the fields are perpendicular to the fish (our situation), the fish probably would not even feel the field. He also advised that in his experience, watching fish behavior is the best indication of electrical field effects.

We have no doubt now that the antennas were leaking before October 2001, and the videotapes from the end of September did not show any fish hesitating before going through the different orifices. In addition, Earl Prentice, Sandra Downing, and Robert Stansell and his group from the COE have watched hundreds of hours of videotapes of fish transiting orifices during the past 3 years. Any fish behavior modification during passage through these orifices would almost certainly have been noticed during the later observations.

Since each antenna has a unique leaking pattern, it is impossible to calculate specific information on what an individual fish transiting an orifice with a leaking antenna housing would be subjected to. It seems at this point that the videotape observations showing no behavioral modification near the leaking antenna housings is the best biological evidence presently available. Based this evidence, we cannot conclude that antenna leakage has any adverse effect on fish. 


\section{APPENDIX B: Performance of Interrogation Systems in Fish Ladders for Adult Salmonids (Spring 2002)}

Over the 2001-2002 winter, the COE and BPA installed adult interrogation systems into orifices in the remaining three ladders at Bonneville Dam and the two ladders at McNary Dam. In addition, a prototype system with two antennas was installed into the counting-station area on the Oregon Ladder at McNary Dam (MOL). Here we present an update on the performance of these interrogation systems as of spring 2002.

In December 2001, NMFS, Digital Angel, and PSMFC personnel confirmed that the significant degradation in the performance of some of the units in the Washington Shore Ladder at Bonneville Dam was caused by water leaking into the antenna housings and some connectors. It is important to remember that they were still reading tagged fish.

Further investigation revealed that one cause for water being able to leak into the antennas was an incompatibility of materials in relation to manufacturing method. Although the manufacturing process for the fiberglass antenna housings was improved in December and January (i.e., amount of foam used in the antenna was significantly reduced and resin was added to cover the back of the connector plug and surround the capacitors), some of the housings that were installed in 2002 have been identified as leaking (Appendix Table B1).

Limited time before the fish ladders had to be watered up prevented these antenna housings from being fixed. For the antenna housings in the Washington Shore Ladder at Bonneville Dam, only the connectors were cleaned and reconnected using a new procedure designed to reduce the likelihood of water leakage. No work was done on the antenna housings. Thus for this update, we had three objectives:

I) Assess tag-reading performance of identified leaking antennas

II) Compare reading efficiencies for different combinations of weirs with orifice detectors

III) Compare the orifice-based interrogation system with the counting-station interrogation system 
Appendix Table B1. List of coils containing leaking antennas for each ladder

Ladder

Bradford A branch

Bradford B branch

Cascades Island

Washington Shore Ladder

McNary Oregon Ladder

McNary Washington Ladder
Coil IDs for leaking antennas

02, $0 \mathrm{~A}, 0 \mathrm{~F}$

$14,17,1820$

0F, 10

BA, CA, DA, DB, 4B, 5B, 7A, 8A, 8B, 9A

07, 08, 0D, 0E, 0F, 10, 11

01, 03, 07, 0E, 0F, 10

The main peak of the 2002 spring migration was approximately 2 weeks later than usual; it reached McNary Dam during the first two weeks of May with about $10 \mathrm{~K}$ fish passing the dam on 8 May (Appendix Figure B1). To get this update out quickly to the community, we chose to focus the data analysis on fish passage through the Oregon Ladder between 1 and 14 May (Calendar dates 121-134). We also examined data from the Washington Shore Ladder at Bonneville Dam to compare performance between this year and last year with antenna housings we know to be of lower quality. 

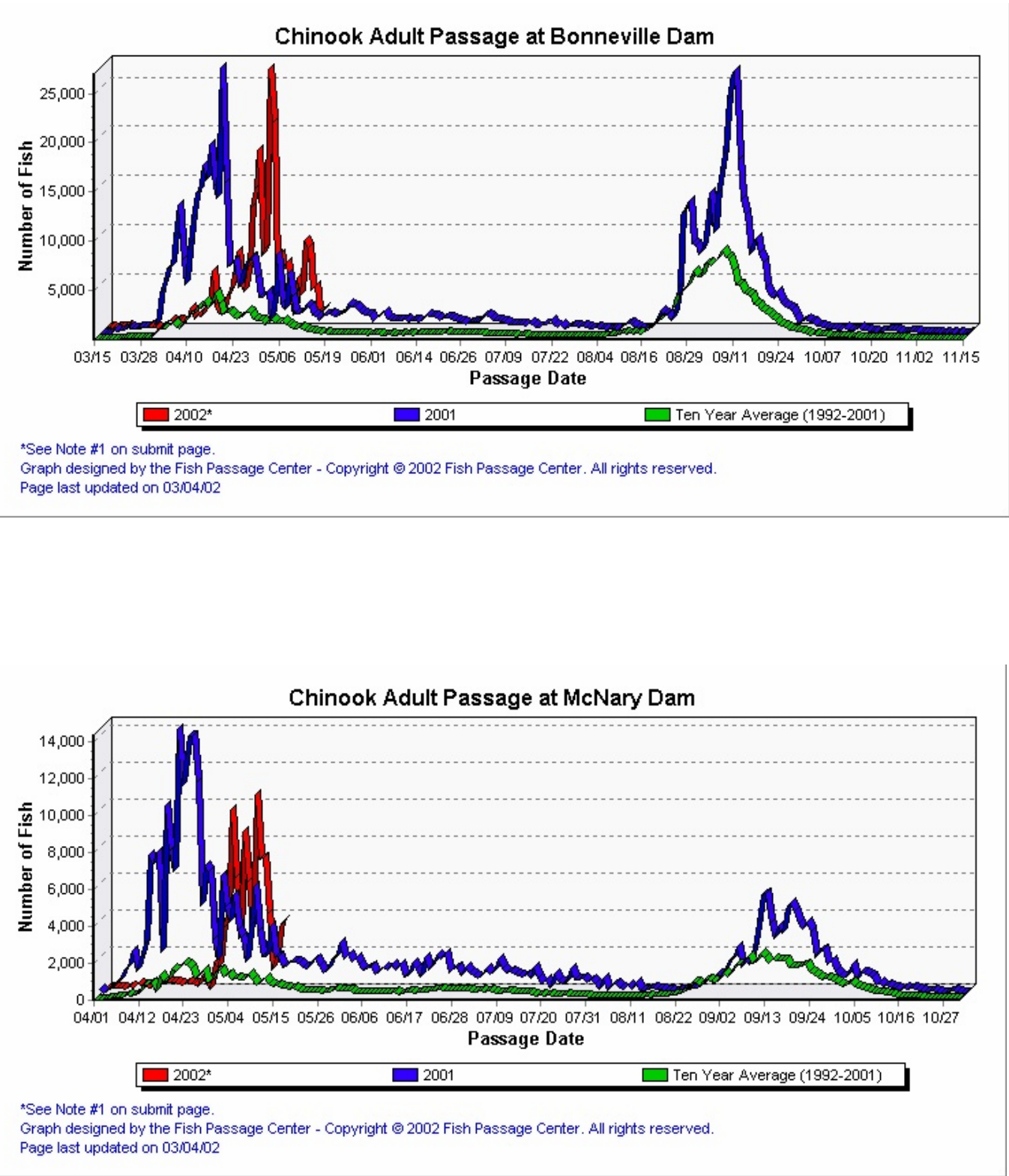

Appendix Figure B1. Adult chinook passage at Bonneville and McNary Dams (from Fish Passage Center website). 


\section{Objective I: Assess Tag-Reading Performance of Identified Leaking Antennas}

The number of reads per fish for the Washington Shore Ladder at Bonneville Dam for 2001 and 2002 (Appendix Table B2) illustrates that the performance of the leaking antennas in 2002 was equal to or better than in 2001. Furthermore, a $t$-test comparing the number of reads per fish for leaking and non-leaking antennas (excluding 9B which is low because of a high-voltage line running underneath the orifice) in 2002 was insignificant, with means of 19.0 and 18.9 reads/fish, respectively.

Obviously, we only really need to read a fish once, but this variable of number of reads/fish is a useful tool for demonstrating degradation in performance over time. For example, with four antennas confirmed as leaking last December, the variable shows how the number of reads per fish decreased over time (Appendix Table B3). We thought in June that we had a transceiver problem, but by October the data were definitely pointing toward leaking antennas. As stated above, this was confirmed in December.

Luckily, until water gets to the high-voltage areas of the antennas (i.e., the capacitors and the wires behind the connector), adjustments to the transceivers can be made to compensate for water leaking into the antenna housings. Even when water had reached the capacitors last fall in 7B, the interrogation unit was still reading fish. The reads/fish data for 2002 confirm that water has not reached the high-voltage areas in any of the leaking antennas. In addition, the high averages (15+ reads/fish) confirm that the interrogation units are collecting solid data (i.e., if a PIT-tagged fish transits an orifice, then its tag is being recorded).

Typically, to compensate for the leaking antennas, the exciter voltage needs to be increased in order to tune the transceiver properly. This is also done for longer cable runs. Running the transceivers constantly at higher voltages than they were designed for could reduce their life span; however, in a conference call in early May, Digital Angel was more worried about the few transceivers having very long cable runs (i.e., over $80 \mathrm{ft}$ ) than those connected to leaking antennas.

The main message, as stated above, is that at this time the identified leaking antennas are performing equal to the identified non-leaking antennas. 
Appendix Table B2. The number of reads per fish for the Washington Shore Ladder at Bonneville Dam for two dates in 2001 and 2002. The table also indicates how many adult salmonids transited a particular orifice or coil on those dates. The shaded columns show the antennas identified as containing moisture.

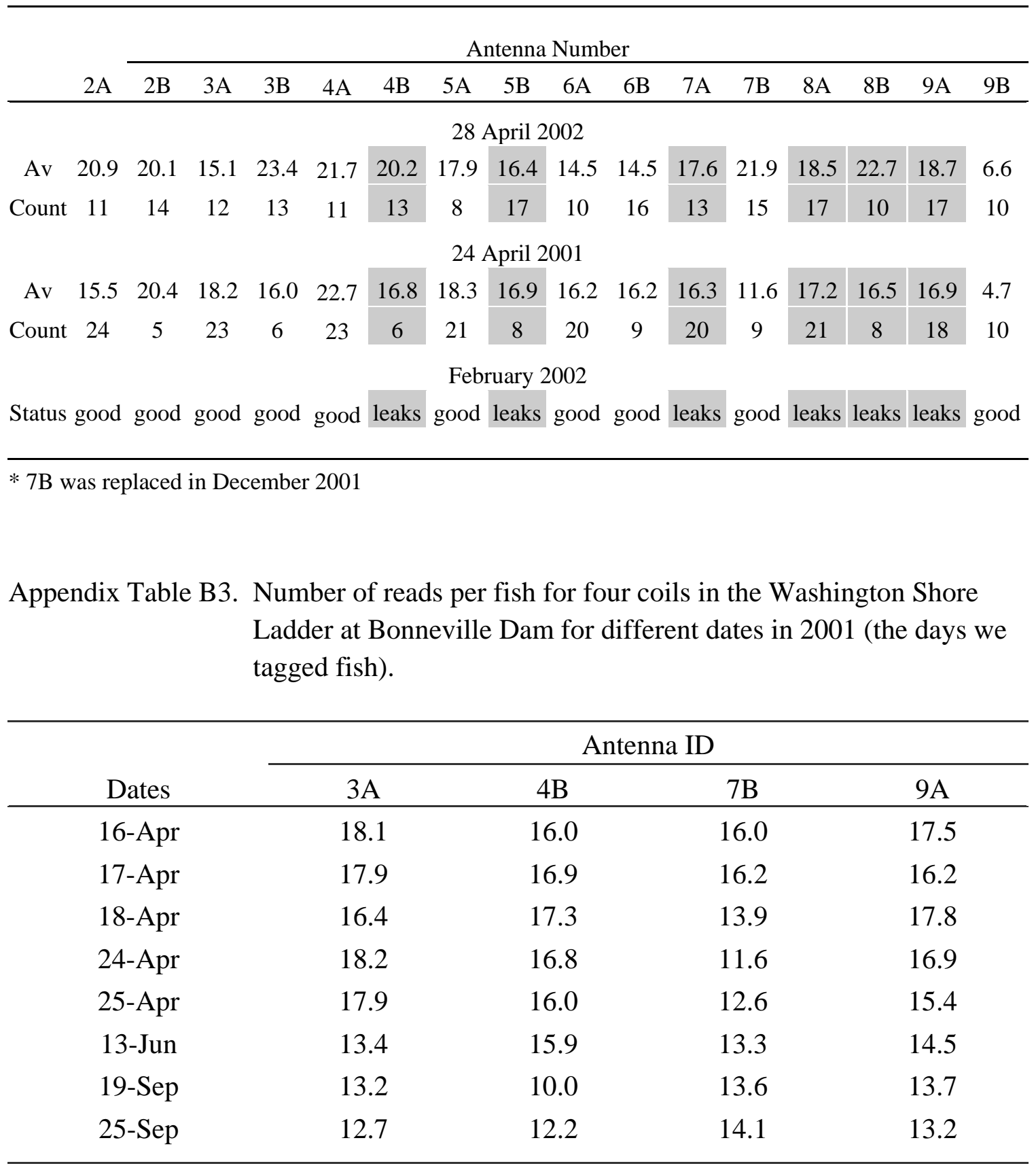




\section{Objective II: Relative Reading Efficiencies for Different Combinations of Weirs with Orifice Detectors}

During 2001 at Washington Shore Ladder at Bonneville Dam, the data for spring chinook salmon indicated that basically having four consecutive weirs would have been sufficient to yield a reading efficiency of 95\%. The problem with the orifice-based system did not occur until the fall, when species such as coho and fall chinook appeared to use the weir overflows at a much higher rate than the biologists expected. We thought it would be useful to run a similar evaluation with the Oregon Ladder at McNary Dam because the data could also be used to compare the orifice-based system with the counting-station interrogation system.

Using the 2002 data collected from the Oregon Ladder at McNary between 1 and 14 May (Calendar dates 121-134), we generated a unique list of fish that transited all eight weirs. To generate this list, we eliminated any juvenile fish, eliminated any fish that were just read on one or a few lower weirs and then went back down the ladder, and used only fish that had been read on both the first weir and the upper two weirs (i.e., to get a list of fish definitely transiting this ladder).

We did not include the two adult fish that were exclusively observed at the counting station system; therefore, the number of adult salmonids read on all eight weirs $(n=1,038)$ represented the relative reading efficiency of $100 \%$. Surprisingly during the peak of the spring migration, we would have read $98 \%$ of the fish if only the bottom two or upper two weirs had been wired (Appendix Table B4). Furthermore, three out of the four coils in the bottom two weirs have been identified as leaking while none of the coils in the upper two weirs has been.

Therefore, similar to the findings at Bonneville Dam in 2001, during the spring migration the orifice-based interrogation system performed quite well. These results also indirectly support the conclusion that performances of the leaking antennas are satisfactory. 
Appendix Table B4. Number of fish read on different combinations of weirs installed with orifice detectors in the Oregon Ladder at McNary Dam. The relative reading efficiencies for the 2 -week period for the different combinations of weirs is also presented.

\begin{tabular}{lcccc}
\hline Date & Lower 2 weirs & Lower 3 weirs & Upper 2 weirs & All 8 weirs \\
\hline 1 May & 65 & 67 & 67 & 67 \\
2 May & 118 & 118 & 118 & 118 \\
3 May & 97 & 97 & 96 & 97 \\
4 May & 51 & 52 & 51 & 53 \\
5 May & 134 & 135 & 133 & 135 \\
6 May & 75 & 75 & 75 & 75 \\
7 May & 74 & 74 & 73 & 74 \\
8 May & 187 & 190 & 187 & 190 \\
9 May & 37 & 37 & 36 & 38 \\
10 May & 48 & 48 & 48 & 48 \\
11 May & 40 & 40 & 39 & 16 \\
12 May & 14 & 15 & 14 & 23 \\
13 May & 18 & 19 & 21 & 63 \\
14 May & 61 & 62 & 61 & 100.0 \\
Total & 1,019 & 1,029 & 1,019 & 8 of 8 weirs \\
Reading & & & & \\
efficiencies (\%) & 98.2 & 99.1 & 2 of 8 weirs & \\
& 2 of 8 weirs & 3 of 8 weirs & & \\
\hline
\end{tabular}




\section{Objective III: Compare the Orifice-Based Interrogation System with the Counting-Station Interrogation System}

Based in part on technology gained in developing systems to work in small streams, Digital Angel realized that it was possible to read tags in much larger antennas than had previously been envisioned for fish ladder applications. It was only 2 years ago when we were worried about reading tags in a 26- by 26-in orifice, much less covering a space of 24- by 72-in. Therefore, Digital Angel proposed to the Corps and BPA that it develop a prototype system for the counting-station area for the Oregon Ladder at McNary Dam.

The two-antenna system was installed in January and February 2002. The fisheries community is excited about this system as the migrating adult salmonids have to go through these antennas because unlike the orifice-based system, there are no overflows. Biologists did raise concerns that tagged fish might transit together or hang out at an antenna and impact the reading performance of the system.

We used the same criteria as above to generate lists of tag codes that were unique for both the weirs and counting station. Thus, juvenile fish and adult salmonids that did not transit all of the weirs were eliminated. The objective was to get a list of adult salmonids that were actively transiting the Oregon Ladder for 1-14 May and then to determine if any of these were not read on the counting station.

In addition, this objective included getting a list of tag codes for adult salmonids that was only read on the counting-station system. Between 1 and 14 May, there were 67 fish read by the orifice-based system that were not read by the counting-station system and there were 2 fish read exclusively by the counting-station system. It is interesting to note that most of the 67 fish were missed during midday (1100-1400 h). Of the 67 fish, 6 of them were radio tagged at Bonneville Dam. Radiotelemetry information recorded for McNary Dam showed four of them passing the Oregon Ladder. The other two fish definitely passed McNary Dam as they were recorded shortly afterward at Lower Granite and Wells Dams.

Therefore, 67 out of approximately 1,000 fish or approximately 6\% were missed by the counting-station system. This is quite good considering this is a prototype system and Digital Angel is still working on it. They have tried a couple of different grounding options, different power arrangements, and switched analog boards. In fact, Sean Casey is out there this week trying out some solutions that they tested in the laboratory the past couple of weeks. 
Other reasons that fish may have been missed include that some fish may have turned around instead of transiting the counting-station area. In addition, there was a juvenile steelhead that hung out near the counting station over the entire 2-week period and may have affected the ability to read other tags. A few days it was read five or more times during the day, though it stayed for a maximum of 2 seconds just once. Anyway this technology looks promising; however, the results do suggest that it would be better to have more than two antennas for these large-antenna systems. It will be interesting to see how these two systems compare in the fall when coho and fall chinook salmon are transiting the ladder. 


\title{
APPENDIX C: Preliminary Data Analysis Report on \\ Adult Ladder PIT-Tag Detection Efficiency at Bonneville Powerhouse II
}

\author{
James Lady and John R. Skalski \\ Columbia Basin Research \\ School of Fisheries and Aquatic Sciences \\ University of Washington \\ $13254^{\text {th }}$ Ave., Suite 1820 \\ Seattle, WA 98101-2509
}

Prepared for

\author{
Earl Prentice and Sandra Downing \\ National Marine Fisheries Service \\ Northwest Fisheries Science Center \\ and \\ Carter Stein \\ The Columbia Basin PIT Tag Operations Center
}

May 25, 2001 


\section{Introduction}

A total of 315 PIT-tagged adult Chinook salmon were released over a period of two weeks between weirs 37 and 52 at the Washington Side adult ladder at Bonneville Dam. The releases were as follows:

\begin{tabular}{ll}
\hline Release Date & Number Released \\
\hline April 11 & 45 \\
April 16 & 59 \\
April 17 & 30 \\
April 18 & 75 \\
April 24 & 30 \\
April 25 & 76 \\
Total Number Released & 315 \\
\hline
\end{tabular}

In addition, PIT-tagged wild adult returns, numbering 161 as of May 11, were detected.

\section{Overall Detection Probability}

An intuitive estimator of overall detection probability at the Weirs is simply the number detected anywhere at the ladder divided by the total number released:

\begin{tabular}{lllll}
\hline $\begin{array}{l}\text { Release } \\
\text { Date }\end{array}$ & $\begin{array}{l}\text { Number } \\
\text { Detected }\end{array}$ & $\begin{array}{l}\text { Number } \\
\text { Released }\end{array}$ & $\begin{array}{l}\text { Detection } \\
\text { Efficiency }\end{array}$ & $\begin{array}{l}\text { Standard } \\
\text { Error }\end{array}$ \\
\hline April 11 & 44 & 45 & 0.9778 & 0.0220 \\
April 16 & 54 & 59 & 0.9153 & 0.0363 \\
April 17 & 30 & 30 & 1.0000 & 0.0000 \\
April 18 & 75 & 75 & 1.0000 & 0.0000 \\
April 24 & 30 & 30 & 1.0000 & 0.0000 \\
April 25 & 74 & 76 & 0.9737 & 0.0184 \\
Combined & 307 & 315 & 0.9746 & 0.0089 \\
\hline
\end{tabular}

This estimator is based on the number released, and thus is not applicable to estimating detection efficiency for wild adult returns. 


\section{Detection Probability per Weir}

Manly and Parr (1968) suggest a method of estimating detection efficiency based solely on the fish detected above the weir in question. The Manly-Parr estimator estimates the probability of detection as follows:

$$
\hat{P}_{i}=\frac{n_{11}}{n_{11}+n_{01}}
$$

where,

$\hat{P}_{i} \quad \quad$ The detection efficiency estimate for weir $i$.

$n_{11}=\quad$ The total number detected at the weir $i$ and at one or more subsequent upstream weirs

$n_{01}=\quad$ The total number detected at one or more subsequent upstream weirs, but not at weir $i$.

The estimate of the standard error of the detection efficiency estimates is based on the Binomial distribution as follows:

$$
\text { s.e. }\left(\hat{P}_{i}\right)=\sqrt{\frac{\hat{P}_{i}\left(1-\hat{P}_{i}\right)}{n_{11}+n_{01}}}
$$

One drawback of the Manly-Parr estimator is that it cannot be used to estimate the detection efficiency for weir 59 since there are no detections above weir 59. The estimator of detection efficiency for weir 59 has been defined as:

where

$$
\hat{P}_{59}=\frac{n_{59}}{n^{*}}, \text { s.e. }\left(\hat{P}_{59}\right)=\sqrt{\frac{\hat{P}_{59}\left(1-\hat{P}_{59}\right)}{n^{*}}}
$$

$$
\begin{array}{ll}
n_{59}= & \text { The number detected at weir 59, } \\
n^{*}= & \text { The number detected at weirs } 52 \text { through 59, excluding "fallback } \\
& \text { fish" that went down the ladder before reaching weir } 59 .
\end{array}
$$

The estimates of detection efficiency, along with their standard errors, for the experimental release groups and the adult returns are as follows: 
Appendix Table C1. April 11 release.

\begin{tabular}{lllll}
\hline Weir & Detected & Out of & $\begin{array}{l}\text { Detection } \\
\text { Efficiency }\end{array}$ & $\begin{array}{l}\text { Standard } \\
\text { Error }\end{array}$ \\
\hline 52 & 37 & 43 & 0.8605 & 0.0528 \\
53 & 37 & 42 & 0.8810 & 0.0500 \\
54 & 38 & 42 & 0.9048 & 0.0453 \\
55 & 37 & 42 & 0.8810 & 0.0500 \\
56 & 40 & 42 & 0.9524 & 0.0329 \\
57 & 38 & 39 & 0.9744 & 0.0253 \\
58 & 32 & 34 & 0.9412 & 0.0404 \\
59 & 34 & 42 & 0.8095 & 0.0606 \\
\hline
\end{tabular}

Appendix Table C2. April 16 release.

\begin{tabular}{lllll}
\hline Weir & Detected & Out of & $\begin{array}{l}\text { Detection } \\
\text { Efficiency }\end{array}$ & $\begin{array}{l}\text { Standard } \\
\text { Error }\end{array}$ \\
\hline 52 & 50 & 51 & 0.9804 & 0.0194 \\
53 & 49 & 51 & 0.9608 & 0.0272 \\
54 & 49 & 51 & 0.9608 & 0.0272 \\
55 & 49 & 50 & 0.9800 & 0.0198 \\
56 & 47 & 49 & 0.9592 & 0.0283 \\
57 & 45 & 48 & 0.9375 & 0.0349 \\
58 & 45 & 46 & 0.9783 & 0.0214 \\
59 & 46 & 50 & 0.9200 & 0.0384 \\
\hline
\end{tabular}

Appendix Table C3. April 17 release.

\begin{tabular}{lllll}
\hline Weir & Detected & Out of & $\begin{array}{l}\text { Detection } \\
\text { Efficiency }\end{array}$ & $\begin{array}{l}\text { Standard } \\
\text { Error }\end{array}$ \\
\hline 52 & 29 & 30 & 0.9667 & 0.0328 \\
53 & 29 & 30 & 0.9667 & 0.0328 \\
54 & 28 & 30 & 0.9333 & 0.0455 \\
55 & 28 & 29 & 0.9655 & 0.0339 \\
56 & 27 & 27 & 1.0000 & 0.0000 \\
57 & 27 & 27 & 1.0000 & 0.0000 \\
58 & 25 & 25 & 1.0000 & 0.0000 \\
59 & 25 & 30 & 0.8333 & 0.0680 \\
\hline
\end{tabular}


Appendix Table C4. April 18 release.

\begin{tabular}{lllll}
\hline Weir & Detected & Out of & $\begin{array}{l}\text { Detection } \\
\text { Efficiency }\end{array}$ & $\begin{array}{l}\text { Standard } \\
\text { Error }\end{array}$ \\
\hline 52 & 72 & 72 & 1.0000 & 0.0000 \\
53 & 67 & 70 & 0.9571 & 0.0242 \\
54 & 69 & 70 & 0.9857 & 0.0142 \\
55 & 70 & 70 & 1.0000 & 0.0000 \\
56 & 70 & 70 & 1.0000 & 0.0000 \\
57 & 68 & 68 & 1.0000 & 0.0000 \\
58 & 64 & 65 & 0.9846 & 0.0153 \\
59 & 65 & 72 & 0.9028 & 0.0349
\end{tabular}

Appendix Table C5. April 24 release.

\begin{tabular}{lllll}
\hline Weir & Detected & Out of & $\begin{array}{l}\text { Detection } \\
\text { Efficiency }\end{array}$ & $\begin{array}{l}\text { Standard } \\
\text { Error }\end{array}$ \\
\hline 52 & 30 & 30 & 1.0000 & 0.0000 \\
53 & 30 & 30 & 1.0000 & 0.0000 \\
54 & 30 & 30 & 1.0000 & 0.0000 \\
55 & 30 & 30 & 1.0000 & 0.0000 \\
56 & 30 & 30 & 1.0000 & 0.0000 \\
57 & 30 & 30 & 1.0000 & 0.0000 \\
58 & 28 & 29 & 0.9655 & 0.0339 \\
59 & 29 & 30 & 0.9667 & 0.0328 \\
\hline
\end{tabular}

Appendix Table C6. April 25 release.

\begin{tabular}{lllll}
\hline Weir & Detected & Out of & $\begin{array}{l}\text { Detection } \\
\text { Efficiency }\end{array}$ & $\begin{array}{l}\text { Standard } \\
\text { Error }\end{array}$ \\
\hline 52 & 68 & 70 & 0.9714 & 0.0199 \\
53 & 67 & 69 & 0.9710 & 0.0202 \\
54 & 66 & 69 & 0.9565 & 0.0246 \\
55 & 68 & 68 & 1.0000 & 0.0000 \\
56 & 67 & 68 & 0.9853 & 0.0146 \\
57 & 66 & 68 & 0.9706 & 0.0205 \\
58 & 67 & 67 & 1.0000 & 0.0000 \\
59 & 67 & 71 & 0.9437 & 0.0274 \\
\hline
\end{tabular}


Appendix Table C7. Combined Experimental Fish.

\begin{tabular}{lllll}
\hline Weir & Detected & Out of & $\begin{array}{l}\text { Detection } \\
\text { Efficiency }\end{array}$ & $\begin{array}{l}\text { Standard } \\
\text { Error }\end{array}$ \\
\hline 52 & 286 & 296 & 0.9662 & 0.0105 \\
53 & 279 & 292 & 0.9555 & 0.0121 \\
54 & 280 & 292 & 0.9589 & 0.0116 \\
55 & 282 & 289 & 0.9758 & 0.0090 \\
56 & 281 & 286 & 0.9825 & 0.0077 \\
57 & 274 & 280 & 0.9786 & 0.0087 \\
58 & 261 & 266 & 0.9812 & 0.0083 \\
59 & 266 & 295 & 0.9017 & 0.0173 \\
\hline
\end{tabular}

Appendix Table C8. Wild Adult Returns

\begin{tabular}{lllll}
\hline Weir & Detected & Out of & $\begin{array}{l}\text { Detection } \\
\text { Efficiency }\end{array}$ & $\begin{array}{l}\text { Standard } \\
\text { Error }\end{array}$ \\
\hline 34 & 123 & 160 & 0.7688 & 0.0333 \\
35 & 133 & 158 & 0.8418 & 0.0290 \\
36 & 139 & 155 & 0.8968 & 0.0244 \\
37 & 127 & 146 & 0.8699 & 0.0278 \\
52 & 128 & 142 & 0.9014 & 0.0250 \\
53 & 122 & 141 & 0.8652 & 0.0288 \\
54 & 118 & 137 & 0.8613 & 0.0295 \\
55 & 120 & 134 & 0.8955 & 0.0264 \\
56 & 117 & 126 & 0.9286 & 0.0229 \\
57 & 116 & 121 & 0.9587 & 0.0181 \\
58 & 110 & 116 & 0.9483 & 0.0206 \\
59 & 116 & 159 & 0.7296 & 0.0352 \\
\hline
\end{tabular}

If we make an additional assumption that the detection at one weir is independent of detection at subsequent weirs, an estimator of overall detection efficiency can be calculated from the individual detection efficiencies at each weir, as follows:

$$
\hat{P}_{\text {overall }}=1-\prod_{i=52}^{59}\left(1-\hat{P}_{i}\right)
$$

This estimator yields estimates of overall detection efficiency greater than 0.9999 with standard errors less than 0.00001 for all experimental groups and for the wild adult returns. This is not consistent with the results from the experimental release groups, with 
$2.5 \%$ of the experimental fish not detected at the ladder. Examination of the individual capture histories shows that the individuals that are detected at a weir are detected at nearly all of the weirs, but $2.5 \%$ of the individuals are not detected at all. This suggests that not all fish have the same probability of detection, and the detection efficiencies of the individual weirs are not independent.

\section{A Robust Estimator of Overall Detection Probability}

The estimate of overall detection probability used in Section 1 above does not depend on the independence of the weirs. This estimator can be adapted for use with wild adult returns by using only the individuals detected at a given weir. For example, if the detections at weir 52 are used, an estimator of overall detection probability could be defined as:

$$
\begin{array}{ll}
\hat{P}_{52(1)}=\frac{n_{52 \& 53}}{n_{52}}, \\
\text { where } \begin{array}{ll}
\hat{P}_{52(1)}= & \begin{array}{l}
\text { Estimate of overall detection efficiency based on weir } 52 \text { and one } \\
\text { subsequent weir (weir } 53) .
\end{array} \\
n_{52}= & \text { The number detected at weir } 52, \\
n_{52 \& 53}= & \text { The number detected both at weirs } 52 \text { and } 53 .
\end{array}
\end{array}
$$

An estimator using two subsequent weirs is:

where

$$
\begin{aligned}
& \hat{P}_{52(2)}=\frac{n_{52 \&(5354)}}{n_{52}}, \\
& n_{52 \&(5354)}=\quad \begin{array}{l}
\text { The number detected at weir } 52 \text { and at least once at weirs } 53 \\
\text { through } 54 .
\end{array}
\end{aligned}
$$

Subsequent estimators could be defined by adding additional subsequent weirs until the estimates asymptote to a final value. This has been done for the graphs in Appendix Figure C1, comparing estimates based on wild adult returns and experimental fish. 
Appendix Figure C1. Analysis of Robust Estimator
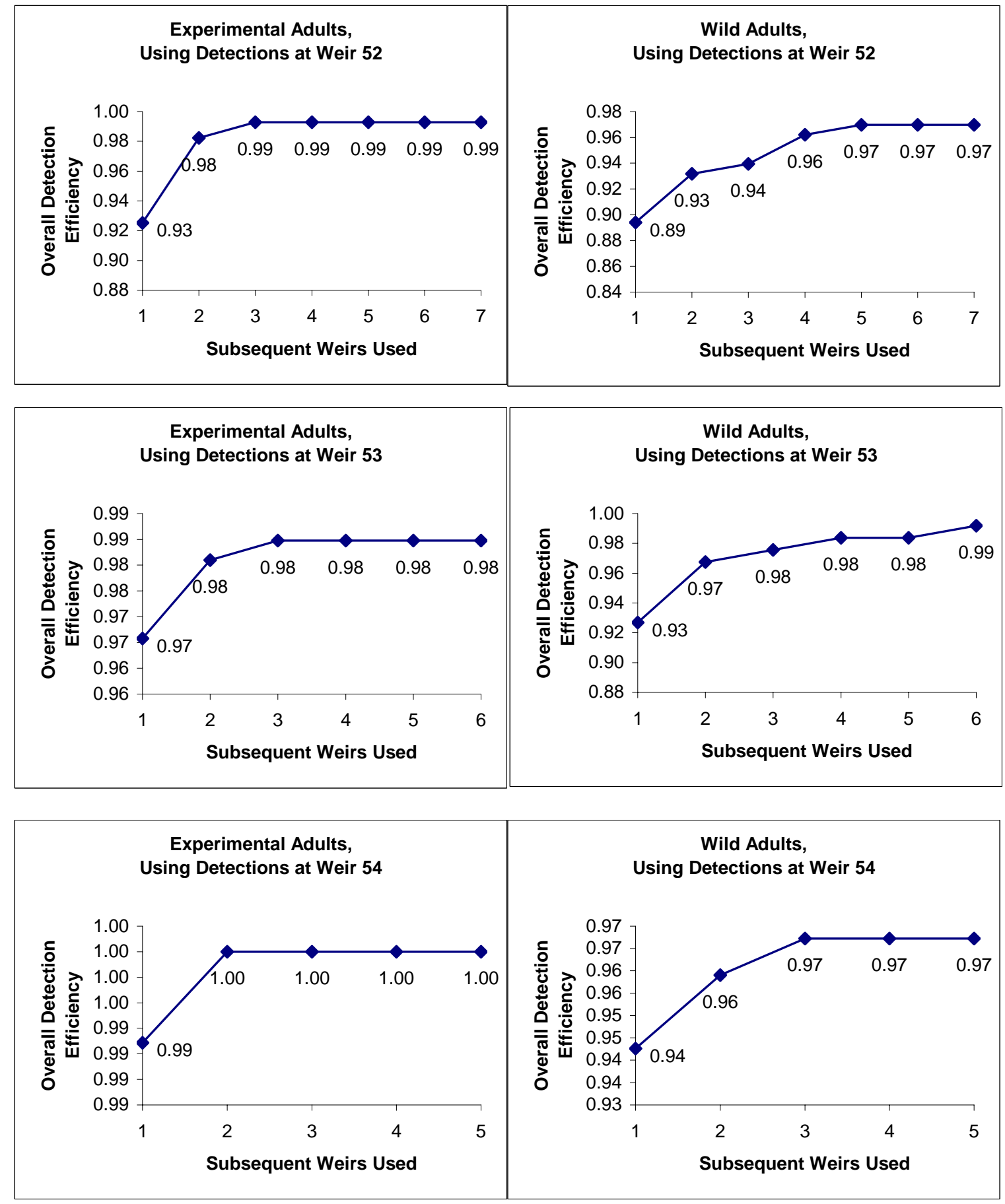
These graphs indicate that the detection efficiency does not increase after including 5 or more subsequent weirs in all but one case; for the wild adult returns using weir 53, the final detection efficiency was reached in 6 weirs. The graphs suggest that this method of estimating is more consistent with the results in Section 1 above; the detection efficiency is less than 1.0 in all but one instance. The graphs also suggest that the minimum number of successive weirs that should have PIT-tag detectors is about 5; the benefit of having more than 5 sequential weirs with PIT-Tag detectors is minimal.

\section{Conclusions}

Some conclusions that can be made from the study are as follows:

1. The overall detection probability of the experimental fish at weirs 52 through 59 was 0.9746 (s.e. $=0.0089$ ).

2. The overall detection probability is approximately the same as the robust estimator of overall detection efficiency. The robust estimator suggests an overall detection probability of 0.97 to 0.99 .

3. The Manly-Parr estimates provide estimates of the detection efficiency of individual weirs between 0.77 and 1.00 .

4. The data suggest that probabilities of detection are not independent between weirs. Fish behavior is the probable cause for this lack of independence. It appears that some fish purposefully avoid the detectors, choosing instead to jump above rather than pass through the detectors.

5. If fish are prone to avoid the detectors, these fish will not be accounted for in the estimate of detection efficiency for wild adult returns. Therefore, both the ManlyParr estimates of detection efficiencies for individual weirs, and the robust estimator of overall detection efficiency must be seen as upper limits for the actual detection efficiencies

\section{References}

Manly, B. F. J. and Parr, M. J. 1968. A new method of estimating population size, survivorship and birth rate from capture-recapture data. Trans. Soc. Brit. Ent. 18: 81-9. 